\title{
What the Wild Things Do: Mechanisms of Plant Host Manipulation by Bacterial Type III-Secreted Effector Proteins
}

\author{
Karl J. Schreiber ${ }^{1}$, Ilea J. Chau-Ly ${ }^{1}(1)$ and Jennifer D. Lewis ${ }^{1,2, *}$ \\ 1 Department of Plant and Microbial Biology, University of California, Berkeley, CA 94710, USA; \\ karl.j.schreiber@gmail.com (K.J.S.); ilea_chau@berkeley.edu (I.J.C.-L.) \\ 2 Plant Gene Expression Center, United States Department of Agriculture, University of California, \\ Berkeley, CA 94710, USA \\ * Correspondence: jdlewis@berkeley.edu
}

check for updates

Citation: Schreiber, K.J.; Chau-Ly, I.J.; Lewis, J.D. What the Wild Things Do:

Mechanisms of Plant Host

Manipulation by Bacterial Type

III-Secreted Effector Proteins.

Microorganisms 2021, 9, 1029.

https: / / doi.org/

10.3390/microorganisms 9051029

Academic Editors: Dor Salomon

and Guido Sessa

Received: 30 March 2021

Accepted: 4 May 2021

Published: 11 May 2021

Publisher's Note: MDPI stays neutral with regard to jurisdictional claims in published maps and institutional affiliations.

Copyright: (c) 2021 by the authors. Licensee MDPI, Basel, Switzerland. This article is an open access article distributed under the terms and conditions of the Creative Commons Attribution (CC BY) license (https:// creativecommons.org/licenses/by/ $4.0 /)$

\begin{abstract}
Phytopathogenic bacteria possess an arsenal of effector proteins that enable them to subvert host recognition and manipulate the host to promote pathogen fitness. The type III secretion system (T3SS) delivers type III-secreted effector proteins (T3SEs) from bacterial pathogens such as Pseudomonas syringae, Ralstonia solanacearum, and various Xanthomonas species. These T3SEs interact with and modify a range of intracellular host targets to alter their activity and thereby attenuate host immune signaling. Pathogens have evolved T3SEs with diverse biochemical activities, which can be difficult to predict in the absence of structural data. Interestingly, several T3SEs are activated following injection into the host cell. Here, we review T3SEs with documented enzymatic activities, as well as T3SEs that facilitate virulence-promoting processes either indirectly or through nonenzymatic mechanisms. We discuss the mechanisms by which T3SEs are activated in the cell, as well as how T3SEs modify host targets to promote virulence or trigger immunity. These mechanisms may suggest common enzymatic activities and convergent targets that could be manipulated to protect crop plants from infection.
\end{abstract}

Keywords: type III secreted effector; biochemical activity; Pseudomonas syringae; Ralstonia; Xanthomonas; virulence promotion; effector-triggered immunity; host activation; host targets

\section{Introduction}

The outcome of plant-pathogen interactions is determined by a complex network of molecular events that involve proteins and other macromolecules from both the host and pathogen. The presence of a potential pathogen in host tissues is first detected in the extracellular space by plant pattern recognition receptors (PRRs) which recognize conserved molecular signatures known as pathogen-associated molecular patterns (PAMPs). Two of the most well-studied PAMPs are bacterial flagellin and translational elongation factor Tu, which are recognized by the receptor-like kinase (RLK) PRRs FLAGELLIN-SENSING 2 (FLS2) and ELONGATION FACTOR RECEPTOR (EFR), respectively [1-3]. Following PAMP recognition, PRRs associate with additional transmembrane RLKs such as BRI1ASSOCIATED RECEPTOR KINASE1 (BAK1) as well as receptor-like cytoplasmic kinases (RLCKs) to transduce an intracellular signal via mitogen-activated protein (MAP) kinase cascades for the activation of PAMP-triggered immunity (PTI) [4-6]. This immune response involves transcriptional reprogramming, callose deposition in the cell wall, production of reactive oxygen species (ROS), and secretion of antimicrobial compounds, all of which serve to prevent an infection from becoming established. Faced with this defensive barrier, many phytopathogenic bacteria have evolved virulence effector proteins that are introduced into host cells via a needle-like structure known as a type III secretion system [7]. These type III-secreted effectors (T3SEs) are targeted to multiple locations in the host intracellular space where they act to suppress host immune responses and restore bacterial virulence [8-10]. Depending on the genetic background of the host, the advantage conferred by T3SEs 
can become a liability, as plants have evolved intracellular nucleotide-binding leucine rich repeat (NLR) proteins to recognize T3SEs, either by direct interaction or by detecting the enzymatic activity of the T3SE [11,12]. Indirect mechanisms of T3SE recognition may involve an NLR "guarding" a virulence target and monitoring for T3SE-mediated modifications to its "guardee", or the NLR may interact with a "decoy" protein that mimics a true virulence target in order to detect T3SE activity [13]. Some NLRs have evolved as translational fusions with decoy proteins, referred to as "integrated domains". Recognition of a T3SE elicits a more intense immune response (effector-triggered immunity, or ETI) that may culminate in a localized programmed cell death response known as a hypersensitive response (HR), ultimately restricting the spread of an infection in host tissues. The evolution of additional T3SEs that interfere with ETI in turn drives further NLR evolution, resulting in a dynamic molecular interface between plants and prospective pathogens. Beyond the PRR and NLR surveillance systems, plants have also evolved a complex signaling network to coordinate appropriate immune responses, mediated by phytohormones such as salicylic acid (SA), jasmonic acid (JA), ethylene, abscisic acid, auxins, cytokinins, gibberellins, and brassinosteroids [14]. Furthermore, elicitation of defense responses locally at the site of infection may stimulate the release of additional mobile signaling molecules that reduce the susceptibility of distal tissues to infection, in a phenomenon known as systemic acquired resistance (SAR) [15,16]. Altogether, the signaling infrastructure of plant immunity provides numerous targets for potential virulence-promoting T3SEs.

One of the most remarkable aspects of bacterial T3SEs is that they have evolved in prokaryotic cells as tools that must be functional in eukaryotic cells. This requires the T3SE to be correctly localized within the host cell, to interact with substrates that may be different from any endogenous bacterial proteins, and to provide adequate enzymatic activity in the eukaryotic intracellular milieu. In this review, we provide a survey of T3SEs from phytopathogenic bacteria with a particular emphasis on the enzymatic activities utilized by these proteins to promote pathogen virulence. We also note instances where this activity is known to stimulate NLR-mediated ETI. Our focus is largely on T3SEs with documented enzymatic activities, although we also discuss T3SEs that facilitate virulence-promoting processes either indirectly or through non-enzymatic mechanisms. Where appropriate, we consider the evolutionary origins of different T3SE activities and enumerate the hostmediated modifications of certain T3SEs that are required for their function in host cells. Cumulatively, these details reveal a striking convergence in both the enzymatic activities and host targets of T3SEs in plant cells (summarized in Figure 1 and Table 1). 


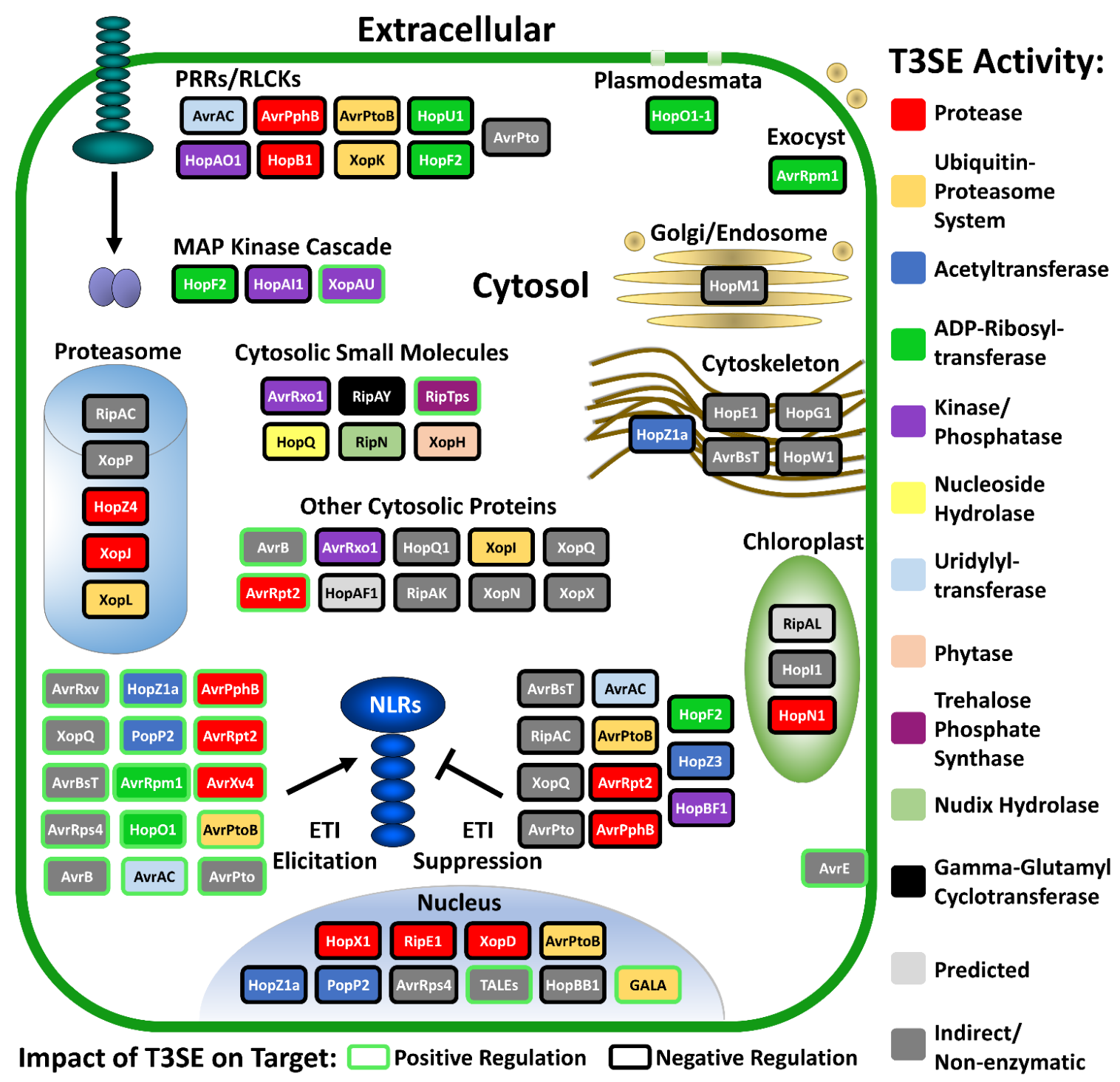

Figure 1. Schematic overview of bacterial type III-secreted effector (T3SE) activities in the plant intracellular space. The T3SEs discussed in this review are arranged in functional categories based on their characterized target(s) in terms of biological process or subcellular location. For each T3SE, a black border indicates that the T3SE negatively regulates its target in some manner, while T3SEs with a green border function as positive regulators. Note that the GALA family of T3SEs interacts with several target proteins that are primarily nuclear-localized but may be found in other subcellular locations as well. Limited data are available for the localization of AvrE-type T3SEs, but AvrE1 is known to associate with the plasma membrane. 
Table 1. Summary of biochemical activities and (a)virulence functions of type III-secreted effector proteins from phytopathogenic bacteria.

\begin{tabular}{|c|c|c|c|c|c|c|}
\hline Activity & Effector & Pathogen & In planta Activation & $\begin{array}{c}\text { Host } \\
\text { Target(s)/Substrate(s) }\end{array}$ & $\begin{array}{l}\text { Consequences of Activity for Pathogen } \\
\text { Virulence/Avirulence }\end{array}$ & Ref. \\
\hline \multirow[t]{8}{*}{ Acetyltransferase } & AvrBsT & $\begin{array}{l}\text { Xanthomonas } \\
\text { euvesicatoria }\end{array}$ & Phosphorylation & ACIP1 & $\begin{array}{c}\text { Suppresses PTI and ETI; acetylated ACIP1 forms } \\
\text { aggregates whose association with microtubules } \\
\text { may be altered }\end{array}$ & [17] \\
\hline & & & & Unknown & $\begin{array}{c}\text { Suppresses AvrBs1-mediated ETI in a } \\
\text { SnRK1-dependent manner }\end{array}$ & [18] \\
\hline & HopZ1a & Pseudomonas syringae & $\begin{array}{l}\text { Myristoylation, phytate } \\
\text { binding }\end{array}$ & Tubulin & $\begin{array}{l}\text { Decreases microtubule networks, disrupts } \\
\text { secretory pathways, and suppresses cell } \\
\text { wall-based immunity }\end{array}$ & [19] \\
\hline & & & & JAZ proteins & $\begin{array}{l}\text { Promotes degradation of JAZ proteins and } \\
\text { activates JA signaling, acetylation not shown }\end{array}$ & [20] \\
\hline & & & & ZED1 & Activates ZAR1-mediated ETI & [21] \\
\hline & HopZ3 & Pseudomonas syringae & Phytate binding & $\begin{array}{l}\text { AvrB, AvrRpm1, RIN4, } \\
\text { RIPK }\end{array}$ & Suppresses RPM1-mediated ETI & [22] \\
\hline & PopP2 & Ralstonia solanacearum & Phytate binding & WRKY proteins & $\begin{array}{l}\text { Prevents WRKY proteins from binding DNA and } \\
\text { activating immunity genes }\end{array}$ & {$[23,24]$} \\
\hline & & & & RRS1 & Activates RRS1/RPS4-mediated ETI & {$[23,24]$} \\
\hline \multirow[t]{7}{*}{$\begin{array}{l}\text { ADP- } \\
\text { ribosyltransferase }\end{array}$} & AvrRpm1 & Pseudomonas syringae & Myristoylation/Palmitoylation & RIN4 & $\begin{array}{l}\text { Promotes RIN4 phosphorylation, which enhances } \\
\text { associations between RIN4 and exocyst subunits } \\
\text { and dampens flg22-induced callose deposition; } \\
\text { activates RPM1-mediated ETI }\end{array}$ & [25-27] \\
\hline & HopF2 & Pseudomonas syringae & Myristoylation & RIN4 & $\begin{array}{l}\text { Inhibits proteolytic cleavage of RIN4 by AvrRpt2 } \\
\text { to prevent AvrRpt2-induced ETI }\end{array}$ & [28] \\
\hline & & & & MKK4, MKK5 & Disrupts MAP kinase cascade to block PTI & {$[29,30]$} \\
\hline & & & & BAK1 & $\begin{array}{c}\text { Inhibits multiple downstream signaling events, } \\
\text { including the phosphorylation of BIK1 and } \\
\text { MAPKs, to block PTI }\end{array}$ & [31] \\
\hline & HopO1-1 ${ }^{1}$ & Pseudomonas syringae & Myristoylation & PDLP7 & $\begin{array}{c}\text { Destabilizes PDLP7 to increase } \\
\text { plasmodesmata-mediated molecular flow and } \\
\text { enhance bacterial spread within tissues }\end{array}$ & [32] \\
\hline & (HopO1 allele) & & & Unknown & Activates ZAR1-mediated ETI & {$[33,34]$} \\
\hline & HopU1 & Pseudomonas syringae & - & GRP7 & $\begin{array}{c}\text { Interferes with GRP7 binding to PRR transcripts, } \\
\text { thus reducing PTI }\end{array}$ & {$[35,36]$} \\
\hline \multirow[t]{3}{*}{$\begin{array}{l}\text { Cysteine } \\
\text { protease }\end{array}$} & AvrPphB & Pseudomonas syringae & Myristoylation/Palmitoylation & $\begin{array}{l}\text { BIK1 and other PBS1-like } \\
\text { protein kinases }\end{array}$ & Suppresses PTI & [37] \\
\hline & & & & RIPK & Blocks the recognition of AvrB by RPM1 & {$[38]$} \\
\hline & & & & PBS1 & Activates RPS5-mediated ETI & {$[39,40]$} \\
\hline
\end{tabular}


Table 1. Cont.

\begin{tabular}{|c|c|c|c|c|c|c|}
\hline Activity & Effector & Pathogen & In planta Activation & $\begin{array}{c}\text { Host } \\
\text { Target(s)/Substrate(s) }\end{array}$ & $\begin{array}{c}\text { Consequences of Activity for Pathogen } \\
\text { Virulence/Avirulence }\end{array}$ & Ref. \\
\hline & AvrRpt2 & Pseudomonas syringae & $\begin{array}{l}\text { Folding assisted by host } \\
\text { cyclophilin ROC1 }\end{array}$ & RIN4 & $\begin{array}{c}\text { Activates RPS2-mediated ETI, but suppresses PTI } \\
\text { in plants lacking RPS2; blocks recognition of } \\
\text { AvrRpm1 and AvrB by RPM1 }\end{array}$ & [41-43] \\
\hline & HopN1 & Pseudomonas syringae & - & PsbQ & $\begin{array}{l}\text { Reduces pathogen-induced ROS production and } \\
\text { necrotic disease symptoms }\end{array}$ & {$[44]$} \\
\hline & HopX1 & Pseudomonas syringae & - & JAZ proteins & $\begin{array}{c}\text { Enhances JA signaling, repressing SA signaling } \\
\text { and promoting susceptibility to (hemi)biotrophic } \\
\text { pathogens }\end{array}$ & {$[45]$} \\
\hline & HopZ4 & Pseudomonas syringae & Myristoylation & RPT6, proteasome & Inhibits proteasome activity & [46] \\
\hline & RipE1 & Ralstonia solanacearum & - & JAZ proteins & $\begin{array}{c}\text { Enhances JA signaling, repressing SA signaling } \\
\text { and promoting susceptibility to (hemi)biotrophic } \\
\text { pathogens }\end{array}$ & [47] \\
\hline & XopJ & $\begin{array}{l}\text { Xanthomonas } \\
\text { euvesicatoria }\end{array}$ & Myristoylation & RPT6, proteasome & $\begin{array}{c}\text { Inhibits and degrades RPT6, suppresses cell } \\
\text { wall-based immunity and SA signaling }\end{array}$ & {$[48,49]$} \\
\hline SUMO protease & AvrXv4 & $\begin{array}{l}\text { Xanthomonas } \\
\text { euvesicatoria }\end{array}$ & - & Unknown & Elicits a hypersensitive response in $N$. benthamiana & {$[50]$} \\
\hline $\begin{array}{l}\text { Threonine } \\
\text { protease }\end{array}$ & HopB1 & Pseudomonas syringae & - & BAK1 & Suppresses PTI & [53] \\
\hline \multirow[t]{4}{*}{ Protein kinase } & \multirow[t]{2}{*}{ AvrRxo1 } & $\begin{array}{l}\text { Xanthomonas spp. (and } \\
\text { Acidovorax, } \\
\text { Burkholderia) }\end{array}$ & \multirow[t]{2}{*}{ Myristoylation } & NAD & $\begin{array}{l}\text { Production of } 3^{\prime} \text {-NADP (uncharacterized } \\
\text { mechanism of virulence promotion) }\end{array}$ & {$[54,55]$} \\
\hline & & & & SINAT4 & $\begin{array}{c}\text { Enhances degradation of RD21A which suppresses } \\
\text { drought-induced immunity }\end{array}$ & [56] \\
\hline & HopBF1 & Pseudomonas syringae & - & Hsp90 & $\begin{array}{l}\text { Inactivates Hsp90 to destabilize NLRs and dampen } \\
\text { ETI; may also promote cell death during the } \\
\text { necrotrophic phase of } P \text {. syringae infection }\end{array}$ & [57] \\
\hline & XopAU & $\begin{array}{l}\text { Xanthomonas } \\
\text { euvesicatoria }\end{array}$ & - & MKK2 & $\begin{array}{c}\text { Activates MKK2 to manipulate MAPK signaling } \\
\text { and promote chlorosis }\end{array}$ & [58] \\
\hline $\begin{array}{l}\text { Phosphothreonine } \\
\text { lyase }\end{array}$ & HopAI1 & Pseudomonas syringae & - & MPK3, MPK6 & $\begin{array}{l}\text { Disrupts MAPK signaling cascade and suppresses } \\
\text { PTI }\end{array}$ & [59] \\
\hline $\begin{array}{c}\text { Tyrosine } \\
\text { phosphatase }\end{array}$ & HopAO1 & Pseudomonas syringae & - & $\begin{array}{l}\text { MPK4 } \\
\text { EFR, LORE, and possibly } \\
\text { FLS2 }\end{array}$ & $\begin{array}{c}\text { Activates SUMM2-mediated ETI } \\
\text { Suppresses PTI }\end{array}$ & $\begin{array}{c}{[60]} \\
{[61,62]}\end{array}$ \\
\hline
\end{tabular}


Table 1. Cont.

\begin{tabular}{|c|c|c|c|c|c|c|}
\hline Activity & Effector & Pathogen & In planta Activation & $\begin{array}{c}\text { Host } \\
\text { Target(s)/Substrate(s) }\end{array}$ & $\begin{array}{c}\text { Consequences of Activity for Pathogen } \\
\text { Virulence/Avirulence }\end{array}$ & Ref. \\
\hline \multirow[t]{12}{*}{$\begin{array}{l}\text { Ubiquitin- } \\
\text { proteasome } \\
\text { machinery }\end{array}$} & AvrPtoB & Pseudomonas syringae & Phosphorylation/Ubiquitination & $\begin{array}{l}\text { EFR, FLS2, BAK1, } \\
\text { CERK1 }\end{array}$ & Degrades PRRs to suppress PTI & [63-65] \\
\hline & & & & NPR1 & $\begin{array}{c}\text { Degrades NPR1 to disrupt SA-mediated signaling } \\
\text { and SAR }\end{array}$ & {$[66]$} \\
\hline & & & & Fen & Degrades Fen to block AvrPtoB-mediated ETI & [67] \\
\hline & & & & Pto & $\begin{array}{c}\text { Activates Pto/Prf-mediated ETI (Pto is neither } \\
\text { ubiquitinated nor degraded) }\end{array}$ & {$[68,69]$} \\
\hline & GALA proteins & Ralstonia solanacearum & - & SKP1-like proteins & Promotes virulence via an unknown mechanism & {$[70,71]$} \\
\hline & RipAR & Ralstonia solanacearum & - & Unknown & Suppresses PTI & [72] \\
\hline & RipAW & Ralstonia solanacearum & - & Unknown & Suppresses PTI & {$[72]$} \\
\hline & RipV2 & Ralstonia solanacearum & - & Unknown & Suppresses PTI & [73] \\
\hline & XopAE & $\begin{array}{l}\text { Xanthomonas } \\
\text { euvesicatoria }\end{array}$ & - & Unknown & Suppresses PTI & [74] \\
\hline & XopI & $\begin{array}{l}\text { Xanthomonas oryzae pv. } \\
\text { oryzae }\end{array}$ & - & OsTrxh2 & $\begin{array}{l}\text { Degradation of OsTrxh2 represses } \\
\text { OsNPR-mediated signaling and SAR }\end{array}$ & [75] \\
\hline & XopK & $\begin{array}{l}\text { Xanthomonas oryzae pv. } \\
\text { oryzae }\end{array}$ & - & OsSERK2 & Virulence promotion & [76] \\
\hline & XopL & $\begin{array}{l}\text { Xanthomonas } \\
\text { euvesicatoria }\end{array}$ & - & SH3P2 & $\begin{array}{l}\text { Suppresses PTI and promotes virulence by } \\
\text { inhibiting autophagy }\end{array}$ & {$[77,78]$} \\
\hline \multirow[t]{2}{*}{ Uridylyltransferase } & AvrAC & $\begin{array}{l}\text { Xanthomonas campestris } \\
\text { pv. campestris }\end{array}$ & - & BIK1, RIPK & Suppresses PTI and RPM1-mediated ETI & [79] \\
\hline & & & & PBL2 & Activates ZAR1-mediated ETI & [80] \\
\hline Phytase/Phosphatase & ХopH & $\begin{array}{l}\text { Xanthomonas } \\
\text { euvesicatoria }\end{array}$ & - & Phytate & Suppresses PTI, activates Bs7-mediated ETI & {$[81]$} \\
\hline $\begin{array}{l}\text { Trehalose } \\
\text { phosphate } \\
\text { synthase }\end{array}$ & RipTps & Ralstonia solanacearum & - & Glucose-6-phosphate & $\begin{array}{l}\text { Promotes trehalose synthesis (uncharacterized } \\
\text { impact on virulence) }\end{array}$ & [82] \\
\hline $\begin{array}{l}\text { Gamma- } \\
\text { glutamyl } \\
\text { cyclo- } \\
\text { transferase }\end{array}$ & RipAY & Ralstonia solanacearum & Thioredoxin binding & Glutathione & Suppresses PTI & [83] \\
\hline $\begin{array}{l}\text { Nudix } \\
\text { hydrolase }\end{array}$ & RipN & Ralstonia solanacearum & - & ADP-ribose, NADH & Suppresses PTI & [84] \\
\hline
\end{tabular}


Table 1. Cont.

\begin{tabular}{|c|c|c|c|c|c|c|}
\hline Activity & Effector & Pathogen & In planta Activation & $\begin{array}{c}\text { Host } \\
\text { Target(s)/Substrate(s) }\end{array}$ & $\begin{array}{l}\text { Consequences of Activity for Pathogen } \\
\text { Virulence/Avirulence }\end{array}$ & Ref. \\
\hline $\begin{array}{l}\text { Nucleoside } \\
\text { hydrolase }\end{array}$ & HopQ1 & Pseudomonas syringae & Phosphorylation & Cytokinin precursors & Increases cytokinin accumulation to suppress PTI & {$[85]$} \\
\hline $\begin{array}{l}\text { Deamidase } \\
\text { (predicted) }\end{array}$ & HopAF1 & Pseudomonas syringae & Myristoylation/Palmitoylation & MTN1, MTN2 & $\begin{array}{l}\text { Inhibits MTN activity to reduce ethylene } \\
\text { biosynthesis and suppress PTI }\end{array}$ & {$[87]$} \\
\hline $\begin{array}{c}\text { Lipase } \\
\text { (predicted) }\end{array}$ & RipAL & Ralstonia solanacearum & - & $\begin{array}{l}\text { Chloroplast lipids } \\
\text { (predicted) }\end{array}$ & $\begin{array}{l}\text { Stimulates JA biosynthesis, repressing SA } \\
\text { signaling and promoting susceptibility to } \\
\text { (hemi)biotrophic pathogens }\end{array}$ & {$[88]$} \\
\hline \multirow[t]{11}{*}{$\begin{array}{l}\text { Indirect/Non- } \\
\text { enzymatic } \\
\text { mechanisms }\end{array}$} & AvrB & Pseudomonas syringae & $\begin{array}{l}\text { Phosphorylation/ } \\
\text { Myristoylation }\end{array}$ & RIPK and other RLCKs & $\begin{array}{l}\text { Enhances kinase activity to phosphorylate RIN4 } \\
\text { and suppress PTI; can trigger ETI through RPM1 }\end{array}$ & {$[89,90]$} \\
\hline & & & & MPK4 & $\begin{array}{l}\text { Upregulates jasmonate signaling to enhance } \\
\text { pathogen susceptibility }\end{array}$ & [91] \\
\hline & AvrBsT & $\begin{array}{l}\text { Xanthomonas } \\
\text { euvesicatoria }\end{array}$ & Phosphorylation & SGT1 homologs & Activates AvrBsT-mediated ETI & {$[92]$} \\
\hline & AvrE-type T3SEs & $\begin{array}{l}\text { Pseudomonas syringae } \\
\text { (AvrE), Pantoea } \\
\text { stewartii subsp. } \\
\text { stewartii (WtsE), } \\
\text { Erwinia amylovora } \\
\text { (DspA/E) }\end{array}$ & - & PP2A B' subunits & $\begin{array}{c}\text { Enhances phosphatase activity, which may disrupt } \\
\text { sphingolipid biosynthesis }\end{array}$ & {$[93,94]$} \\
\hline & AvrPto & Pseudomonas syringae & \multicolumn{2}{|c|}{ Phosphorylation/Myristoylation FLS2, EFR, CERK1, } & Suppresses PTI & {$[95,96]$} \\
\hline & & & \multirow{2}{*}{ Palmitoylation } & Pto & Activates Pto/Prf-mediated ETI & [97] \\
\hline & & & & SOBIR1 & Suppresses Cf-4-mediated ETI & [98] \\
\hline & AvrRpm1 & Pseudomonas syringae & $\begin{array}{l}\text { Myristoylation/ } \\
\text { Palmitoylation }\end{array}$ & RIPK and other RLCKs & $\begin{array}{l}\text { Enhances kinase acitivity to phosphorylate RIN4 } \\
\text { and suppress PTI; activates RPM1-mediated ETI }\end{array}$ & {$[89,90]$} \\
\hline & AvrRps4 & Pseudomonas syringae & $\begin{array}{l}\text { Host-mediated proteolytic } \\
\text { cleavage }\end{array}$ & BTS & $\begin{array}{c}\text { Enhances apoplastic iron accumulation to promote } \\
\text { pathogen proliferation }\end{array}$ & [99] \\
\hline & & & & RRS1 & Activates RRS1/RPS4-mediated ETI & {$[24,100]$} \\
\hline & AvrRpt2 & Pseudomonas syringae & $\begin{array}{l}\text { Folding assisted by host } \\
\text { cyclophilin ROC1 }\end{array}$ & $\begin{array}{l}\text { Aux/IAA proteins, e.g., } \\
\text { AXR2, AXR3 }\end{array}$ & $\begin{array}{l}\text { Enhances auxin signaling to promote susceptibility } \\
\text { to infection }\end{array}$ & [101] \\
\hline
\end{tabular}


Table 1. Cont.

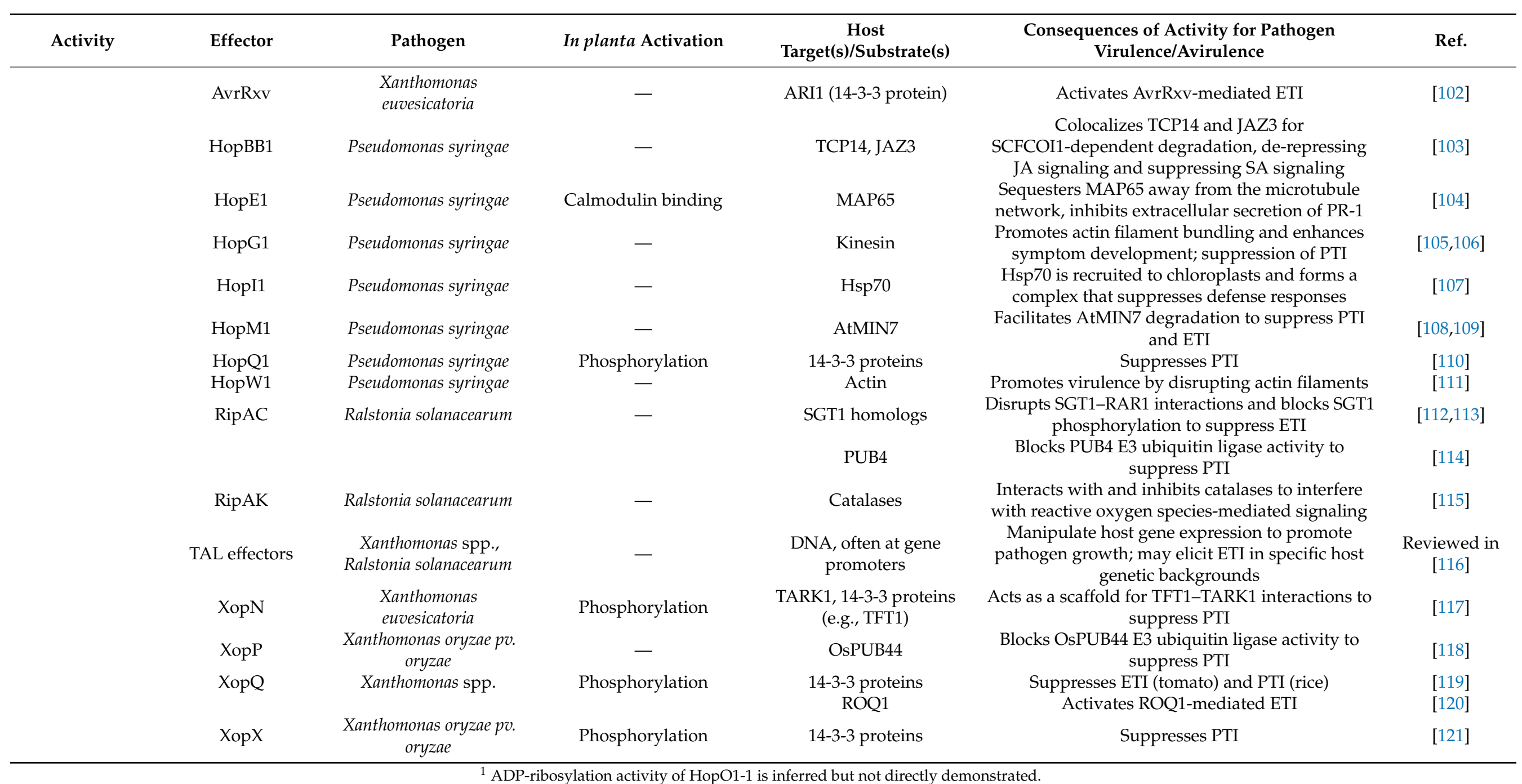




\section{T3SEs with Protease Activity}

One effective and widely adopted pathogen virulence strategy involves the elimination of key plant immune regulators by proteolytic cleavage. Protease enzymes cleave peptide bonds within proteins and are classified into seven broad groups based on their catalytic residues as aspartic, cysteine, glutamic, serine, threonine, or metalloproteases, in addition to asparagine peptide lyases $[122,123]$. These enzymes are distributed throughout all kingdoms of life, which provides a feedstock for T3SE evolution from endogenous bacterial proteases, interbacterial horizontal gene transfer, and gene acquisition from non-bacterial sources. The wide diversity of known protease substrates also implies that proteolytic T3SEs can be highly versatile tools with which pathogens can influence host immunity.

2.1. T3SEs with Cysteine Protease Activity—AvrRpt2, AvrPphB, HopN1, HopX1, RipE1, XopJ, HopZ4, XopD, and AvrXv4

One of the most well-characterized proteolytic T3SEs is AvrRpt2, which was initially identified in P. syringae pv. tomato JL 1065 as an elicitor of the HR on certain Arabidopsis ecotypes and soybean (Glycine max) cultivars [124]. Subsequent genetic analysis pinpointed RESISTANCE TO PSEUDOMONAS SYRINGAE 2 (RPS2) as the NLR responsible for AvrRpt2 recognition [125]. This recognition is not direct, however, but involves a complex of RPS2 with the immune regulator RPM1-INTERACTING PROTEIN 4 (RIN4), and RPS2 is activated by the AvrRpt2-mediated elimination of RIN4 [25,126,127]. For functional characterization, the predicted secondary structure of AvrRpt2 was found to be similar to the solved crystal structures of some cysteine protease enzymes, including the presence of a putative catalytic triad (cysteine, histidine, aspartic acid) in AvrRpt2 [126]. The catalytic triad is required both for the elimination of RIN4 by AvrRpt2 and for recognition of this T3SE by RPS2. Interestingly, RIN4 is also used by the NLR RESISTANCE TO PSEUDOMONAS SYRINGAE PV. MACULICOLA 1 (RPM1) to recognize the T3SEs AvrB and AvrRpm1, so the presence of AvrRpt2 can interfere with RPM1-mediated ETI [41-43,128]. In the absence of RPS2, cleavage of RIN4 by AvrRpt2 facilitates suppression of PTI through a yet-undetermined mechanism, albeit one which is dependent on the catalytic triad of AvrRpt2 [89,129]. Some degree of virulence-promoting activity for AvrRpt2 is still detectable in a rin 4 background, suggesting that there are additional AvrRpt2 virulence targets $[130,131]$. Indeed, RIN4 belongs to a diverse family of nitrate-induced (NOI) domain-containing proteins, and several other members of this family can be cleaved by AvrRpt2, with a consensus cleavage site of [LVI] PxFGxW [132,133]. One notable RIN4-independent AvrRpt2 activity is the suppression of flg22-induced activation of the MAPKs MPK4 and MPK11 [133]. The role of NOI family proteins in this process is unclear, however, as individual knockouts of NOI protein genes did not alter the MPK suppression phenotype, although not all NOI protein genes were tested and functional redundancy could be a complicating issue. More generally, the NOI protein family is largely uncharacterized aside from the presence of conserved PxFGxW and Y/FTxxF motifs, and despite their name, NOI domain-containing proteins are not involved in nitrogen metabolism [134]. Nonetheless, the discovery of AvrRpt2 orthologs in diverse bacterial species, capable of cleaving RIN4 and other NOI proteins, suggests that AvrRpt2 is an important contributor to bacterial virulence.

The T3SE AvrPphB (or hopAR1) was also first described as an avirulence determinant, based on the ability of a protein from P. syringae pv. phaseolicola 1301A to elicit an HR on specific cultivars of bean (Phaseolus vulgaris) [135]. Sequence analyses revealed that AvrPphB was similar to the YopT T3SE family from various Yersinia species and highlighted a conserved cysteine/histidine/aspartic acid triad typically found in cysteine proteases [136]. Indeed, AvrPphB is proteolytically processed in Pseudomonas prior to secretion [137], and this cleavage is dependent on the cysteine/histidine/aspartic acid triad, indicative of an autocatalytic mechanism [136]. The avirulence function of AvrPphB also requires the catalytic triad. The recognition of AvrPphB involves the NLR RESISTANCE TO PSEUDOMONAS SYRINGAE 5 (RPS5) [138] in complex with the RLCK AVRPPHB SUSCEPTIBLE 1 (PBS1) $[39,139,140]$. Cleavage of PBS1 by AvrPphB elicits RPS5-mediated ETI, 
although the activation of RPS5 likely involves sensing a general conformational change in PBS1 rather than the generation of free protein ends resulting from cleavage [141]. The activity of AvrPphB as a protease is further evidenced by observations that PBS1 cleavage requires an intact catalytic triad in AvrPphB [40] and that this cleavage is largely blocked by incubation with the protease inhibitor E-64 [142]. Additionally, the AvrPphB crystal structure closely resembles structures of other cysteine proteases [142]. In terms of virulence function, AvrPphB suppresses PTI-associated gene expression and callose deposition in a mostly PBS1-independent manner [37]. A survey of PBS1-like (PBL) proteins revealed that AvrPphB cleaves additional RLCKs including BOTRYTIS-INDUCED KINASE 1 (BIK1) and two PBLs designated PBL1 and PBL2. These RLCKs interact with and act directly downstream of PRRs such as FLS2 and EFR, so their cleavage by AvrPphB compromises PTI and promotes pathogen proliferation. Likewise, signaling downstream of the chitin receptor CERK1 is predicted to be disrupted by AvrPphB-mediated cleavage of PBL27 $[143,144]$. Effector-triggered immunity is also impacted by AvrPphB, specifically the recognition of the T3SE AvrB by the NLR RPM1. This recognition occurs when AvrB associates with RPM1-INTERACTING PROTEIN KINASE (RIPK), which phosphorylates the immune regulator RIN4 and thus activates RPM1 $[89,90]$. The cleavage of RIPK by AvrPphB blocks the recognition of AvrB to restore the virulence of strains carrying this T3SE [38]. Overall, the sequences of known AvrPphB substrates reveal that cleavage occurs C-terminal to a moderately conserved GDK motif, although additional residues are involved in substrate engagement, as the GDK sequence is necessary but not sufficient for cleavage [37,40,142].

In contrast to the broad range of putative substrates for AvrRpt2 and AvrPphB, the T3SE HopN1 appears to act on one specific target. Initial functional characterization of HopN1 determined that this T3SE was capable of suppressing necrotic disease symptoms on susceptible hosts and inhibiting nonhost HRs [145]. A predicted cysteine protease catalytic triad was verified as being essential for these suppressive phenotypes, and cysteine protease activity was demonstrated in vitro with purified recombinant HopN1 and resorufin-labeled casein as a generic protease substrate [145]. Purified HopN1 was also used for an in vitro pull-down from tomato leaf extract, which identified PsbQ, a member of the oxygen-evolving complex of photosystem II, as a HopN1 interactor [44]. The interaction was validated in vitro, and interestingly, a catalytic mutant of HopN1 did not bind PsbQ. Notably, HopN1 localizes to chloroplasts and reduces the electron transport activity of photosystem II [44]. Proteolysis of PsbQ was observed when thylakoid samples were incubated with partially purified HopN1, again dependent on the catalytic triad [44]. PsbQsilenced tobacco plants exhibit reduced ROS production following exposure to a virulent pathogen, as well as diminished nonhost HRs [44]. Although a direct effect of HopN1 on bacterial growth could not be detected in planta, it is possible that HopN1 reduces ROS accumulation during infection and could suppress cell death responses elicited by other T3SEs.

Proteolytic T3SEs may also target a specific family of proteins, as illustrated by HopX1 from P. syringae pv. tabaci 11528 and RipE1 from R. solanacearum. For HopX1, it was known that $P$. syringae pv. tabaci 11528 lacks coronatine but can still overcome PTI-associated stomatal closure, suggesting that this strain might possess another virulence factor that mimics coronatine as a strategy for modulating stomatal aperture $[45,146]$. Coronatine facilitates the interaction of CORONATINE-INSENSITIVE 1 (COI1) and JASMONATEZIM DOMAIN (JAZ) proteins, which results in JAZ degradation and de-repression of jasmonate signaling $[147,148]$. With this in mind, Gimenez-lbanez et al. [45] conducted a screen to identify T3SEs from P. syringae pv. tabaci 11528 capable of destabilizing JAZ proteins. They noted that HopX1 possessed such activity, and that the amino acid sequence of this T3SE included a cysteine protease-like cysteine/histidine/aspartic acid catalytic triad. Proteolytic activity was confirmed in vitro using JAZ5 as a substrate, and HopX1 activity was shown to be sensitive to protease inhibitors [45]. In planta, JAZ1, JAZ2, JAZ5, JAZ9, and JAZ10 all interact with and are degraded by HopX1, and degradation requires 
the HopX1 catalytic triad [45]. Ultimately, JAZ protein degradation induces jasmonateresponsive gene expression, which suppresses SA-dependent gene expression and enhances the susceptibility of Arabidopsis plants to infection by P. syringae. Similarly, RipE1 was identified in a screen for $R$. solanacearum T3SEs capable of suppressing a flg22-induced ROS burst [47]. Subsequent characterization in yeast two-hybrid experiments indicated that RipE1 interacts with JAZ4, JAZ9, and JAZ10. These three proteins are degraded by RipE1 in planta, and a cysteine protease-like catalytic triad within RipE1 is required for this degradation [47]. As with HopX1, JAZ degradation by RipE1 increases host susceptibility to infection by suppressing SA-mediated gene expression. Despite the similar enzymatic activities of HopX1 and RipE1, only RipE1 can suppress flg22-induced ROS accumulation and PTI-related gene expression [47], indicating some mechanistic differences that remain to be explored.

Another avenue for the manipulation of phytohormone signaling involves proteolysis of components of the proteasome, which is a key mediator of protein turnover. The Xanthomonas euvesicatoria T3SE XopJ and P. syringae T3SE HopZ4 are both members of the widely distributed and highly diverse YopJ superfamily [149]. Although several members of this family exhibit acetyltransferase activity (see Section 5), the conserved catalytic site of these enzymes (histidine, aspartic acid/glutamic acid, cysteine) resembles that of cysteine proteases, and weak protease activity can be detected for some acetyltransferase T3SEs [18,150]. Importantly, the catalytic triad is conserved in both XopJ and HopZ4 [46,48,151]. Functionally, XopJ directly interacts with and degrades a subunit of the host proteasome, REGULATORY PARTICLE TRIPLE-A ATPASE 6 (RPT6) [48,151]. This degradation is impaired by mutation of the putative catalytic cysteine and by treatment with the cysteine protease inhibitor E-64, suggesting that the disappearance of RPT6 is due to XopJ-mediated proteolysis. RPT6 degradation inhibits the proteasome and impairs the turnover of NONEXPRESSOR OF PATHOGENESIS-RELATED GENES 1 (NPR1), a major regulator of SA-dependent defense responses [48,151]. Accordingly, X. euvesicatoria $\triangle x o p J$ mutants trigger early necrosis in susceptible pepper plants, but not in pepper plants with reduced expression of NPR1, indicating that XopJ interferes with SA responses in order to delay the onset of necrosis [151]. This likely has many additional downstream effects, as supported by the suppression of callose deposition and other defense responses in transgenic Arabidopsis plants expressing XopJ [49]. Interference with SA signaling also plays a role in XopJ avirulence activity, as XopJ triggers an HR only upon application of SA in N. benthamiana and this HR is abolished when NPR1 is silenced [152]. Similar to XopJ, HopZ4 was also shown to interact with RPT6 in yeast and in planta [46]. Moreover, HopZ4 was shown to suppress proteasome activity in a manner dependent on an intact catalytic triad, suggesting it also acts as a protease to degrade RPT6 and could similarly affect SA signaling [46].

Cysteine protease T3SEs can also target specific post-translational modifications in host proteins, as illustrated by the X. euvesicatoria T3SE XopD [153]. An examination of the XopD amino acid sequence indicated that the C-terminus of this T3SE is similar to the C48 family of cysteine proteases, which contains enzymes that deconjugate small ubiquitin-like modifier (SUMO) moieties from protein substrates [51]. Notably, XopD was found to be homologous to the ubiquitin-like, de-SUMOylating protease Ulp1, including the conservation of catalytic residues (histidine, aspartic acid, cysteine) and residues from the Ulp1 crystal structure that are important for substrate recognition. Determination of the XopD crystal structure later confirmed the homology with Ulp1 [154]. In vitro assays with purified XopD and a ${ }^{35}$ S-tomato SUMO-HA substrate demonstrated that XopD can proteolytically cleave SUMO precursor proteins [51]. Similar to other cysteine proteases from the C48 family, XopD SUMO protease activity was blocked by the protease inhibitors iodoacetamide and N-ethylmaleimide, as well as by mutation of the catalytic residues [51]. Similarly, XopD exhibits isopeptidase activity to deSUMOylate proteins both in vitro and in planta, which is also dependent on the protease catalytic residues. Functionally, XopD inhibits the expression of genes associated with ethylene biosynthesis in tomato, resulting 
in enhanced susceptibility to X. euvesicatoria, yet reduced development of chlorotic disease symptoms [52,155]. This activity is facilitated by the association of XopD with the transcription factor SOLANUM LYCOPERSICON ETHYLENE RESPONSE FACTOR 4 (SIERF4) [52]. This transcription factor is mono-SUMOylated in planta, and the removal of this modification by XopD destabilizes SIERF4 and impairs the expression of SlERF4-activated genes [52]. These deSUMOylation events are dependent on XopD protease activity but are also mitigated by the proteasome inhibitor MG132 [52]. In addition, XopD contains an ERF-associated amphiphilic repression (EAR) motif that contributes significantly to SIERF4 deSUMOylation, independent of any role as a simple binding interface. Interestingly, XopD also activates the expression of a putative basic helix-loop-helix transcription factor (bHLH132) in tomato through a yet-unknown mechanism, although this induction is also dependent on XopD SUMO protease activity [156]. In this case, however, bHLH132 expression is associated with host defense activation, indicating a potential liability to the virulence function of XopD arising from "off-target" T3SE activity. X. euvesicatoria possesses another T3SE, AvrXv4, whose sequence includes a conserved SUMO protease-like catalytic triad [50]. Enzymatic activity could not be detected in vitro, but transient expression of AvrXv4 in planta reduced the accumulation of co-expressed SUMO substrates in a catalytic site-dependent manner, suggesting that a plant co-factor is required [50]. Functionally, AvrXv4 elicits an HR in N. benthamiana via an unidentified NLR, and this phenotype is dependent on the catalytic residues of AvrXv4 [50]. X. euvesicatoria $\Delta a v r X v 4$ deletion mutants exhibit slightly reduced growth in tomato leaves, indicating that AvrXv4 does promote pathogen virulence in the absence of ETI, although the host targets of this T3SE are currently unknown [50].

\subsection{T3SEs with Threonine Protease Activity-HopB1}

While the majority of documented T3SE proteases are members of the cysteine protease family, the P. syringae T3SE HopB1 belongs to a relatively small family of threonine proteases. This T3SE was initially examined due to its ability to suppress flg22-induced expression of the PTI marker gene FRK1 [53]. In vitro pull-down assays identified FLS2 as a direct interactor with HopB1, and further in planta assays indicated that this interaction occurs regardless of the presence or absence of flg22 [53]. While HopB1 does not affect the abundance of FLS2, BAK1 disappears rapidly in flg22-treated protoplasts when HopB1 is present. The phosphorylation of BAK1 is essential for this event, indicating that HopB1 only targets activated BAK1. The disappearance of BAK1 results from the cleavage of this protein within the kinase P-loop region, between amino acids arginine-297 and glycine-298 [53]. Three other BAK1-related SOMATIC-EMBRYOGENESIS RECEPTORLIKE KINASEs (SERKs) are also cleaved by HopB1 between the same residues [53]. Given that neither the sequence nor predicted structure of HopB1 resembles any other known proteases, the sensitivity of HopB1 to class-specific protease inhibitors was assessed. Only serine protease inhibitors (PMSF and AEBSF) significantly reduced HopB1 protease activity [53]. Subsequent systematic mutagenesis of serine and threonine residues in HopB1 identified threonine-370 as a critical catalytic residue, and additional mutagenesis suggested a putative catalytic quartet (threonine, histidine, aspartic acid, aspartic acid) that is important for PTI suppression. Based on the composition of these catalytic residues, HopB1 is now classified as a threonine protease [123]. Overall, the model of HopB1 function posits that flg22 stimulates recruitment of BAK1 to FLS2, whereupon BAK1 is phosphorylated and subsequently cleaved by HopB1 to block downstream PTI responses [53].

\section{T3SE Manipulation of the Ubiquitin-Proteasome System}

The ubiquitin-proteasome system (UPS) in plants plays a critical role in mediating biotic stress responses not only through the removal of misfolded and defective proteins but also through the regulation of protein stability $[157,158]$. Proteins destined for degradation by the UPS are ubiquitinated by a cascade of three enzymatic reactions: (1) ubiquitin activation by the E1 enzyme; (2) transfer to the ubiquitin-conjugating enzyme, 
E2, and (3) attachment to the substrate by the E3 ligase [159]. E3 ligases confer specificity to the UPS through target protein selection [160]. As a result, plants encode a large number of E3 ligases, many of which have been shown to function as regulators of plant immunity and hormone signaling [161,162]. Given the importance of the UPS in regulating immune responses, it follows that pathogens have evolved T3SEs to manipulate the UPS machinery in order to promote virulence during plant-pathogen interactions.

\subsection{T3SEs That Mimic Eukaryotic E3 Ligases-AvrPtoB, GALAs, and XopI}

Several T3SEs have evolved to exploit the host UPS for the targeted degradation of host proteins by exhibiting E3 ubiquitin ligase activity. Perhaps the most well-characterized example of this is the T3SE AvrPtoB (also known as HopAB2) from P. syringae pv. tomato DC3000. AvrPtoB is a modular protein with two distinct subdomains [163]. The N-terminal region acts to suppress basal immunity and plays a key role in interactions with host proteins $[63,64,164]$. Meanwhile, the C-terminal domain displays structural homology to eukaryotic U-box/RING E3 ligases and has demonstrated ubiquitin ligase activity, initially confirmed by immunodetection of in vitro autoubiquitinated AvrPtoB [165]. Ubiquitination of host proteins by AvrPtoB has been shown to facilitate the subversion of multiple layers of plant immunity. In Arabidopsis, AvrPtoB catalyzes the ubiquitination and programmed degradation of several components of PTI, including the PRRs EFR, FLS2, BAK1, and CERK1 [63-65]. This degradation allows P. syringae to overcome PRR-mediated immunity, as evidenced by the reduced growth of P. syringae $\triangle a v r P t o B$ knockouts in Arabidopsis, which is not observed in cerk1 mutants [64]. In addition to suppressing PTI, AvrPtoB E3 ligase activity also interferes with SAR via the degradation of NPR1, a master regulator of SA signaling [66]. In tomato, AvrPtoB can be recognized by the NLR Prf, which interacts with the kinase decoys Fen or Pto [67]. For a Prf-Fen complex, the C-terminal E3 ligase activity of AvrPtoB serves to suppress ETI. This is mediated by an interaction between the kinase Fen and an N-terminal region of AvrPtoB, leading to Fen ubiquitination and proteasome-mediated degradation [67]. Importantly, AvrPtoB was initially discovered as an interactor with the tomato cytosolic kinase Pto [97]. In contrast to Fen, which only interacts with one domain of AvrPtoB, Pto interacts with a second AvrPtoB site distal to the E3 ligase domain [68]. The interaction of a Prf/Pto complex with this distal site in AvrPtoB results in ETI [69]. This demonstrates the role of AvrPtoB not only in promoting virulence but also in triggering immunity in the presence of a cognate NLR.

Similar to AvrPtoB, the highly conserved GALA family of T3SEs in $R$. solanacearum manipulates the host UPS machinery by mimicking eukaryotic E3 ubiquitin ligases, specifically components of SCF-type E3 ligases. SCF-type E3 ligases are multi-unit complexes consisting of SKP1, Cullin1, and F-box protein subunits. Sequence analysis of GALA proteins revealed that each of these T3SEs possesses a 48aa domain characteristic of eukaryotic F-box proteins [70]. Further, GALA proteins were found to directly interact with Arabidopsis SKP1-like proteins in a yeast two-hybrid screen, suggesting that GALAs can be incorporated into the host SCF complex [70]. Although single GALA knockouts do not have a significant effect on $R$. solanacearum virulence, mutants lacking all seven GALA proteins demonstrate significantly attenuated disease symptoms in Arabidopsis and tomato [70,71]. While specific targets have not yet been identified, this suggests a semi-redundant role for the GALA proteins, likely involving the ubiquitination of host defense-related proteins via SCF-type E3 ligase activity. More recently, the T3SE XopI from Xanthomonas oryzae pv. oryzae has also been identified as an F-box protein that contributes to bacterial virulence in rice. Yeast two-hybrid screens revealed that XopI interacts with the SKP1-like protein OSK1 through its F-box domain and with the thioredoxin OsTrxh2, a positive regulator of rice immunity, through its C-terminal domain [75]. As a result of these interactions, OsTrxh2 is degraded in a UPS-dependent manner. Degradation of OsTrxh2 further leads to the suppression of OsNPR1-dependent signaling, suggesting a role for XopI in suppressing SAR in rice [75]. 


\subsection{T3SEs That Possess Novel E3 Ligase Domains—RipAR, RipAW, RipV2, XopK, XopL, and XopAE}

Beyond mimicking eukaryotic E3 ligases, there is mounting evidence that bacteria have also evolved novel E3 ubiquitin ligase domains in order to leverage the host UPS. For example, the R. solanacearum T3SEs RipAR, RipAW, and RipV2 do not share homology with any known eukaryotic E3 ubiquitin ligases but instead possess a novel E3 ubiquitin ligase (NEL) domain from the IpaH family of Salmonella T3SEs $[72,73,166]$. Notably, RipAR, RipAW, and RipV2 all demonstrate E3 ubiquitin ligase activity in vitro and can suppress PTI responses in Nicotiana benthamiana [72], although the specific targets of these three T3SEs remain to be identified. The T3SE XopK from X. oryzae pv. oryzae also lacks significant similarity to any known E3 ubiquitin ligase but was observed to mediate the proteasome-dependent degradation of OsSERK2, a key regulator of rice immunity [76]. The E3 ubiquitin ligase activity of XopK was confirmed in vitro and shown to be necessary for full pathogen virulence.

Similarly, the T3SE XopL from X. euvesicatoria possesses E3 ubiquitin ligase activity but shows no structural similarity to known E3 ubiquitin ligases [77]. The crystal structure of XopL revealed an E3 ligase domain with a novel fold (termed the XL-domain), which was not present in any previously characterized E3 ubiquitin ligases. Additionally, XopL interacts with specific plant E2 enzymes, suggesting that this T3SE can utilize the existing host machinery for ubiquitination [77]. Recently, a yeast two-hybrid screen identified the autophagy component SH3P2 as a potential interactor with XopL [78]. Further, in vitro ubiquitination assays demonstrated that XopL can ubiquitinate SH3P2. Transient co-expression of XopL and SH3P2 in N. benthamiana reduced the abundance of SH3P2 and suppressed autophagy in planta [78]. This suppression was dependent on the proteasome as well as the E3 ligase domain of XopL, indicating that XopL ubiquitinates SH3P2 to target it for degradation by the UPS [78]. SH3P2 was previously found to associate with proteins that play a role in the later stages of autophagy mediated by NEIGHBOR OF BRCA 1 (NBR1) [167,168]. In mammalian systems, NBR1-mediated autophagy plays a key role in immunity by targeting pathogens to the autophagosome for degradation [169]. Plant homologs of NBR1 also influence immunity, indicating that XopL may promote $X$. euvesicatoria virulence by disrupting NBR1-mediated autophagic degradation. Interestingly, XopL undergoes autoubiquitination in planta, and ubiquitinated XopL is targeted for NBR1-mediated autophagic degradation [78]. Taken together, these data suggest XopL may undergo self-modification in order to access the host autophagy machinery and ultimately suppress host degradation mechanisms by targeting SH3P2. Following the identification of the novel XL-domain in XopL, another XL-domain-possessing T3SE, XopAE, was reported in X. euvesicatoria [74]. As seen with XopL, ubiquitination assays indicated that XopAE displays E3 ubiquitin ligase activity in vitro. Furthermore, this ligase activity was required for XopAE inhibition of PTI signaling, suggesting XopAE may target components of PTI for degradation [74].

\section{ADP-Ribosyltransferase T3SEs}

The ADP-ribosyltransferases (ADP-RTs) comprise a structurally diverse family of enzymes that are distributed throughout all kingdoms of life $[170,171]$. These enzymes catalyze the reversible transfer of ADP-ribose from nicotinamide adenine dinucleotide $\left(\mathrm{NAD}^{+}\right)$to proteins or other macromolecules [172-174]. Within this family, mono(ADPribosyl)transferases (mADP-RTs) attach a single ADP-ribose to their substrates, while poly(ADP-ribosyl)transferases (pADP-RTs) transfer multiple ADP-ribose moieties. The first identified mADP-RTs were bacterial in origin and included diphtheria toxin and cholera toxin, which are key mediators of pathogen virulence in mammalian hosts $[175,176]$. More recently, endogenous pADP-RT activity in Arabidopsis was shown to regulate host gene expression during immune responses and significantly influence susceptibility to pathogen infection [177-179]. The manipulation of host protein ADP-ribosylation thus represents a potentially important virulence target for T3SEs. 


\section{T3SEs with mADP-RT Activity-HopF2, HopU1, HopO1-1, and AvrRpm1}

The first hint that phytopathogens might use ADP-ribosylation to subvert host immunity was derived from the crystal structure of the T3SE HopF1 (formerly AvrPphF) from P. syringae pv. phaseolicola 1449B [180]. A subdomain of this protein is structurally similar to the catalytic domain of diphtheria toxin and includes conserved surface-exposed residues (arginine-72, aspartic acid-174) that were shown to contribute to the virulence function of HopF1 in bean plants. Subsequent advances in the functional characterization of this T3SE family have come from HopF2, a related allele from P. syringae pv. tomato DC3000. In Arabidopsis, HopF2 suppresses numerous PAMP-induced responses including callose deposition, ROS bursts, MAPK activation, and expression of PTI marker genes [29,30]. The effect on marker gene expression was abolished by mutation of the conserved surfaceexposed residues arginine-71 and aspartic acid-175. Furthermore, HopF2 interacts with the MAP kinase kinases (MKKs) MKK4 and MKK5 [29]. For MKK5, this prevents the key autophosphorylation event in MKK5 activation, blocking the downstream phosphorylation of MAPK6 and activation of PTI. The ADP-RT activity of HopF2 was demonstrated in vitro using MKK5 as a substrate in combination with biotinylated NAD as an ADP-ribose donor, followed by immunodetection of biotinylated substrates [29]. While the detected ADP-RT activity was arginine-71/aspartic acid-175-dependent, R71A and D175A substitutions eliminated the HopF2-MKK5 interaction, suggesting that these residues may comprise an important interaction interface rather than participate in reaction catalysis [29]. Further upstream in the PTI signaling pathway, HopF2 blocks the phosphorylation of BIK1, PBL1, and PBS1, which are RLCKs that interact with PRRs and transduce signals for immune activation [31]. This blockage is accomplished by the interaction of HopF2 with the transmembrane and kinase domains of the PRR-associated protein BAK1, although direct ADP-ribosylation remains to be demonstrated. It is hypothesized that this modification would interfere with the ability of BAK1 to activate downstream RLCKs and thereby disrupt the signaling cascade from MKK1/MKK2 to MAPK4 to PTI execution.

In addition to PTI, HopF2 also ADP-ribosylates host proteins involved in ETI. Wilton et al. [28] observed that bacterial expression of HopF2 can block the HR elicited in Arabidopsis by the cysteine protease T3SE AvrRpt2. Further investigation revealed that HopF2 interacts with and ADP-ribosylates RIN4 to prevent the AvrRpt2-mediated degradation of RIN4 that would normally elicit ETI [28,29]. These phenotypes were not observed in a HopF2 D175A mutant. Beyond interfering with ETI mediated by other T3SEs, the ADP-RT activity of a HopF2 allele (HopF1r) from P. syringae pv. aceris M302273PT can be recognized by the NLR HOPZ ACTIVATED RESISTANCE 1 (ZAR1) in combination with the RLCK ZED1-RELATED KINASE 3 (ZRK3) [181]. As HopF2a does not ADP-ribosylate ZRK3, there is likely another protein in the ZAR1-ZRK3 complex that senses this enzymatic activity prior to the activation of ETI.

In contrast to HopF2, HopU1 was first posited as an ADP-RT based on sequence analyses that highlighted conserved catalytic residues (R-ST-E) that are also found in cholera toxin [35]. An in vitro assay using ${ }^{32}$ P-labeled NAD and the generic substrate polyL-arginine confirmed that HopU1 possesses ADP-RT activity [35]. Proteomic screening identified two glycine-rich RNA-binding proteins, GRP7 and GRP8, as HopU1 substrates that are ADP-ribosylated at two sites in their RNA recognition motifs [35]. Both GRP7 and GRP8 bind to the $3^{\prime}$ UTR of mRNAs encoding the PRRs FLS2 and EFR, and ADP-ribosylation by HopU1 reduces the binding affinity of GRP7/8 for these transcripts [36,182]. The resulting impairment of FLS2/EFR translation attenuates PRR accumulation in response to infection and reduces host PTI induction. The crystal structure of HopU1 exhibits little similarity to that of HopF1, and HopU1 more closely resembles cholera toxin versus the diphtheria toxin-like structure of HopF1 [182].

The T3SE HopO1-1 was also identified as a putative ADP-RT based on a search for conserved amino acid sequence motifs, which indicated that HopO1-1 and HopU1 share the same conserved catalytic residues [32,35]. The enzymatic activity of purified recombinant HopO1-1 was verified using poly-L-arginine as an ADP-ribosylation substrate and 
shown to be dependent on the predicted catalytic residues [32]. Mechanistically, HopO1-1 interacts with the plasmodesmata-localized proteins PDLP5 and PDLP7, causing their proteasome-dependent degradation in vitro [32]. In planta, only PDLP7 was destabilized by HopO1-1 and thus likely represents the biologically relevant target. Although direct ribosylation of PDLP7 could not be demonstrated, mutation of two arginine residues in the HopO1-1-binding C-terminal region of PDLP7 prevented the degradation of this protein, presumably by blocking its ADP-ribosylation by HopO1-1 [32]. Overall, HopO1-1 is thought to destabilize PDLP7 to enhance molecular flux through plasmodesmata and facilitate the spread of bacteria in infected tissues. Interestingly, the NLR ZAR1 in complex with ZRK3 recognizes a HopO1 allele and elicits ETI in a manner dependent on the catalytic sites of the T3SE $[33,34]$. As with HopF1r, the direct ADP-ribosylation substrate for HopO1 recognition remains to be identified.

The P. syringae T3SE AvrRpm1 was one of the first bacterial avirulence factors to be identified [26,183], yet direct evidence for its enzymatic activity has been obtained only recently. It has long been known that AvrRpm1 facilitates the phosphorylation of RIN4 [25], but AvrRpm1 does not exhibit detectable kinase activity. Structural homology modeling identified a region of AvrRpm1 with similarity to a fold from the catalytic domain of poly(ADP-ribosyl)polymerase-1, and the mutation of putative catalytic residues abolished the function of AvrRpm1 in virulence or avirulence, depending on the genetic background of the host [184]. Furthermore, a recent experiment involving transient coexpression of AvrRpm1 and a soybean RIN4 homolog (GmRIN4b) in N. benthamiana followed by immunoprecipitation and mass spectrometry revealed two sites of mono-ADPribosylation in GmRIN4b [27]. This AvrRpm1-mediated modification was also detected in GmRIN4a, Arabidopsis RIN4, and several other NOI domain-containing proteins from Arabidopsis [27]. Amino acid substitutions in the putative catalytic residues of AvrRpm1 impaired this activity. In terms of functional relevance, RIN4 phosphorylation at threonine166 is necessary and sufficient for activation of RPM1-mediated ETI [89], and the ADPribosylation of RIN4 at aspartic acid-153 promotes this phosphorylation, contributing additively to RPM1 activation [27]. On the virulence side, AvrRpm1-mediated ADPribosylation of RIN4 promotes the association of RIN4 with exocyst subunits EXO70B1, EXO70E1, EXO70E2, and EXO70F1, which is speculated to interfere with PAMP-induced callose deposition to compromise PTI [27]. A potential connection between EXO70 proteins and ADP-ribosylation of RIN4 by HopF2 is intriguing but remains to be explored.

While a relatively small number of examples of ADP-RT T3SEs are known, it is interesting to note that all of the currently known ADP-RT T3SEs catalyze mono-ADPribosylation. This includes XopAI from Xanthomonas axonopodis pv. citri, whose solved crystal structure resembles a mADP-RT but whose activity and substrate(s) remain to be demonstrated [185]. Endogenous mADP-RTs in prokaryotes are primarily known to regulate enzymes involved in nitrogen fixation [186], and it is possible that T3SEs could have evolved from these enzymes. Alternatively, genes encoding ADP-RTs could originate from lysogenic phages. Evidence for this mechanism comes from cholera toxin, whose two components are encoded by the genome of the bacteriophage $\operatorname{CTX} \varphi$, which exists as a prophage integrated into the Vibrio cholerae genome $[187,188]$. A similar example of "lysogenic conversion" remains to be shown in phytopathogens, but the P. syringae and Xanthomonas spp. genomes contain prophage sequences, some of which harbor virulence factors [189-191]. Horizontal gene transfer from animal pathogens to plant pathogens is another avenue for T3SE evolution. Overall, ADP-RT T3SEs comprise a diverse group in sequence, structure, and substrates. There appears to be considerable variation in T3SE ADP-RT activity, with HopU1 exhibiting significantly greater activity than HopO1-1 [32]. The ADP-RT activity of HopF2 is quite weak and could only be demonstrated in vitro using biotin-labeled NAD [29], which is likely more sensitive than previous in vitro assays or in vivo radiolabeling assays that were unable to detect ADP-RT activity [28]. Direct in vitro comparisons with AvrRpm1 are complicated by the instability of the recombinant protein, such that AvrRpm1 ADP-RT activity has only been detected in planta thus far [27,184]. 


\section{Acetyltransferase T3SEs}

The YopJ/AvrRxv/HopZ family of T3SEs is an unusual T3SE family with acetyltransferase activity and is present in bacteria infecting mammals as well as plants. These T3SEs contain a conserved catalytic triad composed of histidine, glutamic acid, and cysteine and were originally believed to be cysteine proteases [192]. Well-characterized members of the superfamily are found in P. syringae (HopZ), Xanthomonas species (AvrRxv, AvrBsT, XopJ, and others), R. solanacearum (PopP2), and Erwinia species, as well as in animalinfecting bacterial genera such as Yersinia (YopJ), Salmonella (AvrA), and Vibrio (VopJ) [149]. Within P. syringae, HopZ1 diversified in response to recognition from the host immune system $[150,193,194]$. Other members of the HopZ family in P. syringae appear to have been acquired by horizontal gene transfer from Xanthomonas (HopZ2, HopZ4, and HopZ5) or Erwinia species (HopZ3) [46,150,195]. PopP2 is mostly closely related to a T3SE from Xanthomonas that is recognized in cabbage $[150,196]$. Here, we focus on members of the YopJ/AvrRxv/HopZ family that have acetyltransferase activity and which are found in plant pathogens $[17,19,23,197]$. Acetyltransferase activity is activated by inositol phosphate after the T3SE is introduced into the host cell $[17,19,23,197,198]$.

\subsection{T3SEs That Target the Cytoskeleton-HopZ1a and AvrBsT}

HopZ1a and AvrBsT interfere with microtubule networks, which are important for vesicular trafficking and plant immunity. HopZ1a was found to interact with tubulin from human cells by LC-MS/MS and with tubulin from plant extracts by co-immunoprecipitation, as well as with polymerized tubulin through a microtubule sedimentation assay. HopZ1a acetylates tubulin in vitro, as detected by the incorporation of ${ }^{14} \mathrm{C}$-labeled acetyl CoA. This causes the disruption of microtubule networks and reduces trafficking to the apoplastic space [19]. As a result, PTI is suppressed, as observed by reduced callose deposition, reduced ROS production, and suppression of MAPK activation [19,199]. AvrBsT was shown to interact with microtubule-associated protein ACIP1 (ACETYLATED INTERACTING PROTEIN 1) in yeast and in GST pull-down assays. AvrBsT acetylates ACIP1 and promotes the formation of ACIP1 aggregates, disrupting the normal localization of this protein to rodlike microtubule structures [17]. Silencing of ACIP1 in Arabidopsis results in weaker PTI and ETI. Interestingly, AvrBsT does not acetylate tubulin and HopZ1a does not acetylate ACIP1, indicating that they have different strategies for disrupting microtubule networks. It is noteworthy that several other YopJ family members also appear to affect vesicular trafficking. XopJ interferes with the secretion of an apoplastic version of GFP, suggesting that it affects vesicular trafficking [49]. HopZ2 interacts with MLO2, which regulates vesicular trafficking dependent on the PEN1 syntaxin in response to pathogens [19,200,201]. Acetyltransferase activity has not been shown for XopJ or HopZ2, although the putative acetyltransferase catalytic cysteine is required for the virulence-promoting activity of both T3SEs [49,193].

\subsection{T3SEs That Target Transcriptional Regulation-HopZ1a and PopP2}

Some acetyltransferase T3SEs target transcription factors that regulate host susceptibility to infection. Similar to HopX1 (see Section 2.1), HopZ1a induces JA signaling by targeting JAZ proteins. As the SA and JA pathways are antagonistic, this results in lower SA production and reduced immune responses. HopZ1a was found to interact with soybean GmJAZ1 using yeast two-hybrid assays, in vitro pull-down assays, and bimolecular fluorescence complementation (BiFC) experiments [20]. This interaction depends on the Jas motif which is conserved within the JAZ protein family [202]. In addition, HopZ1a interacts with Arabidopsis JAZ2, JAZ5, JAZ6, JAZ8, and JAZ12 in vitro, and the JAZ6 interaction was confirmed in planta [202]. HopZ1a acetylates GmJAZ1 and AtJAZ6 proteins in vitro [20]. This results in the degradation of JAZ proteins and activation of JA signaling. Interestingly, some $P$. syringae strains carry the phytotoxin coronatine, which is a mimic of JA and causes JAZ degradation [147]. Thus P. syringae has multiple strategies to promote susceptibility through the JA pathway. 
PopP2 targets the WRKY family of transcription factors, characterized by a highly conserved WRKYGQK motif within a DNA-binding domain that adopts a zinc finger structure [203]. The PopP2-mediated acetylation of multiple WRKY proteins can be detected using in planta and in vitro acetylation assays, and this modification interferes with DNA binding by WRKYs [24]. For WRKY22, the primary acetylation site was pinpointed to the C-terminal lysine residue of the WRKYGQK motif, which likely explains the consequent impairment of DNA binding [24]. While there are many WRKYs with roles in biotic stress, PopP2 appears to have some specificity for the WRKYs it acetylates [24,203]. Ultimately, the acetylation of WRKY transcription factors by PopP2 causes a dampening of PTI and associated immune-triggered transcriptional activation.

\subsection{T3SEs That Target Secondary Metabolites-HopZ1a and HopZ1b}

HopZ1a and HopZ1b affect the production of isoflavones, which are secondary metabolites that influence plant-microbe interactions. Both T3SEs interact with a soybean 2-hydroxyisoflavanone dehydratase (GmHID1), as shown with yeast two-hybrid assays, in vitro pull-down experiments, and BiFC detection. GmHID1 is important for the synthesis of isoflavones such as daidzein and genistein [204]. When P. syringae infects soybean, GmHID1 expression is induced and daidzein is produced [204]. HopZ1b suppresses daidzein production, while HopZ1a enhances it [204]. Silencing GmHID1 results in higher growth of P. syringae [204]. While GmHID1 has not been shown to be acetylated by HopZ1b, the catalytic cysteine of HopZ1b is necessary for its virulence function.

\subsection{T3SEs Whose Acetyltransferase Activity Triggers ETI-HopZ1a and PopP2}

The acetylation activity of HopZ1a and PopP2 is critical for triggering immune responses [193,194]. HopZ1a is recognized by the pseudokinase HOPZ ETI-DEFICIENT 1 (ZED1) and the NLR ZAR1, which were both identified in genetic screens [21,194]. HopZ1a and ZED1 interact, as shown by yeast two-hybrid assays, BiFC, and surface plasmon resonance technology. HopZ1a acetylates ZED1 [21] as well as a related family of RCLKs known as PBS1-like kinases (PBLs), which form a ternary complex with ZED1 and ZAR1 [205]. ZED1 and ZAR1 normally interact in the absence of pathogens to prevent autoactivation of ZAR1 [21,206,207]. Acetylation of ZED1 is believed to cause conformational changes to ZAR1, which triggers ETI $[21,206,207]$. After activation, ZAR1 likely forms a plasma membrane-associated pore which aids in cell death [208-210]. HopZ5 is also an acetyltransferase whose activity is necessary for resistance; however, the targets of its activity are unknown [211]. XopJ4 is recognized in N. benthamiana through ZAR1 and a homolog of ZED1, JIM2 (XOPJ4 IMMUNITY 2); however, enzymatic activity has not been demonstrated for XopJ4 [212].

PopP2 is recognized by RRS1 (RESISTANT TO RALSTONIA SOLANACEARUM 1), a NLR with an integrated WRKY domain, in complex with the NLR RPS4 (RESISTANT TO P. SYRINGAE 4) $[23,213,214]$. RRS1 was first identified in Arabidopsis ecotypes that differ in their resistance to $R$. solanacearum carrying PopP2 [213,214]. Subsequently, RRS1 was shown to function with RPS4 to trigger ETI $[215,216]$. PopP2 acetylates RRS1 in the WRKY domain, which disrupts its association with DNA and activates RPS4-mediated ETI [24]. The WRKY domain of RRS1 thus acts as an integrated decoy domain for PopP2 recognition.

\subsection{T3SEs That Suppress the HR-HopZ3 and AvrBsT}

HopZ3 contributes to the epiphytic growth of $P$. syringae pv. syringae B728a by suppressing the HR associated with multiple effectors, including AvrB3 and AvrRpm1, which are recognized by RPM1 (see Section 2) [22,217,218]. HopZ3 interacts with AvrB3 and AvrRpm1, as well as RIN4 and several RLCKs, including RIPK, with evidence from yeast two-hybrid assays, BiFC experiments, and GST pull-downs [22]. While HopZ3 is localized to the nucleus when expressed alone [193,199], its interaction with AvrB3, AvrRpm1, RIN4, or RIPK relocalizes it to the cell periphery, in the vicinity of the RPM1 immune complex [22]. HopZ3 acetylates AvrB3 and AvrRpm1, as well as the plant RLCKs 
RIN4, RIPK, PBS1, and BIK1 [22]. HopZ3 exhibits varying activity on different RLCK ligands because it does not acetylate MPK4 even though it can interact with MPK4. Interestingly, HopZ3 acetylates RIPK and AvrB3 in regions that are important for kinase activity, protein-protein interactions, and/or AvrB3-triggered immunity, thereby blocking plant immunity [22]. HopZ3 reduces AvrB3/AvrRpm1-mediated phosphorylation of RIN4, which normally triggers immunity through RPM1 [22]. In addition, transgenic HopZ3expressing Arabidopsis lines suppress PTI, as well as flg22-triggered ROS production and MAPK activation, in a catalytic cysteine-dependent manner [199]. Thus, HopZ3 has multiple strategies for immune suppression.

AvrBsT suppresses the HR that is induced by an unrelated Xanthomonas T3SE, AvrBs1 [18]. This suppression depends on the catalytic triad of AvrBsT and involves SNF1-RELATED KINASE 1 (SnRK1) [18]. While AvrBsT has been shown to possess acetyltransferase activity [17], acetylation of SnRK1 has not yet been shown [18].

\section{T3SEs That Alter Host Protein Phosphorylation}

A wide range of proteins in both prokaryotes and eukaryotes are regulated by reversible phosphorylation $[219,220]$, including proteins at the molecular interface of host-microbe interactions. Phosphorylation is particularly important for immune signaling following PAMP perception, including auto- and transphosphorylation events within RLK-RLCK complexes prior to the activation of downstream kinase signaling cascades $[4,221]$. The elicitation and execution of ETI responses are also influenced by phosphorylation [12]. As such, T3SEs have evolved to manipulate various members of the defensive phosphoproteome.

\subsection{T3SEs Targeting PRRs-HopAO1}

One efficient mechanism for T3SE-mediated suppression of PTI involves disabling the PRRs responsible for PAMP perception. Sequence analysis of the P. syringae T3SE HopAO1 indicated the presence of a conserved [LIVMF]HCxAGxxR[STC][STAG] motif found in the catalytic site of protein tyrosine phosphatase enzymes [222-224]. Enzymatic activity was demonstrated in vitro using an artificial substrate (paranitrophenyl phosphate) as well as phosphotyrosine peptides derived from the insulin receptor or the epidermal growth factor receptor $[223,224]$. In Arabidopsis, transgenic expression of HopAO1 enhances the growth of a type III secretion-deficient $P$. syringae pv. tomato DC3000 hrp $A^{-}$mutant and suppresses callose deposition elicited by this strain in a catalytic site-dependent manner, suggesting that HopAO1 targets PTI [225]. Indeed, HopAO1 interacts with the kinase domains of EFR and FLS2 and reduces EFR autophosphorylation [61]. This reduction is only partially dependent on HopAO1 catalytic activity, suggesting that the physical interaction with HopAO1 also contributes to EFR inhibition [61]. In this system, FLS2 kinase activity was too weak to assess the impact of HopAO1, but the interaction of HopAO1 with FLS2 and the suppression of flg22-induced responses by this T3SE suggest that FLS2 is affected in a similar manner. More recently, a G-type lectin RLK designated LIPOOLIGOSACCHARIDE-SPECIFIC REDUCED ELICITATION (LORE) was found to perceive medium-chain 3-hydroxy fatty acids as PAMPs from Pseudomonas spp. and autophosphorylate prior to PTI activation [62,226]. As with EFR, HopAO1 interacts with LORE and reduces its autophosphorylation as a mechanism of PTI suppression [62].

\subsection{T3SEs Targeting MAPK Signaling Cascades-HopAI1 and XopAU}

Downstream of PRRs, MAPK signaling cascades are also targeted by T3SEs. The T3SE HopAI1 from $P$. syringae can suppress a range of PTI responses, including flg22-induced marker gene expression, callose deposition, ROS burst, and activation of the MAPKs MPK3 and MPK6 [59,227]. In vitro pull-down experiments and in planta co-IP assays indicated that HopAI1 interacts with MPK3/6, and phospho-specific antibodies were used to demonstrate that HopAI1 dephosphorylates MPK3/6 [59]. MAPKs are phosphorylated at TXY motifs on both threonine and tyrosine residues [228], but mass spectrometry analysis 
showed that only the threonine is dephosphorylated, indicating that HopAI1 is a phosphothreonine lyase [59]. Examination of a homologous T3SE (OspF) from Shigella flexneri [229] identified a catalytic histidine residue that was shown to be critical for HopAI1-mediated MAPK dephosphorylation and PTI suppression [59]. Mechanistically, HopAI1 and OspF likely act by attacking the $\mathrm{C}-\mathrm{O}$ bond of phosphorylated threonine, yielding a dephosphorylated residue that lacks a hydroxyl group and thus cannot be rephosphorylated, which differs from other phosphatases. Interestingly, HopAI1 activity can be recognized in hosts that possess the NLR SUPPRESSOR OF MKK1 MKK2 2 (SUMM2) [60]. A key component of this recognition is the MAPK MPK4, which also interacts with HopAI1 and whose flg22induced kinase activity is impaired by HopAI1, although direct dephosphorylation was not tested. To detect HopAI1 activity, SUMM2 interacts with CALMODULIN-BINDING RECEPTOR-LIKE CYTOPLASMIC KINASE 3 (CRCK3), which in turn interacts with and is phosphorylated by MPK4 in vivo [230]. It is likely that CRCK3 acts as a decoy, and that ETI is stimulated when CRCK3 steady-state phosphorylation levels are reduced by HopAI1mediated disruption of MPK4 activity. Interestingly, HopAI1 activity can be mitigated by host-mediated S-nitrosylation of HopAI1 at a conserved cysteine residue, which reduces the ability of HopAI1 to suppress MAPK activity [231].

In contrast to phosphatase-mediated suppression of MAPK signaling, the X. euvesicatoria T3SE XopAU stimulates this signaling cascade. A search of the XopAU sequence for conserved domains predicted that this T3SE belongs to the serine/threonine kinase family [58]. This was verified in vitro by the detection of autophosphorylation in the presence of radiolabeled ATP, and was shown to be dependent on a conserved ATP binding site (lysine-240). Transient expression of XopAU in pepper and N. benthamiana causes cell death, MAPK phosphorylation, and PR protein expression, all of which are lost in a kinase-deficient K240A mutant [58]. Yeast two-hybrid analyses revealed that XopAU interacts with MAP kinase kinases, including tomato MKK2, N. benthamiana MEK2, and pepper MKK2 [58]. In vitro and in planta assays confirmed that XopAU phosphorylates tomato MKK2. Given that the phosphorylation and subsequent activation of MKK2 result in host cell death and immune activation, the virulence function of XopAU remains unclear.

\subsection{T3SEs That Modulate ETI by Phosphorylation-HopBF1 and AvrRxo1}

Effector-triggered immunity can also be modulated by phosphorylation. The T3SE HopBF1 is widely distributed across bacterial genera, including plant and animal pathogens [57]. Bioinformatic analyses suggested that HopBF1 is distantly related to classical protein kinases and aminoglycoside phosphotransferases. The crystal structure of HopBF1 from the human pathogen Ewiginella americana revealed that the T3SE includes a minimal and unusual protein kinase-like fold. Functionally, HopBF1 interacts with and phosphorylates the chaperone Hsp90 from both plant and human sources [57]. This phosphorylation reduces the ATPase activity used by Hsp90 to catalyze the folding of client proteins [57]. While the impact of HopBF1 on Hsp90 chaperone function has primarily been evaluated in mammalian cells, HopBF1 was shown to delay and generally reduce the HR elicited by an autoactive variant of the NLR RPM1 in N. benthamiana [57]. As such, the virulence function of HopBF1 is thought to derive from the inhibition of Hsp90 chaperone activity, which destabilizes NLRs and dampens ETI. In addition, HopBF1 actually promotes cell death in the later stages of compatible pathogen interactions, suggesting a second activity in facilitating the transition of P. syringae to a necrotrophic lifestyle in advanced infections [57].

Cell death promotion is also exhibited by the T3SE AvrRxo1, which is found in a wide range of Xanthomonas, Burkholderia, and Acidovorax species [232]. The crystal structure of AvrRxo1 resembles the $\mathrm{N}$-terminal kinase domain of T4 polynucleotide kinase from an enterobacterial phage [233]. A putative ATP-binding residue (threonine-167) is required for AvrRxo1-mediated cell death in Escherichia coli as well as in several different plant species [233]. In rice, however, AvrRxo1 enhances the virulence of X. oryzae pv. oryzicola. Biochemical analyses demonstrated that AvrRxo1 phosphorylates NAD and its precursor NAAD at the $3^{\prime}$ hydroxy of their adenosines to form $3^{\prime}$-NADP and $3^{\prime}$-NAADP, 
respectively [54,55]. These products may interfere with the function of NADP-dependent enzymes, and $3^{\prime}-\mathrm{NAADP}$ may modulate $\mathrm{Ca}^{2+}$ signaling to promote bacterial virulence. A recent investigation of drought-induced immunity found that AvrRxo1 also interacts with the dehydration-induced cysteine protease RESPONSIVE TO DESICCATION 21 (RD21A) and the E3 ubiquitin ligase SEVEN IN ABSENTIA 4 (SINAT4) [56]. Here, AvrRxo1 significantly enhances SINAT4 self-ubiquitination, and SINAT4 promotes RD21A degradation via the $26 \mathrm{~S}$ proteasome pathway to compromise drought-induced immunity [56]. Although direct phosphorylation of SINAT4 by AvrRxo1 was not tested, the activity of AvrRxo1 in this context was dependent on the ATP-binding residue threonine- 167.

\section{T3SEs with Other Activities}

A number of T3SEs have evolved unique activities that illustrate the utility of deploying a biochemically diverse collection of T3SEs to manipulate an equally diverse range of host targets. Here, we highlight some of these unique T3SEs and their characterized virulence functions.

\subsection{T3SEs with Nucleoside Hydrolase Activity-XopQ and HopQ1}

The modification of endogenous small molecules in host cells can significantly impact plant immunity. The amino acid sequences of XopQ and HopQ1 bear some resemblance to inosine/uridine-preferring nucleoside hydrolase enzymes, including a conserved DXXXDXDD nucleoside binding motif $[85,86,234]$. Nucleoside hydrolases (NHs) cleave the $\mathrm{N}$-glycosidic bond of nucleosides to release a ribose sugar from the nucleobase. Indeed, the crystal structure of XopQ from X. oryzae pv. oryzae was deduced from this protein in complex with adenosine diphosphate ribose, which contains a ribosyl moiety and serves as an important regulator of $\mathrm{Ca}^{2+}$-mediated immune signaling [235]. Furthermore, the virulence functions of both $\mathrm{XopQ}$ and HopQ1 require an intact nucleoside binding site [85,234]. For XopQ, NH activity could not be demonstrated in vitro using common plant nucleosides, but weak ribose hydrolase activity was detected with the substrate p-nitrophenyl $\beta$-D-ribofuranoside [86]. A XopQ nucleoside binding site mutant displayed lower substrate binding affinity and cleavage efficiency. As such, XopQ is likely a functional NH whose natural substrate remains to be confirmed. In N. benthamiana, XopQ triggers ETI following its detection by the NLR RECOGNITION OF XOPQ 1 (ROQ1) $[120,236]$. Interestingly, this recognition involves a direct interaction between the $\mathrm{C}$-terminus of ROQ1 and the putative $\mathrm{NH}$ active site of $\mathrm{XopQ}$, serving to block XopQ ligand binding in addition to eliciting an HR.

The biochemical activity of HopQ1 is more thoroughly understood. Transgenic expression of wild-type HopQ1, but not a nucleoside binding site mutant, suppresses the ROS burst and MPK3/MPK6 phosphorylation that are induced by flg22 treatment and inhibits expression of the FLS2 gene [85]. Intriguingly, HopQ1 expression in seedlings caused a number of developmental defects reminiscent of cytokinin signaling mutants, also in a nucleoside binding site-dependent manner. This observation spurred additional phytochemical analyses, revealing that HopQ1 expression stimulates the production of various cytokinins, including N6-(2-isopentenyl)adenine (iP), trans-zeatin, cis-zeatin, and dihydrozeatin, as well as the upregulation of cytokinin-responsive genes [85]. Exogenous trans-zeatin mimics HopQ1 expression phenotypes in terms of reduced FLS2 expression and attenuated PTI responses [85]. In vitro, HopQ1 was shown to hydrolyze the iP precursor, iP-9-riboside-5'-monophosphate, in a nucleoside binding site-dependent manner [85]. Overall, it appears that the $\mathrm{NH}$ activity of HopQ1 facilitates cytokinin accumulation to suppress PTI. It is possible that the virulence function of XopQ involves a similar mechanism.

\subsection{Uridylyltransferase-AvrAC}

Rather than directly altering the phosphostatus of in planta targets, some T3SEs have instead evolved to block the activity of host kinases. The T3SE AvrAC from Xanthomonas campestris pv. campestris inhibits plant immunity through the targeting of 
the receptor-like kinases BIK1 and RIPK, which are known to play roles in PTI and ETI, respectively $[79,90,237]$. AvrAC is composed of three domains: an N-terminal domain of unknown function, a leucine-rich repeat (LRR) domain, and a C-terminal region with a Fic (filamentation induced by cAMP) domain that includes a conserved $\operatorname{HPFx}(\mathrm{D} / \mathrm{E}) \mathrm{GN}(\mathrm{G} / \mathrm{K}) \mathrm{R}$ motif necessary for nucleotide binding and catalysis $[79,238]$. Mass spectrometry analysis revealed multiple serine and threonine residues on AvrAC which possess mono-UMP (uridine 5'-monophosphate) modifications, indicating that AvrAC likely acts as a uridylyltransferase [79]. In vitro assays with radiolabeled UTP showed that BIK1 and RIPK are uridylylated upon incubation with AvrAC. Further, this uridylylation occurs specifically at conserved residues in the activation loop of these kinases, as AvrAC failed to uridylylate the BIK1(S236A) and BIK1(T237A) mutants [79]. UMP-modified BIK1 and RIPK exhibited reduced autophosphorylation in E. coli, indicating the uridylylation of conserved phosphorylation sites in the activation loops of both proteins prevents their phosphorylation and inhibits downstream signal transduction.

The modification of BIK1 and RIPK by AvrAC markedly compromises both PTI and ETI in Arabidopsis. Transgenic lines expressing avrAC supported significantly more growth of the type III secretion-deficient strains $X$. campestris pv. campestris $\Delta h r c V$ and P. syringae pv. tomato $\Delta h r c C$ [79]. Additionally, flg22-triggered MAPK activation and $\mathrm{H}_{2} \mathrm{O}_{2}$ accumulation were strongly diminished in the transgenic lines when compared to the wild type [79]. The avrAC transgenic lines also support significantly more growth of $P$. syringae pv. tomato strains delivering AvrB, which triggers RPM1-dependent ETI in Arabidopsis [79]. Consistent with this, plants pretreated with $X$. campestris $\mathrm{pv}$. campestris do not exhibit an $\mathrm{HR}$ when subsequently infiltrated with $P$. syringae pv. tomato carrying avrB, whereas an HR was still observed in plants pretreated with $X$. campestris pv. campestris $\triangle a v r A C$ and those receiving no pretreatment [79].

Notably, AvrAC plays a dual role in plant immunity, not only contributing to bacterial virulence but also triggering immunity in some plants. AvrAC was initially identified as an avirulence factor in Arabidopsis, as an X. campestris pv. campestris knockout of AvrAC was found to be more capable of causing disease than the wild-type strain when infiltrated into the Arabidopsis vasculature [239]. More recently, it was discovered that PBL2, a paralog of BIK1, is also uridylylated by AvrAC in planta [80]. The modification of PBL2 does not contribute to virulence but instead triggers immunity via recognition by the ZAR1-RKS1 complex $[80,208,209]$. These observations suggest that PBL2 may have evolved as a decoy to enable AvrAC detection.

\subsection{Phytase-XopH}

The T3SE XopH (also known as avrBs1.1) from X. euvesicatoria was initially believed to be a phosphatase due to its sequence similarity to known phosphatases $[240,241]$. While XopH does possess the conserved P loop and WPD loop residues associated with protein phosphatases, it demonstrates weaker enzymatic activity than other known phosphatases [81]. Instead, XopH appears to act primarily as a phytase. Phytases dephosphorylate phytate (myo-inositol hexakisphosphate or $\mathrm{InsP}_{6}$ ) to lower phosphorylated myo-inositol derivatives. In in vitro assays, $\mathrm{XopH}$ is capable of dephosphorylating phytate at position 1 to produce $\mathrm{InsP}_{5}$ [81]. Interestingly, $\mathrm{XopH}$ does not dephosphorylate alternative phytase substrates, indicating that it has high substrate specificity [81]. The phytase activity of $\mathrm{XopH}$ was also confirmed in planta, as $\mathrm{N}$. benthamiana plants expressing $x о \mathrm{pH}$ showed an accumulation of InsP $\mathrm{P}_{5}$ concomitant with decreased $\mathrm{InsP}_{6}$ [81]. However, it remains unclear how this phytase activity contributes to virulence. When delivered by a P. syringae strain lacking the T3SE-rich conserved effector locus (CEL), XopH was shown to significantly inhibit callose deposition and enhance P. syringae pv. tomato DC3000 $\triangle$ CEL disease symptoms in Arabidopsis [242]. Additionally, $\mathrm{XopH}$ induces the expression of genes associated with ethylene and JA signaling pathways in N. benthamiana [81]. While the precise role of phytate and its derivatives in these effects is unclear, upregulation of JA/ethylene signaling could enhance host susceptibility to hemibiotrophic pathogens such 
as X. euvesicatoria. Additional virulence functions for $\mathrm{XopH}$ may include the liberation of phosphate for pathogen nutrition and/or the attenuation of host immune responses due to reduced $\mathrm{InsP}_{6}$ levels [243]. On the other hand, $\mathrm{XopH}$ is recognized in pepper by the protein Bs7 to trigger an HR [241]. This recognition requires an active phytase domain, suggesting Bs7 recognizes the biochemical activity of $\mathrm{XopH}$ rather than the physical protein [81].

\subsection{Trehalose-6-Phosphate Synthase-RipTPS}

The T3SE RipTPS from $R$. solanacearum is a conserved effector in the $R$. solanacearum complex that functions as a trehalose-6-phosphate synthase (TPS) within the trehalose biosynthetic pathway [82]. In plants, trehalose influences a range of processes, including plant growth and development, carbohydrate metabolism, and responses to abiotic stress [244]. This molecule has also been shown to promote pathogen virulence in multiple pathosystems, although the underlying mechanisms remain unclear [245]. Deletion of a trehalose synthase gene in the fungal pathogen Magnaporthae oryzae weakened its overall pathogenicity [246]. Pseudomonas aeruginosa, a pathogen often found in immunocompromised humans, can also cause soft rot symptoms in susceptible Arabidopsis ecotypes when infiltrated at high inoculum levels [247]. Similar to M. oryzae, bacterial growth and the severity of chlorosis on Arabidopsis infected with P. aeruginosa were dependent on trehalose synthesis [247]. While trehalose synthesis appears to contribute significantly to the virulence of plant pathogens, RipTPS remains the only known example of a TPS that is translocated into plant cells by the T3SS [82]. The enzymatic activity of this T3SE has been demonstrated by the ability of RipTPS to catalyze trehalose-6-phosphate biosynthesis in yeast and to rescue the growth defects of yeast TPS-deficient mutants, with both phenotypes being dependent on three putative catalytic residues: tyrosine-154, tryptophan163, and aspartic acid-208 [82]. However, the contribution of RipTPS to R. solanacearum virulence is not known. RipTPS knockouts do not demonstrate any deficiencies in plant infection [82]. Given the known role of trehalose synthesis in promoting pathogen virulence, it is possible that RipTPS acts redundantly with another effector within the $R$. solanacearum T3SE suite. Conversely, RipTPS can activate plant immunity, as heterologous expression in Nicotiana tabacum elicits an HR [82]. Although trehalose has been previously implicated as an elicitor of plant defense, the HR in N. tabacum is triggered independently of RipTPS enzymatic activity [82,248]. RipTPS is currently the only T3SE known to play a role in trehalose synthesis, but RipTPS homologs do exist in other species, indicating that this T3SE activity may be more broadly deployed than previously thought [82].

\subsection{Nudix Hydrolase-RipN}

The $R$. solanacearum T3SE RipN was recently discovered to be a functional Nudix hydrolase [84]. Nudix hydrolases act on substrates composed of a nucleoside diphosphate linked to another moiety $(x)$ and share a conserved Nudix motif of Gx5Ex5[UA]xREx2EExGU, where $U$ is an aliphatic hydrophobic residue. Several Nudix substrates have been shown to play key roles as regulatory molecules in immune signaling. For example, the Arabidopsis Nudix hydrolase NUDT7 acts on ADP-ribose and NADH to regulate cellular antioxidant status and modulate plant defense responses [249]. Similarly, RipN has ADPribose/NADH pyrophosphorylase activity in vitro [84]. However, RipN does not appear to impact the levels of mono-/poly-ADP-ribosylated proteins in planta. Instead, RipN primarily affects $\mathrm{NADH} / \mathrm{NAD}^{+}$levels in planta, indicating that $\mathrm{NADH}$ is the preferred substrate for RipN [84]. Importantly, RipN Nudix hydrolase activity is necessary for its contribution to virulence. RipN transgenic Arabidopsis plants supported significantly higher populations of $P$. syringae and R. solanacearum compared to wild-type Arabidopsis or transgenic plants expressing a catalytically inactive ripN mutant [84]. Further, RipN transgenic plants demonstrated significantly decreased callose deposition when induced by the PAMP flg22 [84]. Taken together, these data suggest that RipN utilizes its Nudix hydrolase activity to modulate the levels of $\mathrm{NADH} / \mathrm{NAD}^{+}$in planta and ultimately suppress PTI responses. 


\section{6. $\gamma$-Glutamyl Cyclotransferase-RipAY}

The R. solanacearum T3SE repertoire also includes RipAY, which interferes with redox homeostasis in the plant host. RipAY possesses a ChaC domain, which had previously been reported to be associated with $\gamma$-glutamyl cyclotransferase activity, specifically glutathione degradation in yeast and mammals [250]. Heterologous expression of RipAY in yeast resulted in inhibited growth and significantly decreased intracellular glutathione levels, confirming that RipAY also exhibits $\gamma$-glutamyl cyclotransferase activity to degrade glutathione [83]. Glutathione acts a master redox buffer in eukaryotes and is known to influence plant immune responses [251,252]. Inoculation of wild-type $R$. solanacearum into eggplant leaves resulted in a significant decrease in glutathione levels [83]. However, an $R$. solanacearum $\triangle$ ripAY knockout was unable to alter glutathione accumulation, indicating that RipAY functions as a $\gamma$-glutamyl cyclotransferase in planta [83]. In competitive assays, RipAY significantly contributes to $R$. solanacearum fitness in eggplant, which implies a role for the manipulation of glutathione levels in promoting virulence [253]. In support of this, transient expression of RipAY in N. benthamiana resulted in a significant reduction in the flg22-triggered ROS burst and the SA-induced expression of the N. benthamiana ortholog of Arabidopsis PR1, NbPR1 [254]. Arabidopsis plants deficient in glutathione accumulation similarly exhibit a reduced flg22-induced ROS burst [254]. In total, these data suggest that RipAY suppresses immune responses and that this suppression is dependent on its $\gamma$-glutamyl cyclotransferase activity to decrease glutathione levels. Notably, RipAY is activated in planta by host cytosolic thioredoxins to degrade glutathione specifically in eukaryotic cells [83,255-257]. Effector activation in planta is further discussed in Section 10 "Context Matters".

\section{T3SEs with Indirect and/or Non-Enzymatic Mechanisms of Action}

While we have primarily focused on characterized T3SEs that catalyze a specific biochemical reaction, several other effectors contribute to pathogen virulence independently of any direct enzymatic activity. The interaction of these T3SEs with host proteins may allosterically inhibit host enzymes, occlude substrate binding sites, disrupt oligomeric structures, sequester proteins away from their intended interactors, or recruit enzymes to act on a given target protein. Other T3SEs bind DNA to manipulate host gene expression.

\subsection{T3SEs That Target PRRs and RLCKs-AvrPto}

PRRs and RLCKs are commonly targeted by T3SEs, as described in multiple previous sections. AvrPto interferes with PRR signaling by physically binding the kinase domain of PRRs, including FLS2, EFR, CERK1, and possibly BAK1/SERK3 [65,95,96]. Physical occlusion of the kinase domain by AvrPto prevents signaling through PRRs after recognition of PAMPs and suppresses downstream immune responses [237,258]. AvrPto can also interact with a number of other kinases, including the brassinosteroid-signaling kinases BSK1 and BSK3 $[95,96]$. Consistent with this, transgenic expression of AvrPto in Arabidopsis appears to result in phenotypes that resemble brassinosteroid-insensitive mutants [65]. Interestingly, the targeting of kinases by AvrPto is co-opted by the host for recognition. AvrPto is recognized by an oligomeric complex composed of the RLCK Pto and NLR Prf [97,259-262]. AvrPto is able to inhibit the kinase activity of Pto [263]. However, since there are multiple Pto molecules in the Pto/Prf complex, inhibition of the kinase activity of one Pto molecule disrupts the interaction between Pto and Prf, which then activates the kinase activity of another Pto molecule [264]. This results in transphosphorylation of other Pto proteins in the Pto/Prf complex and induces ETI [264].

In addition, AvrPto is able to suppress cell death induced by the overexpression of SUPPRESSOR OF BAK1-INTERACTING RECEPTOR-LIKE KINASE 1 (SOBIR1) in $N$. benthamiana, as well as cell death induced by a fungal effector, Avr4, in N. benthamiana plants that express tomato RLP Cf-4 (Cladosporium fulvum-4) [98]. Cf-4 functions with SOBIR1 to recognize Avr4, a secreted protein from the fungal pathogen Cladosporium fulvum. While AvrPto interacts with SOBIR1 and the RLK SERK3, it does not affect Cf- 
4/SISOBIR1/SISERK3 complex formation [98]. It is not yet clear whether AvrPto interferes with SOBIR1/SERK3 phosphorylation status or whether it blocks the kinase domain of these proteins as seen with other virulence targets [98].

8.2. T3SEs That Target 14-3-3 Proteins-XopN, HopQ, XopQ, XopX, AvrRxv, XopE1, XopE2, and $\mathrm{XopO}$

It is increasingly apparent that 14-3-3 proteins are common T3SE targets, especially for Xanthomonas pathogens. As a group, 14-3-3 proteins comprise a eukaryote-specific protein family that regulates signaling pathways by sensing the phosphorylation status of client proteins and then modulating client activity [265]. Several members of this family are known to influence plant immunity. One of the most well-characterized 14-3-3 protein-targeting T3SEs is $\mathrm{XopN}$, which suppresses PTI responses in rice and tomato and is required for full virulence in various Xanthomonas species [266-268]. Yeast two-hybrid screens and other interaction assays demonstrated that XopN interacts with the protein TOMATO FOURTEEN-THREE-THREE 1 (TFT1) as well as the cytosolic domain of an LRR-RLK designated TOMATO ATYPICAL RECEPTOR-LIKE KINASE 1 (TARK1) [267]. Both TFT1 and TARK1 are positive regulators of immunity, although TARK1 lacks autophosphorylation activity and is likely a pseudokinase $[117,267]$. Interestingly, TFT1 and TARK1 interact in the presence of $\mathrm{XopN}$, and it is thought that $\mathrm{XopN}$ promotes pathogen virulence by acting as a scaffold to stabilize TFT1-TARK1 interactions and sequester TFT1 in a non-functional PTI signaling complex [117]. The P. syringae T3SE HopQ also suppresses PTI through interactions with the 14-3-3 proteins TFT1 and TFT5 in tomato [110]. The underlying mechanisms for this suppression remain to be elucidated, but the 14-3-3 proteins exhibit a nucleocytoplasmic distribution when transiently expressed in $N$. benthamiana, yet are mostly cytoplasmic when co-expressed with HopQ1, so altered subcellular localization may be part of the virulence function of HopQ1 [269]. Similarly, PTI is suppressed in rice by the interaction of XopQ from X. oryzae pv. oryzae and the rice 14-3-3 proteins Gf14f and Gf14g [119], as well as by XopX interacting with Gf14d and Gf14e [121]. In X. euvesicatoria, XopQ was shown to suppress ETI in tomato, pepper, and N. benthamiana [270]. This suppression is dependent on the interaction of XopQ with the tomato 14-3-3 protein TFT4 and its homologs in other solanaceous species. In this context, XopQ may inhibit the function of TFT4 as a positive regulator of ETI or block interactions with other ETI-promoting proteins. In contrast, AvrRxv (X. euvesicatoria) interacts with a tomato 14-3-3 protein designated AVRRXV INTERACTOR 1 (ARI1), which may enhance AvrRxv-dependent ETI [102]. Finally, a systematic analysis of X. euvesicatoria T3SEs revealed that XopE1, XopE2, and XopO interact with multiple 14-3-3 proteins from tomato, and in planta assays suggested that these T3SEs may function redundantly to reduce the development of chlorotic symptoms in tomato leaves during infection [271].

\subsection{T3SEs That Target the Cytoskeleton-HopW1, HopG1, and HopE1}

The cytoskeleton represents another venue where interactions with T3SE proteins can alter plant immunity. The P. syringae T3SE HopW1 interacts directly with actin, causing a reduction in dynamic actin filaments (F-actin) and an overall disruption of the actin cytoskeleton [111]. Consequently, both endocytosis and intracellular protein trafficking are impaired and host susceptibility to infection is enhanced. The actin cytoskeleton is also targeted by HopG1 (P. syringae), although this T3SE is specifically localized to mitochondria $[105,106]$. Here, HopG1 interacts with an actin-associated kinesin motor protein and not actin itself $[106,272]$. Immunoprecipitation experiments suggest that HopG1 does not disrupt the interaction between kinesin and actin but rather inhibits kinesin function through a yet-undetermined mechanism [106]. Ultimately, HopG1 causes actin filament bundling and an impairment of mitochondrial respiration, which are associated with PTI suppression and increased chlorotic symptom development following inoculation with a virulent strain of $P$. syringae $[105,106]$. The $P$. syringae T3SE HopE1 also suppresses PTI, and yeast two-hybrid screens revealed that HopE1 interacts with calmodulin and the microtubule-associated protein MAP65-1 [104]. Furthermore, calmodulin and MAP65-1 
also interact, but only when HopE1 is present [104]. These interactions cause MAP65-1 to dissociate from microtubules, which impairs protein secretion, including the release of the pathogenesis-related protein PR-1 into the extracellular fluid of SA-treated plants [104]. Overall, then, HopE1 co-opts calmodulin as a co-factor to bind MAP65-1 and sequester it away from the microtubule network. Notably, HopZ1a and AvrBsT also target microtubules or microtubule-associated proteins to disrupt immune responses (see Section 5).

\subsection{T3SEs That Manipulate Oligomeric Complexes-RipAC and AvrBsT}

The strategy of manipulating host protein complexes is also illustrated by the T3SE RipAC from $R$. solanacearum. This effector inhibits ETI but not cell death caused by general elicitors such as the Phytophthora infestans secreted protein INF1 or the mammalian proapoptotic protein Bax, indicating specificity for programmed cell death responses arising from T3SE recognition [112,113]. Interestingly, RipAC contains tandem LRR motifs that are required for ETI suppression, suggesting that it may act as a scaffold for proteinprotein interactions. Indeed, two independent studies found that RipAC interacts with homologs of SUPPRESSOR OF G2 ALLELE OF skp1 (SGT1), a positive regulator of plant immunity [112,113]. A molecular chaperone complex comprising SGT1, RAR1, and Hsp90 is required for NLR stability and function [273], and RipAC interferes with the SGT1-RAR1 interaction in an LRR-dependent manner [113]. This T3SE also blocks the association of SGT1 with the MAPKs MPK3 and MPK6, thus inhibiting the phosphorylation of SGT1 that normally follows ETI activation [112]. The consequent impairment of NLR function underlies the attenuation of ETI by RipAC.

On the other hand, ETI is elicited following the manipulation of a SGT1-containing complex by the X. euvesicatoria T3SE AvrBsT. The RLCK PATHOGEN-INDUCED PROTEIN KINASE 1 (PIK1) normally interacts with and phosphorylates SGT1, likely as a positive regulator of basal defenses [92]. AvrBsT also binds SGT1, forming an AvrBsT-SGT1SGT1-PIK1 complex in which AvrBsT is phosphorylated instead of SGT1 prior to PIK1 dissociation from the complex. The resulting AvrBsT-SGT1-SGT1 association is recognized by a yet-unidentified NLR to stimulate ETI. This avirulence function is independent of the acetyltransferase activity of AvrBsT and appears to derive from the physical occlusion of SGT1 phosphorylation sites.

8.5. T3SEs That Modulate the Ubiquitin-Proteasome System-RipAC, XopP, AvrRps4, HopBB1, and HopM1

While some T3SEs mimic enzymatic components of the UPS (see Section 3), others manipulate the UPS via non-enzymatic mechanisms. In addition to targeting SGT1 complexes, RipAC also directly interacts with the E3 ubiquitin ligase PUB4 in both Arabidopsis and tomato [114]. PUB4 regulates BIK1 homeostasis by preventing BIK1 accumulation prior to PAMP perception and increasing its accumulation following elicitation of PTI [114]. BIK1 plays a key role in immunity as it is involved in several PTI responses, including ROS production, calcium signaling, callose deposition, and stomatal closure [237,274,275]. RipAC association with PUB4 results in overrepresentation of the pre-elicitation form of PUB4, leading to a decrease in BIK1 accumulation and an attenuation of these PTI responses [114]. Similar to RipAC, the X. oryzae pv. oryzae T3SE XopP suppresses the activity of a host E3 ubiquitin ligase, OsPUB44 [118]. OsPUB44 is a positive regulator of PTI in rice, as chitintriggered expression of PTI reporter genes is reduced in OsPUB44 RNAi-silenced lines [118]. XopP physically binds the U-box domain of OsPUB44 and reduces its ligase activity [118]. Though direct targets have not yet been identified, it is possible that OsPUB44 serves a role in regulating the homeostasis of PTI signaling components similar to PUB4 in Arabidopsis.

Along the same lines, the virulence function of the P. syringae T3SE AvrRps4 was recently shown to involve an interaction with an iron-sensing E3 ubiquitin ligase designated BRUTUS (BTS) [99]. Iron deficiency stabilizes the BTS protein, which mediates the 26S proteasome-dependent degradation of transcription factors such as BASIC HELIXLOOP-HELIX 115 (bHLH115) and IAA-LEUCINE RESISTANT 3 (ILR3), thus modulating iron-responsive gene expression [276]. AvrRps4 directly interacts with and suppresses the 
E3 ligase activity of BTS to upregulate bHLH115/ILR3-dependent gene expression and increase the concentration of iron in the apoplast of Arabidopsis leaves [99]. This metabolic reprogramming directly enhances in planta bacterial growth, as also shown with Arabidopsis mutants exhibiting increased iron accumulation or plants treated with exogenous iron, which all support higher populations of P. syringae [99]. The impact of AvrRps4 on pathogen growth is dependent on the genetic background of the host because AvrRps4 is recognized by the NLR pair RRS1/RPS4 [24,100]. As with PopP2, AvrRps4 is detected by the integrated WRKY domain of RRS1, and the lack of demonstrated enzymatic activity for AvrRps4 suggests that recognition is mediated purely by the physical WRKY-AvrRps4 interaction. Notably, RRS1/RPS4-mediated recognition of AvrRps4 blocks the iron accumulation phenotype, although the underlying mechanism is not yet clear [99]. In terms of additional virulence targets, AvrRps4 interacts with several WRKY proteins as well as with EDS1 within the RRS1/RPS4 complex, but the specific contribution of these interactions to the promotion of pathogen virulence remains to be conclusively demonstrated [100,277].

Yet another virulence strategy involves promoting the activity of the host UPS to degrade positive regulators of immunity. For example, the P. syringae T3SE HopBB1 promotes the degradation of the Arabidopsis transcription factor TCP14 [103]. TCP14 has been shown to contribute to ETI and also to be a repressor of JA-responsive genes [103,278]. HopBB1 mediates the physical association of TCP14 with the JA signaling repressor JAZ3, leading to the UPS-dependent degradation of both proteins, and subsequently the derepression of JA responses [103]. The JA and SA pathways are mutually antagonistic, with SA limiting the growth of biotrophic pathogens and JA limiting the growth of necrotrophic pathogens. Therefore, the de-repression of JA responses benefits biotrophic pathogens, such as $P$. syringae, which are normally inhibited by SA [279]. The activity of HopBB1 is consistent with the activity of other P. syringae T3SEs, such as HopX1 and HopZ1a, which also activate the JA pathway to promote virulence (see Sections 2 and 5).

Similarly, the P. syringae T3SE HopM1 acts to promote UPS-dependent degradation of the Arabidopsis protein HOPM INTERACTOR 7 (AtMIN7) [108]. AtMIN7 is an ADPribosylation factor localized to the trans-Golgi network and early endosome which is required for both PTI and ETI [109]. Loss-of-function atmin7 mutant plants are deficient in responses to the defense elicitors flg22 and benzothiadiazole as well as the T3SE AvrRpt2 [109]. As the N-terminus of HopM1 physically interacts with AtMIN7, and AtMIN7 is subsequently ubiquitinated and degraded, it is likely that HopM1 acts as an adaptor protein between AtMIN7 and components of the UPS [108]. Interestingly, there is also evidence that HopM1 acts as a proteasome inhibitor [157]. Transient expression of HopM1 in $N$. benthamiana resulted in decreased breakdown of the fluorogenic proteasomal activity reporter peptide Suc-LLVY-AMC, which suggests that HopM1 may serve dual roles in mediating host UPS activity [157]. Notably, this study identified several other P. syringae T3SEs as proteasome inhibitors, including HopAO1, HopA1, and HopG1. This suggests the existence of additional UPS-targeting T3SEs whose activities have yet to be characterized.

\subsection{T3SEs That Indirectly Affect Host Protein Phosphorylation-AvrB, AvrRpm1,} and AvrE-Type T3SEs

In the case of AvrB and AvrRpm1, pathogen virulence is influenced by indirectly facilitating the phosphorylation of host proteins. Bacterial delivery of either AvrB or AvrRpm1 results in the phosphorylation of RIN4, which is recognized by the NLR RPM1 to elicit ETI $[25,90]$. In terms of virulence function in the absence of RPM1, one regulatory mechanism demonstrated for AvrB involves direct interactions with SGT1 and RAR1 in a complex that also includes Hsp90 [91,280]. Within this complex, both AvrB and Hsp90 bind MAP KINASE 4 (MPK4) to facilitate its activation via phosphorylation [91]. There is currently no evidence for direct phosphorylation of MPK4 by AvrB, so this T3SE may enhance the activity of upstream kinases such as MKK1 or MKK2. Nonetheless, activated MPK4 interacts with and phosphorylates RIN4, followed by RIN4-mediated activation of the plasma membrane H+-ATPases AHA1 and/or AHA2, which stimulates the degradation of negative regulatory proteins from the JAZ family [91,281-283]. Ultimately, AvrB acts 
to upregulate JA signaling pathways, increase stomatal apertures, and suppress PTI in rpm1 mutant plants $[90,91,283]$. In addition, a RIN4 immunoprecipitation experiment in AvrRpm1-expressing plants identified the RLCK RIPK as an additional RIN4-interacting kinase [90]. Five additional RLCKs were later identified that also interact with RIN4, AvrB, and each other [284]. All of these RLCKs catalyze RIN4 phosphorylation, and the addition of a phosphate group at threonine-166 appears to be the most relevant modification for both the virulence and avirulence functions of AvrB [90,284]. It is likely that AvrRpm1 functions in a similar manner to mediate RIN4 phosphorylation.

The AvrE family of T3SEs also indirectly modulates host protein phosphorylation. Members of this family are found in a variety of phytopathogenic bacteria, including Pseudomonas (AvrE1), Ralstonia (PopS), Erwinia (DspA/E), Dickeya (DspE), Pantoea (WtsE), and Pectobacterium (DspE) species [285]. While there is some variation among different host-pathogen combinations, AvrE-type T3SEs contribute significantly to the development of water-soaked lesions and tissue necrosis and may promote pathogen virulence through the suppression of immune responses such as callose deposition [286-292]. The amino acid sequences of AvrE family members frequently contain two conserved features: a WxxxE motif and a putative C-terminal ER membrane retention/retrieval signal [285]. Both of these regions are required for the full virulence activity of AvrE1 and WtsE [293]. Despite the putative ER retention signal, AvrE1 is primarily localized to the plasma membrane as well as plasma membrane-associated vesicle-like structures, and its localization is not affected by the deletion of either the WxxxE motif or the ER retention sequence [294]. The WxxxE motif is also found in T3SEs from animal pathogens, and these T3SEs are thought to mimic host guanine nucleotide exchange factors [295]. While a direct enzymatic activity remains to be elucidated for AvrE-type T3SEs, a yeast two-hybrid screen revealed that WtsE interacts with Protein Phosphatase 2A (PP2A) subunit proteins [93]. In planta experiments also demonstrated that AvrE1 interacts with multiple PP2A B' subunits, and that inhibition of PP2A with the chemical cantharidin delays cell death elicited by either AvrE1 or WtsE [93]. This suggests that AvrE-type T3SEs act to enhance the phosphatase activity of PP2As. The potential functional implications of this enhancement were suggested by the results of synthetic genetic array screens in which WtsE or DspA/E was expressed in a library of yeast gene deletion mutants $[93,94]$. Both of these screens indicated that WtsE and DspA/E disrupt sphingolipid biosynthesis in yeast by depleting sphingolipid precursor molecules [93,94]. More specifically, DspA/E appears to activate the PP2A Cdc55 in yeast to catalyze the dephosphorylation of Orm proteins, which then negatively regulate one of the initial steps in the sphingolipid biosynthetic pathway [94]. An analogous regulatory mechanism has not yet been demonstrated in plant cells, but given that sphingolipid metabolism impacts vesicular trafficking in plants [296,297], this pathway could represent a T3SE target for modulating PTI. Furthermore, the inhibition of sphingolipid metabolism in plants ultimately causes cell death [298,299], which may underlie the necrotic symptoms elicited by AvrE-type T3SEs. Finally, yeast two-hybrid analyses have suggested that WtsE and DspA/E interact with LRR-RLK proteins [93,300], although the impact of this interaction on LRR-RLK kinase activity and in planta bacterial growth is currently unknown.

\subsection{T3SEs That Alter The Subcellular Localization of Host Proteins-HopI1}

The virulence function of the P. syringae T3SE HopI1 involves subcellular relocalization of host proteins. The amino acid sequence of HopI1 contains a C-terminal region that resembles a DnaJ domain, which typically mediates interactions with the chaperone Hsp70 to regulate protein homeostasis [301,302]. Generally, DnaJ proteins deliver unfolded substrates to Hsp70, stimulate Hsp70 ATPase activity, and stabilize interactions with the unfolded client protein as part of a co-chaperone complex [302]. In agreement with this behavior, HopI1 interacts with an Arabidopsis Hsp70 ortholog in a DnaJ domain-dependent manner and stimulates its ATPase activity [107]. Furthermore, HopI1 relocalizes Hsp70 from a largely cytosolic distribution to a significant association with chloroplasts. While the 
specific virulence function of HopI1 remains to be determined, HopI1 localization to chloroplasts results in modifications to the ultrastructure of thylakoid grana, reduced SA accumulation, and suppression of SA-responsive gene expression [303]. The relocalization of Hsp70 to chloroplasts may facilitate this suppression as well as compromise other aspects of host immunity through reductions in the amount of active Hsp70 in the cytosol.

\subsection{T3SEs That Affect Auxin Signaling-AvrRpt2}

Another indirect manipulation of phytohormone signaling appears to be mediated by AvrRpt2. Transgenic Arabidopsis plants with constitutive AvrRpt2 expression exhibit phenotypes associated with altered auxin physiology, including longer primary roots, more lateral roots, enhanced sensitivity to exogenous auxin, and higher levels of endogenous free indole acetic acid (IAA) [304]. In planta co-expression of AvrRpt2 and auxin/IAA transcriptional repressor (AXR) proteins results in AXR degradation, similar to the observed response to exogenous auxin [101]. Intriguingly, AXR degradation and AvrRpt2-mediated induction of auxin-responsive genes require an intact cysteine protease catalytic triad in AvrRpt2, but AXR degradation is reduced by treatment with the proteasome inhibitor MG132. This suggests that AvrRpt2 may stimulate auxin signaling by cleaving a yetunidentified protein that in turn regulates the proteasomal degradation of AXR proteins. Bacterially delivered AvrRpt2 does enhance endogenous IAA accumulation, and exogenous auxin application increases the susceptibility of Arabidopsis to P. syringae infection [304], so AXR degradation represents an important virulence function for AvrRpt2.

\subsection{T3SEs Impacting Reactive Oxygen Species Signaling-RipAK}

Reactive oxygen species (ROS) also play an important role in immune signaling and may directly inhibit pathogen growth $[305,306]$. The T3SE RipAK from $R$. solanacearum is targeted to peroxisomes, and strains lacking this T3SE elicit a more rapid and stronger nonhost HR in tobacco, accompanied by greater ROS accumulation [115]. RipAK binds to and inhibits the activity of catalase enzymes that degrade hydrogen peroxide [115]. Transcriptional profiling of plants inoculated with $R$. solanacearum strains with or without RipAK indicates that this T3SE suppresses immunity during the early stages of infection, likely by interfering with ROS-mediated signaling [115].

\subsection{Transcription Activator-Like Effectors (TALEs)}

The host transcriptome represents an additional host-pathogen interface, and it can be manipulated by a class of T3SEs known as transcription activator-like effectors (TALEs) [116]. Although they are most well studied in Xanthomonas spp., TALE-like proteins have also been characterized in R. solanacearum and the bacterium Mycetohabitans rhizoxinica, which is an endosymbiont of the fungus Rhizopus microspores [307,308]. Typically, TALEs contain several conserved domains, including a T3SS translocation signal, a DNA-binding region, nuclear localization signals, and a transcriptional activation domain [309-315]. Binding to DNA is conferred by a series of tandem amino acid repeats each comprising 33 to 35 residues, within which the hypervariable residues at positions 12 and 13 (the repeat variable diresidues) facilitate binding to specific nucleotide base pairs in the promoters of target genes [316-319]. Transcriptional activation by TALEs involves interactions between the TALE activation domain and the gamma subunit of the plant transcription factor TFIIA [320,321]. Known TALE targets include genes that encode sugar transporters, abscisic acid biosynthetic enzymes, transcription factors, and sulfate transporters [322-326]. Given that the upregulation of these genes enhances susceptibility to infection, mutations within the effector binding site may eliminate TALE activity, although some effectors interact with conserved sequence motifs, such as TATA boxes, that cannot be altered without losing their native function in plants [327,328]. Alternatively, the effects of TALEs can be alleviated by mutations in the TFIIA gamma subunit that no longer bind the TALE activation domain, by "decoy" promoters that trap TALEs into activating cell death-promoting "executor" genes, or by NLR-mediated ETI [329-332]. On the other hand, 
truncated TALEs lacking the activation domain were recently found to interfere with NLRmediated ETI, likely as dominant negative NLR interactors [333,334]. Overall, TALEs are important players in the evolutionary dynamics of several host-pathogen interactions.

\section{T3SEs with Predicted Enzymatic Activities}

Although the structural and sequence features of T3SE proteins can provide hints about their potential enzymatic functions, it may be difficult to obtain conclusive biochemical evidence of such activities. One example of this obstacle is HopAF1, which is a broadly distributed T3SE found in Pseudomonas, Xanthomonas, Ralstonia, and Acidovorax species [87]. Structural homology modeling identified a region of HopAF1 with similarity to deamidase enzymes. These enzymes replace amide side chain groups with a carboxylate group to irreversibly convert asparagine residues to aspartic acid and glutamine to glutamic acid [335]. The amino acid sequence of deamidase proteins includes conserved cysteine and histidine catalytic residues, which are also found in the deamidase-like region of HopAF1 [87]. Transgenic expression of HopAF1 in Arabidopsis enhanced the in planta growth of a P. syringae pv. tomato DC3000 T3SE polymutant (D28E) and ameliorated the flg22-induced inhibition of bacterial growth, suggesting that HopAF1 suppresses PTI [87]. Importantly, the putative cysteine/histidine catalytic residues were required for this suppression. Yeast two-hybrid screening, as well as subsequent co-immunoprecipitation and BiFC assays, indicated that HopAF1 interacts with a methylthioadenosine nucleosidase (MTN1) and its paralog MTN2 [87]. Methylthioadenosine nucleosidases participate in a methionine recycling pathway to maintain methionine as a feedstock for ethylene biosynthesis, which increases following PTI activation [336-338]. Inoculation of Arabidopsis leaves with Pseudomonas fluorescens elicits PTI and ethylene production, while ethylene is not elevated in a $m t n 1 m t n 2$ double mutant, nor when P. fluorescens expresses HopAF1 [87]. Mass spectrometry analyses did not detect any modified amino acids in MTN1 or MTN2 in the presence of HopAF1, but deamidation-mimicking substitutions in both MTN1 and MTN2 resulted in a loss of enzymatic function [87]. As such, it is likely that HopAF1 inhibits MTN1 and MTN2 to reduce ethylene biosynthesis and, in turn, suppress PTI, although the precise mechanism remains to be resolved. It is worth noting, however, that multiple pathogens of other eukaryotic hosts utilize T3SEs with deamidase activity to promote their virulence [335].

Manipulation of phytohormone signaling is also central to the virulence function of the chloroplast-localized $R$. solanacearum T3SE RipAL. Sequence analysis revealed that RipAL bears the hallmarks of a class III lipase enzyme, including a catalytic triad of serine/aspartic acid/histidine with the serine located within a conserved GXSXG motif [88]. Transient expression of RipAL in N. benthamiana inhibits flg22-triggered responses such as a ROS burst and PTI marker gene expression, and this inhibition is dependent on the putative catalytic residues of HopAF1 [88]. The transient expression of RipAL also stimulates increased JA and JA-Ile levels in leaves and induction of JA signaling marker genes, matched by reduced SA accumulation and lower expression of SA marker genes, again in a RipAL catalytic site-dependent manner [88]. Mechanistically, RipAL is similar to known lipases such as Arabidopsis DEFECTIVE IN ANTHER DEHISCENCE1 (DAD1), which act on cellular lipids to release linoleic acid as an important precursor for JA biosynthesis [339-341] The primary barrier to validating RipAL lipase activity appears to be the inability to recover soluble purified protein for in vitro assays [88]. Nonetheless, the requirement for the putative lipase catalytic residues of RipAL for JA induction and pathogen virulence promotion strongly suggests a role for lipase activity. The strategy of suppressing SA signaling by upregulating JA signaling is also well established with the JA-mimicking virulence factor coronatine [342].

\section{Context Matters: T3SE Activation in Eukaryotic Hosts}

Upon delivery into host cells, several T3SE proteins are activated by interactions with endogenous enzymes or small molecules as a prerequisite for their contribution to pathogen 
virulence. The covalent attachment of fatty acids to specific residues within a protein (acylation) is the most common host-mediated modification of T3SE proteins [343]. Myristoylation involves the formation of an amide linkage between myristic acid (a 14-carbon saturated fatty acid) and the $\alpha$-amino group of an $\mathrm{N}$-terminal glycine residue. If the glycine is the second residue in a protein, it can be exposed by methionine aminopeptidase enzymes [344], while glycines at other locations can be exposed by proteolytic cleavage of N-terminal amino acids, as seen with AvrPphB [345]. Proteins can also be modified by S-palmitoylation through the attachment of palmitic acid (a 16-carbon saturated fatty acid) to the thiol side chain of a cysteine residue. While both of these hydrophobic modifications can anchor proteins in membranes, S-palmitoylation confers a stronger membrane association [344]. Much of the evidence for T3SE acylation is indirect, and myristoylation is presumed based on the loss of virulence or avirulence function in glycine-to-alanine substitution mutants of AvrPto, AvrRxo1, HopF2, HopO1-1, HopZ1a, HopZ4, and XopJ [32,46,193,346-349]. Additional substitutions at cysteine residues suggest that AvrRpm1, HopAF1, and HopZ1b are also S-palmitoylated near the N-terminus [87,350,351], and AvrPto is predicted to undergo palmitoylation as well [350]. Radiolabeled myristic acid was used to more directly detect in planta myristoylation of AvrB and AvrRpm1 [350]. A similar experiment using radiolabeled fatty acids showed that AvrPphB undergoes both myristoylation and S-palmitoylation in yeast [345]. These modifications significantly influence the subcellular localization of these T3SEs, and it is likely not coincidental that many of the targets of these effectors are also membrane-localized (Table 1). From an evolutionary perspective, myristoylation appears to be an exclusively eukaryotic modification [352], although prokaryotes do produce methionine aminotransferases [353]. The myristoylation consensus sequence contains an invariant glycine with some restrictions on the amino acid composition at adjacent positions, which can impact the efficacy of the methionine aminotransferase and/or acylation reactions [354]. This sequence may have been encoded within genes obtained through horizontal transfer or may have emerged through mutation and selection over time.

A second group of T3SEs is phosphorylated in host cells, although this modification has variable impacts on effector activity. The full virulence function of AvrPtoB requires in planta phosphorylation at serine-258, which is catalyzed by the Snf1-related kinase SnRK2.8 [355,356]. This can be counteracted, however, by the interaction of AvrPtoB with either Pto kinase or the lectin receptor-like kinase LecRK-IX.2, which phosphorylate AvrPtoB at threonine- 450 or serine-335, respectively, to compromise the virulence-promoting E3 ubiquitin ligase activity of the T3SE [357,358]. For AvrPto, phosphorylation at serine-147 and serine-149 is required for its full virulence-promoting activity on susceptible tomato plants [359,360]. These modifications are also required for AvrPto avirulence in certain Nicotiana species but appear to be dispensable for Pto-mediated ETI in tomato. In contrast to AvrPtoB, AvrPto phosphorylation occurs independently of Pto kinase. Another phosphorylated T3SE is AvrB, shown to be a substrate of RIPK in vitro [90]. The specific phosphorylation site(s) and their functional implications have not been thoroughly characterized, although a non-phosphorylatable AvrB mutant cannot elicit RPM1-mediated ETI [361]. In a similar fashion, the phosphorylation of AvrBsT by PIK1 enhances the AvrBsT-elicited HR in N. benthamiana [92]. Finally, HopQ1, XopN, XopQ, and XopX rely on phosphorylation to varying degrees to facilitate interactions with their 14-3-3 protein targets $[110,117,119,121]$. Notably, HopQ1 can be phosphorylated by multiple calcium-dependent protein kinases and Snf1-related kinases in vitro [269]. Given that 14-3-3 proteins act as intracellular monitors of client protein phosphorylation status [265], these T3SEs may have evolved to use phosphorylation as a decoy to trap their protein targets.

In addition to phosphorylation, ubiquitination also regulates the activity of AvrPtoB. This T3SE appears to autoubiquitinate in vitro at multiple lysine residues in the C-terminal region [165,362]. Alleles of AvrPtoB with several lysine-to-arginine substitutions exhibit significantly less ubiquitin binding and are unable to suppress ETI. These mutants also lose E3 ubiquitin ligase activity, although the precise role of ubiquitin binding in this context remains to be elucidated. 
Host-mediated proteolytic cleavage underlies the activation of AvrRps4 in planta. This processing does not occur in bacteria or yeast cells, indicating that a plant host protease is required [363]. Cleavage occurs between glycine-133 and glycine-134, releasing a chloroplast-localized N-terminal fragment that promotes pathogen virulence and a C-terminal fragment that is sufficient to elicit RRS1/RPS4-mediated ETI [363-365]. Interestingly, this cleavage is required for the virulence function of AvrRps4 but is not necessary for avirulence [363].

The activation of AvrRpt2 involves an association with a eukaryotic cyclophilin peptidyl-prolyl cis-trans isomerase [366]. In Arabidopsis, the cyclophilin ROC1 binds AvrRpt2 at four GPxL motifs and catalyzes the folding of this T3SE by prolyl isomerization [367]. Once folded, AvrRpt2 undergoes self-cleavage to release a 71 amino acid fragment from the N-terminus, and the activated T3SE can then proteolytically cleave host targets such as RIN4 [126,368]. The requirement for AvrRpt2 activation by a eukaryotic factor may have evolved to avoid the presence of potentially detrimental protease activity in the bacterial cytosol.

A similar strategy may underlie the eukaryotic host factor-dependent activation of other T3SEs. Binding of phytic acid (inositol hexakisphosphate) to PopP2 and HopZ1a induces conformational changes that allosterically enhance acetyl-CoA binding and thus increase the acetyltransferase activity of these T3SEs [369,370]. The activation of HopZ3 by phytic acid is implied by the loss of acetyltransferase activity in HopZ3 mutants bearing amino acid substitutions at putative phytic acid binding sites [198]. The calcium sensing protein calmodulin is unique to eukaryotes and is required as a co-factor for HopE1 [104]. This feature may provide an additional layer of spatiotemporal control by limiting HopE1 activity to cells where an immune response has been induced, which is associated with a major upregulation of $\mathrm{Ca}^{2+} /$ calmodulin signaling [371]. The host cell environment is also sensed by RipAY, which preferentially binds to cytosolic $h$-type thioredoxins as a necessary precursor to RipAY activation $[83,255]$. Importantly, $h$-type thioredoxins are encoded by pathogen-inducible genes and mediate immune responses through nitric oxide signaling pathways [372,373]; therefore, they represent a logical stimulus for T3SEs with immunosuppressive functions.

\section{Concluding Remarks}

The T3SE repertoires of bacterial phytopathogens comprise a diverse toolkit for the manipulation of host immunity. A large number of T3SEs are dedicated to the suppression of PTI by targeting PAMP perception and downstream kinase signaling cascades, cytoskeleton-mediated transport of defense-related cargo, phytohormone biosynthesis, and signaling pathways, as well as host gene expression. Effector-triggered immunity is also targeted, and the evolutionary dynamics of plant-microbe interactions are aptly illustrated by the deployment of T3SEs that interfere with the recognition of other T3SEs. Overall, there is remarkable convergence onto common groups of host targets, both within and across pathogen genera. This functional focus highlights the fundamental regulatory components of host immunity and potentially shows the power of horizontal gene transfer in the evolution of virulence-promoting proteins. It is also evident that T3SEs can be multifunctional tools capable of manipulating multiple targets using different mechanisms, such as with HopQ1 or AvrBsT. As T3SEs evolve, those with low specificity and several targets may be more resilient to the mutation or loss of a single virulence target, although these T3SEs must bind their targets with sufficient affinity to modify their substrate and/or compete with endogenous host proteins at common binding sites. There is also a risk that a broadly acting T3SE could inadvertently inactivate a negative regulator of immunity or modify a target in a manner that is recognized by a NLR. These opposing selective forces likely have, and continue to, shape the biochemical properties of bacterial T3SEs.

A number of T3SEs remain to be thoroughly characterized regarding their mechanism of action and contribution to virulence, which can present several challenges. Sequence analyses may not reveal any obvious homologies to known enzymes, especially if there is 
limited amino acid conservation outside of a small number of active site residues. Protein structures can be extremely informative, but protein purification and/or crystallization may not be straightforward for certain T3SEs. Purification of T3SE proteins may also be an obstacle for in vitro enzyme activity assays, which would be further complicated if T3SE activity requires host-mediated modifications or additional host proteins. Some T3SEs provide subtle contributions to pathogen growth in planta, making demonstrations of T3SE virulence function more difficult. Nonetheless, plants expressing individual T3SEs have been widely used in assays of PTI and ETI outputs to provide a starting point for defining the site of action for a particular T3SE. Interactome screens and large-scale T3SE-host protein interaction datasets $[272,374]$ are useful resources for identifying putative T3SE targets. Multiple -omics approaches can be used to pinpoint the activity of a specific T3SE in planta at the transcriptional, proteomic, and metabolic levels. These can be combined with appropriate catalytic site mutants to provide stronger evidence for the enzymatic activity of a given T3SE.

Explorations of pathogen virulence mechanisms have also yielded valuable insights into the molecular systems used by host plants to recognize invading microbes and coordinate immune responses. Many NLRs monitor a decoy or guardee protein to detect T3SE-mediated manipulations. Under selection to evade recognition, it is likely that mutations causing a loss of T3SE enzymatic activity will also compromise virulence function, so the recognition of this activity by NLRs may provide more durable resistance compared to recognition via binding T3SE proteins directly. As such, genes encoding decoys or guardees are important considerations in breeding for disease resistance. Furthermore, engineered decoys/guardees can expand the range of pathogens that are recognized by a single NLR [375,376]. Host defenses may also be enhanced by loss-of-function mutations in T3SE targets that negatively regulate immunity or that are activated by T3SEs to promote pathogen growth. These proteins are referred to as "susceptibility targets" and are of considerable interest as potential mediators of durable pathogen resistance, barring any detrimental effects on plant growth arising from the functional loss of such targets [377-381]. Overall, continued investigations of T3SE functions will address the need to "know thy enemy" and will help drive efforts to breed for durable resistance in agricultural crops.

Author Contributions: Conceptualization: K.J.S., J.D.L. Writing and editing: K.J.S., I.J.C.-L. and J.D.L. All authors have read and agreed to the published version of the manuscript.

Funding: Research on plant immunity in the Lewis laboratory is supported by the USDA ARS 2030-21000-046-00D and 2030-21000-050-00D (J.D.L.), the NSF Directorate for Biological Sciences IOS-1557661 (J.D.L.), and the NSF Graduate Research Fellowship Program (I.J.C.-L.).

Acknowledgments: We thank Jana Hassan and Nathan Diplock from the Lewis Lab for their critical reading of the manuscript.

Conflicts of Interest: The authors declare no conflict of interest.

\section{References}

1. Felix, G.; Duran, J.D.; Volko, S.; Boller, T. Plants have a sensitive perception system for the most conserved domain of bacterial flagellin. Plant J. 1999, 18, 265-276. [CrossRef] [PubMed]

2. Gómez-Gómez, L.; Felix, G.; Boller, T. A single locus determines sensitivity to bacterial flagellin in Arabidopsis thaliana. Plant J. 1999, 18, 277-284. [CrossRef] [PubMed]

3. Zipfel, C.; Kunze, G.; Chinchilla, D.; Caniard, A.; Jones, J.D.G.; Boller, T.; Felix, G. Perception of the bacterial PAMP EF-Tu by the receptor EFR restricts Agrobacterium-mediated transformation. Cell 2006, 125, 749-760. [CrossRef] [PubMed]

4. Thulasi Devendrakumar, K.; Li, X.; Zhang, Y. MAP kinase signalling: Interplays between plant PAMP- and effector-triggered immunity. Cell. Mol. Life Sci. 2018, 75, 2981-2989. [CrossRef]

5. Saijo, Y.; Loo, E.P.; Yasuda, S. Pattern recognition receptors and signaling in plant-microbe interactions. Plant J. 2018, 93, 592-613. [CrossRef]

6. Sun, L.; Zhang, J. Regulatory role of receptor-like cytoplasmic kinases in early immune signaling events in plants. FEMS Microbiol. Rev. 2020, 44, 845-856. [CrossRef]

7. Galán, J.E.; Lara-Tejero, M.; Marlovits, T.C.; Wagner, S. Bacterial type III secretion systems: Specialized nanomachines for protein delivery into target cells. Annu. Rev. Microbiol. 2014, 68, 415-438. [CrossRef] 
8. Lewis, J.D.; Guttman, D.S.; Desveaux, D. The targeting of plant cellular systems by injected type III effector proteins. Semin. Cell Dev. Biol. 2009, 20, 1055-1063. [CrossRef]

9. Varden, F.A.; Carlos, J.; Concepcion, D.; Maidment, J.H.R.; Banfield, M.J. Taking the stage: Effectors in the spotlight. Curr. Opin. Plant Biol. 2017, 38, 25-33. [CrossRef]

10. Khan, M.; Seto, D.; Subramaniam, R.; Desveaux, D. Oh, the places they'll go! A survey of phytopathogen effectors and their host targets. Plant J. 2018, 93, 651-663. [CrossRef]

11. Schreiber, K.J.; Baudin, M.; Hassan, J.A.; Lewis, J.D. Die another day: Molecular mechanisms of effector-triggered immunity elicited by type III secreted effector proteins. Semin. Cell Dev. Biol. 2016, 56, 124-133. [CrossRef]

12. Lolle, S.; Stevens, D.; Coaker, G. Plant NLR-triggered immunity: From receptor activation to downstream signaling. Curr. Opin. Immunol. 2020, 62, 99-105. [CrossRef] [PubMed]

13. Cesari, S. Multiple strategies for pathogen perception by plant immune receptors. New Phytol. 2018, 219, 17-24. [CrossRef]

14. Bürger, M.; Chory, J. Stressed out about hormones: How plants orchestrate immunity. Cell Host Microbe 2019, $26,163-172$. [CrossRef]

15. Klessig, D.F.; Choi, H.W.; Dempsey, D.A. Systemic acquired resistance and salicylic acid: Past, present, and future. Mol. Plant-Microbe Interact. 2018, 31, 871-888. [CrossRef]

16. Shine, M.B.; Xiao, X.; Kachroo, P.; Kachroo, A. Signaling mechanisms underlying systemic acquired resistance to microbial pathogens. Plant Sci. 2019, 279, 81-86. [CrossRef]

17. Cheong, M.S.; Kirik, A.; Kim, J.-G.; Frame, K.; Kirik, V.; Mudgett, M.B. AvrBsT acetylates Arabidopsis ACIP1, a protein that associates with microtubules and is required for immunity. PLoS Pathog. 2014, 10, e1003952. [CrossRef]

18. Szczesny, R.; Büttner, D.; Escolar, L.; Schulze, S.; Seiferth, A.; Bonas, U. Suppression of the AvrBs1-specific hypersensitive response by the YopJ effector homolog AvrBsT from Xanthomonas depends on a SNF1-related kinase. New Phytol. 2010, 187, 1058-1074. [CrossRef]

19. Lee, A.H.Y.; Hurley, B.; Felsensteiner, C.; Yea, C.; Ckurshumova, W.; Bartetzko, V.; Wang, P.W.; Quach, V.; Lewis, J.D.; Liu, Y.C.; et al. A bacterial acetyltransferase destroys plant microtubule networks and blocks secretion. PLoS Pathog. 2012, 8, e1002523. [CrossRef]

20. Jiang, S.; Yao, J.; Ma, K.W.; Zhou, H.; Song, J.; He, S.Y.; Ma, W. Bacterial effector activates jasmonate signaling by directly targeting JAZ transcriptional repressors. PLoS Pathog. 2013, 9, e1003715. [CrossRef]

21. Lewis, J.D.; Lee, A.H.-Y.; Hassan, J.A.; Wan, J.; Hurley, B.; Jhingree, J.R.; Wang, P.W.; Lo, T.; Youn, J.-Y.; Guttman, D.S.; et al. The Arabidopsis ZED1 pseudokinase is required for ZAR1-mediated immunity induced by the Pseudomonas syringae type III effector HopZ1a. Proc. Natl. Acad. Sci. USA 2013, 110, 18722-18727. [CrossRef] [PubMed]

22. Lee, J.; Manning, A.J.; Wolfgeher, D.; Jelenska, J.; Cavanaugh, K.A.; Xu, H.; Fernandez, S.M.; Michelmore, R.W.; Kron, S.J.; Greenberg, J.T. Acetylation of an NB-LRR plant immune-effector complex suppresses immunity. Cell Rep. 2015, 13, 1670-1682. [CrossRef]

23. Tasset, C.; Bernoux, M.; Jauneau, A.; Pouzet, C.; Brière, C.; Kieffer-Jacquinod, S.; Rivas, S.; Marco, Y.; Deslandes, L. Autoacetylation of the Ralstonia solanacearum effector PopP2 targets a lysine residue essential for RRS1-R-mediated immunity in Arabidopsis. PLoS Pathog. 2010, 6, e1001202. [CrossRef]

24. Le Roux, C.; Huet, G.; Jauneau, A.; Camborde, L.; Trémousaygue, D.; Kraut, A.; Zhou, B.; Levaillant, M.; Adachi, H.; Yoshioka, H.; et al. A receptor pair with an integrated decoy converts pathogen disabling of transcription factors to immunity. Cell 2015, 161, 1074-1088. [CrossRef] [PubMed]

25. Mackey, D.; Holt, B.F.; Wiig, A.; Dangl, J.L. RIN4 interacts with Pseudomonas syringae type III effector molecules and is required for RPM1-mediated resistance in Arabidopsis. Cell 2002, 108, 743-754. [CrossRef]

26. Bisgrove, S.R.; Simonich, M.T.; Smith, N.M.; Sattler, A.; Innes, R.W. A disease resistance gene in Arabidopsis with specificity for two different pathogen avirulence genes. Plant Cell 1994, 6, 927-933. [PubMed]

27. Redditt, T.J.; Chung, E.H.; Karimi, H.Z.; Rodibaugh, N.; Zhang, Y.; Trinidad, J.C.; Kim, J.H.; Zhou, Q.; Shen, M.; Dangl, J.L.; et al. AvrRpm1 functions as an ADP-ribosyl transferase to modify NOI domain-containing proteins, including Arabidopsis and soybean RPM1-Interacting Protein4. Plant Cell 2019, 31, 2664-2681.

28. Wilton, M.; Subramaniam, R.; Elmore, J.; Felsensteiner, C.; Coaker, G.; Desveaux, D. The type III effector HopF2 ${ }_{P t o}$ targets Arabidopsis RIN4 protein to promote Pseudomonas syringae virulence. Proc. Natl. Acad. Sci. USA 2010, 107, 2349-2354. [CrossRef]

29. Wang, Y.; Li, J.; Hou, S.; Wang, X.; Li, Y.; Ren, D.; Chen, S.; Tang, X.; Zhou, J.-M. A Pseudomonas syringae ADP-ribosyltransferase inhibits Arabidopsis mitogen-activated protein kinase kinases. Plant Cell 2010, 22, 2033-2044. [CrossRef]

30. Wu, S.; Lu, D.; Kabbage, M.; Wei, H.-L.; Swingle, B.; Records, A.R.; Dickman, M.; He, P.; Shan, L. Bacterial effector HopF2 suppresses Arabidopsis innate immunity at the plasma membrane. Mol. Plant-Microbe Interact. 2011, 24, 585-593. [CrossRef] [PubMed]

31. Zhou, J.; Wu, S.; Chen, X.; Liu, C.; Sheen, J.; Shan, L.; He, P. The Pseudomonas syringae effector HopF2 suppresses Arabidopsis immunity by targeting BAK1. Plant J. 2014, 77, 235-245. [CrossRef]

32. Aung, K.; Kim, P.; Li, Z.; Joe, A.; Kvitko, B.; Alfano, J.R.; Hea, S.Y. Pathogenic bacteria target plant plasmodesmata to colonize and invade surrounding tissues. Plant Cell 2020, 32, 595-611. [CrossRef]

33. Laflamme, B.; Dillon, M.M.; Martel, A.; Almeida, R.N.D.; Desveaux, D.; Guttman, D.S. The pan-genome effector-triggered immunity landscape of a host-pathogen interaction. Science 2020, 367, 763-768. [CrossRef] [PubMed] 
34. Martel, A.; Laflamme, B.; Seto, D.; Bastedo, D.P.; Dillon, M.M.; Almeida, R.N.D.; Guttman, D.S.; Desveaux, D. Immunodiversity of the Arabidopsis ZAR1 NLR is conveyed by receptor-like cytoplasmic kinase sensors. Front. Plant Sci. 2020, 11, 1-10. [CrossRef]

35. Fu, Z.Q.; Guo, M.; Jeong, B.R.; Tian, F.; Elthon, T.E.; Cerny, R.L.; Staiger, D.; Alfano, J.R. A type III effector ADP-ribosylates RNA-binding proteins and quells plant immunity. Nature 2007, 447, 284-288. [CrossRef]

36. Nicaise, V.; Joe, A.; Jeong, B.R.; Korneli, C.; Boutrot, F.; Westedt, I.; Staiger, D.; Alfano, J.R.; Zipfel, C. Pseudomonas HopU1 modulates plant immune receptor levels by blocking the interaction of their mRNAs with GRP7. EMBO J. 2013, 32, 701-712. [CrossRef]

37. Zhang, J.; Li, W.; Xiang, T.; Liu, Z.; Laluk, K.; Ding, X.; Zou, Y.; Gao, M.; Zhang, X.; Chen, S.; et al. Receptor-like cytoplasmic kinases integrate signaling from multiple plant immune receptors and are targeted by a Pseudomonas syringae effector. Cell Host Microbe 2010, 7, 290-301. [CrossRef]

38. Russell, A.R.; Ashfield, T.; Innes, R.W. Pseudomonas syringae effector AvrPphB suppresses AvrB-induced activation of RPM1 but not AvrRpm1-induced activation. Mol. Plant-Microbe Interact. 2015, 28, 727-735. [CrossRef] [PubMed]

39. Ade, J.; DeYoung, B.J.; Golstein, C.; Innes, R.W. Indirect activation of a plant nucleotide binding site-leucine-rich repeat protein by a bacterial protease. Proc. Natl. Acad. Sci. USA 2007, 104, 2531-2536. [CrossRef]

40. Shao, F.; Golstein, C.; Ade, J.; Stoutemyer, M.; Dixon, J.E.; Innes, R.W. Cleavage of Arabidopsis PBS1 by a bacterial type III effector. Science 2003, 301, 1230-1233. [CrossRef]

41. Ritter, C.; Dangl, J.L. Interference between two specific pathogen recognition events mediated by distinct plant disease resistance genes. Plant Cell 1996, 8, 251-257. [CrossRef] [PubMed]

42. Mackey, D.; Belkhadir, Y.; Alonso, J.M.; Ecker, J.R.; Dangl, J.L. Arabidopsis RIN4 is a target of the type III virulence effector AvrRpt2 and modulates RPS2-mediated resistance. Cell 2003, 112, 379-389. [CrossRef]

43. Kim, M.G.; da Cunha, L.; McFall, A.J.; Belkhadir, Y.; DebRoy, S.; Dangl, J.L.; Mackey, D. Two Pseudomonas syringae type III effectors inhibit RIN4-regulated basal defense in Arabidopsis. Cell 2005, 121, 749-759. [CrossRef]

44. Rodríguez-Herva, J.J.; González-Melendi, P.; Cuartas-Lanza, R.; Antúnez-Lamas, M.; Río-Alvarez, I.; Li, Z.; López-Torrejón, G.; Díaz, I.; Del Pozo, J.C.; Chakravarthy, S.; et al. A bacterial cysteine protease effector protein interferes with photosynthesis to suppress plant innate immune responses. Cell. Microbiol. 2012, 14, 669-681. [CrossRef]

45. Gimenez-Ibanez, S.; Boter, M.; Fernández-Barbero, G.; Chini, A.; Rathjen, J.P.; Solano, R. The bacterial effector HopX1 targets JAZ transcriptional repressors to activate jasmonate signaling and promote infection in Arabidopsis. PLoS Biol. 2014, 12, e1001792. [CrossRef]

46. Üstün, S.; König, P.; Guttman, D.S.; Börnke, F. HopZ4 from Pseudomonas syringae, a member of the HopZ type III effector family from the YopJ superfamily, inhibits the proteasome in plants. Mol. Plant-Microbe Interact. 2014, 27, 611-623. [CrossRef]

47. Nakano, M.; Mukaihara, T. Comprehensive identification of PTI suppressors in type III effector repertoire reveals that Ralstonia solanacearum activates jasmonate signaling at two different steps. Int. J. Mol. Sci. 2019, 20, 5992. [CrossRef]

48. Üstün, S.; Börnke, F. The Xanthomonas campestris type III effector XopJ proteolytically degrades proteasome subunit RPT6. Plant Physiol. 2015, 168, 107-119. [CrossRef]

49. Bartetzko, V.; Sonnewald, S.; Vogel, F.; Hartner, K.; Stadler, R.; Hammes, U.Z.; Börnke, F. The Xanthomonas campestris pv. vesicatoria type III effector protein XopJ inhibits protein secretion: Evidence for interference with cell wall-associated defense responses. Mol. Plant-Microbe Interact. 2009, 22, 655-664. [CrossRef] [PubMed]

50. Roden, J.; Eardley, L.; Hotson, A.; Cao, Y.; Mudgett, M.B. Characterization of the Xanthomonas AvrXv4 effector, a SUMO protease translocated into plant cells. Mol. Plant-Microbe Interact. 2004, 17, 633-643. [CrossRef]

51. Hotson, A.; Chosed, R.; Shu, H.; Orth, K.; Mudgett, M.B. Xanthomonas type III effector XopD targets SUMO-conjugated proteins in planta. Mol. Microbiol. 2003, 50, 377-389. [CrossRef]

52. Kim, J.-G.; Stork, W.; Mudgett, M.B. Xanthomonas type III effector XopD desumoylates tomato transcription factor SlERF4 to suppress ethylene responses and promote pathogen growth. Cell Host Microbe 2013, 13, 143-154. [CrossRef]

53. Li, L.; Kim, P.; Yu, L.; Cai, G.; Chen, S.; Alfano, J.R.; Zhou, J.M. Activation-dependent destruction of a co-receptor by a Pseudomonas syringae effector dampens plant immunity. Cell Host Microbe 2016, 20, 504-514. [CrossRef] [PubMed]

54. Schuebel, F.; Rocker, A.; Edelmann, D.; Schessner, J.; Brieke, C.; Meinhart, A. 3'-NADP and 3'-NAADP, two metabolites formed by the bacterial type III effector AvrRxo. J. Biol. Chem. 2016, 291, 22868-22880. [CrossRef] [PubMed]

55. Shidore, T.; Broeckling, C.D.; Kirkwood, J.S.; Long, J.J.; Miao, J.; Zhao, B.; Leach, J.E.; Triplett, L.R. The effector AvrRxo1 phosphorylates NAD in planta. PLoS Pathog. 2017, 13, e1006442. [CrossRef]

56. Liu, Y.; Wang, K.; Cheng, Q.; Kong, D.; Zhang, X.; Wang, Z.; Wang, Q.; Xie, Q.; Yan, J.; Chu, J.; et al. Cysteine protease RD21A regulated by E3 ligase SINAT4 is required for drought-induced resistance to Pseudomonas syringae in Arabidopsis. J. Exp. Bot. 2020, 71, 5562-5576. [CrossRef]

57. Lopez, V.A.; Park, B.C.; Nowak, D.; Sreelatha, A.; Zembek, P.; Fernandez, J.; Servage, K.A.; Gradowski, M.; Hennig, J.; Tomchick, D.R.; et al. A bacterial effector mimics a host HSP90 client to undermine immunity. Cell 2019, 179, 205-218. [CrossRef]

58. Teper, D.; Girija, A.M.; Bosis, E.; Popov, G.; Savidor, A.; Sessa, G. The Xanthomonas euvesicatoria type III effector XopAU is an active protein kinase that manipulates plant MAP kinase signaling. PLoS Pathog. 2018, 14, e1006880. [CrossRef]

59. Zhang, J.; Shao, F.; Li, Y.; Cui, H.; Chen, L.; Li, H.; Zou, Y.; Long, C.; Lan, L.; Chai, J.; et al. A Pseudomonas syringae effector inactivates MAPKs to suppress PAMP-induced immunity in plants. Cell Host Microbe 2007, 1, 175-185. [CrossRef] 
60. Zhang, Z.; Wu, Y.; Gao, M.; Zhang, J.; Kong, Q.; Liu, Y.; Ba, H.; Zhou, J.; Zhang, Y. Disruption of PAMP-induced MAP kinase cascade by a Pseudomonas syringae effector activates plant immunity mediated by the NB-LRR protein SUMM2. Cell Host Microbe 2012, 11, 253-263. [CrossRef]

61. Macho, A.P.; Schwessinger, B.; Ntoukakis, V.; Brutus, A.; Segonzac, C.; Roy, S.; Kadota, Y.; Oh, M.H.; Sklenar, J.; Derbyshire, P.; et al. A bacterial tyrosine phosphatase inhibits plant pattern recognition receptor activation. Science 2014, 343, 1509-1512. [CrossRef]

62. Luo, X.; Wu, W.; Liang, Y.; Xu, N.; Wang, Z.; Zou, H.; Liu, J. Tyrosine phosphorylation of the lectin receptor-like kinase LORE regulates plant immunity. EMBO J. 2020, 39, 1-16. [CrossRef] [PubMed]

63. Göhre, V.; Spallek, T.; Häweker, H.; Mersmann, S.; Mentzel, T.; Boller, T.; de Torres, M.; Mansfield, J.W.; Robatzek, S. Plant pattern-recognition receptor FLS2 is directed for degradation by the bacterial ubiquitin ligase AvrPtoB. Curr. Biol. 2008, 18, 1824-1832. [CrossRef] [PubMed]

64. Gimenez-Ibanez, S.; Hann, D.R.; Ntoukakis, V.; Petutschnig, E.; Lipka, V.; Rathjen, J.P. AvrPtoB targets the LysM receptor kinase CERK1 to promote bacterial virulence on plants. Curr. Biol. 2009, 19, 423-429. [CrossRef] [PubMed]

65. Shan, L.; He, P.; Li, J.; Heese, A.; Peck, S.C.; Nürnberger, T.; Martin, G.B.; Sheen, J. Bacterial effectors target the common signaling partner BAK1 to disrupt multiple MAMP receptor-signaling complexes and impede plant immunity. Cell Host Microbe 2008, 4, 17-27. [CrossRef]

66. Chen, H.; Chen, J.; Li, M.; Chang, M.; Xu, K.; Shang, Z.; Zhao, Y.; Palmer, I.; Zhang, Y.; McGill, J.; et al. A bacterial type III effector targets the master regulator of salicylic acid signaling, NPR1, to subvert plant immunity. Cell Host Microbe 2017, 22, 777-788. [CrossRef]

67. Rosebrock, T.R.; Zeng, L.; Brady, J.J.; Abramovitch, R.B.; Xiao, F.; Martin, G.B. A bacterial E3 ubiquitin ligase targets a host protein kinase to disrupt plant immunity. Nature 2007, 448, 370-374. [CrossRef]

68. Mathieu, J.; Schwizer, S.; Martin, G.B. Pto kinase binds two domains of AvrPtoB and its proximity to the effector E3 ligase determines if it evades degradation and activates plant immunity. PLoS Pathog. 2014, 10, e1004227. [CrossRef]

69. Mucyn, T.S.; Clemente, A.; Andriotis, V.M.E.; Balmuth, A.L.; Oldroyd, G.E.D.; Staskawicz, B.J.; Rathjen, J.P. The tomato NBARCLRR protein Prf interacts with Pto kinase in vivo to regulate specific plant immunity. Plant Cell 2006, 18, 2792-2806. [CrossRef] [PubMed]

70. Angot, A.; Peeters, N.; Lechner, E.; Vailleau, F.; Baud, C.; Gentzbittel, L.; Sartorel, E.; Genschik, P.; Boucher, C.; Genin, S. Ralstonia solanacearum requires F-box-like domain-containing type III effectors to promote disease on several host plants. Proc. Natl. Acad. Sci. USA 2006, 103, 14620-14625. [CrossRef]

71. Cunnac, S.; Occhialini, A.; Barberis, P.; Boucher, C.; Genin, S. Inventory and functional analysis of the large Hrp regulon in Ralstonia solanacearum: Identification of novel effector proteins translocated to plant host cells through the type III secretion system. Mol. Microbiol. 2004, 53, 115-128. [CrossRef]

72. Nakano, M.; Oda, K.; Mukaihara, T. Ralstonia solanacearum novel E3 ubiquitin ligase (NEL) effectors RipAW and RipAR suppress pattern-triggered immunity in plants. Microbiology 2017, 163, 992-1002. [CrossRef]

73. Cheng, D.; Zhou, D.; Wang, Y.; Wang, B.; He, Q.; Song, B.; Chen, H. Ralstonia solanacearum type III effector RipV2 encoding a novel E3 ubiquitin ligase (NEL) is required for full virulence by suppressing plant PAMP-triggered immunity. Biochem. Biophys. Res. Commun. 2021, 550, 120-126. [CrossRef]

74. Popov, G.; Majhi, B.B.; Sessa, G. Effector gene xopAE of Xanthomonas euvesicatoria 85-10 is part of an operon and encodes an E3 ubiquitin ligase. J. Bacteriol. 2018, 200, 1-19. [CrossRef] [PubMed]

75. Ji, H.; Liu, D.; Zhang, Z.; Sun, J.; Han, B.; Li, Z. A bacterial F-box effector suppresses SAR immunity through mediating the proteasomal degradation of OsTrxh2 in rice. Plant J. 2020, 104, 1054-1072. [CrossRef] [PubMed]

76. Qin, J.; Zhou, X.; Sun, L.; Wang, K.; Yang, F.; Liao, H.; Rong, W.; Yin, J.; Chen, H.; Chen, X.; et al. The Xanthomonas effector XopK harbours E3 ubiquitin-ligase activity that is required for virulence. New Phytol. 2018, 220, 219-231. [CrossRef] [PubMed]

77. Singer, A.U.; Schulze, S.; Skarina, T.; Xu, X.; Cui, H.; Eschen-Lippold, L.; Egler, M.; Srikumar, T.; Raught, B.; Lee, J.; et al. A pathogen type III effector with a novel E3 ubiquitin ligase architecture. PLoS Pathog. 2013, 9, e1003121. [CrossRef]

78. Leong, J.-X.; Raffeiner, M.; Spinti, D.; Langin, G.; Franz-Wachtel, M.; Guzman, A.R.; Kim, J.-G.; Pandey, P.; Minina, A.E.; Macek, B.; et al. Self-ubiquitination of a pathogen type-III effector traps and blocks the autophagy machinery to promote disease. bioRxiv 2021. [CrossRef]

79. Feng, F.; Yang, F.; Rong, W.; Wu, X.; Zhang, J.; Chen, S.; He, C.; Zhou, J.-M. A Xanthomonas uridine 5'-monophosphate transferase inhibits plant immune kinases. Nature 2012, 485, 114-118. [CrossRef] [PubMed]

80. Wang, G.; Roux, B.; Feng, F.; Guy, E.; Li, L.; Li, N.; Zhang, X.; Lautier, M.; Jardinaud, M.-F.; Chabannes, M.; et al. The decoy substrate of a pathogen effector and a pseudokinase specify pathogen-induced modified-self recognition and immunity in plants. Cell Host Microbe 2015, 18, 285-295. [CrossRef]

81. Blüher, D.; Laha, D.; Thieme, S.; Hofer, A.; Eschen-Lippold, L.; Masch, A.; Balcke, G.; Pavlovic, I.; Nagel, O.; Schonsky, A.; et al. A 1-phytase type III effector interferes with plant hormone signaling. Nat. Commun. 2017, 8, 2159. [CrossRef]

82. Poueymiro, M.; Cazalé, A.C.; François, J.M.; Parrou, J.L.; Peeters, N.; Genin, S. A Ralstonia solanacearum type III effector directs the production of the plant signal metabolite trehalose-6-phosphate. mBio 2014, 5, e02065-14. [CrossRef] [PubMed]

83. Fujiwara, S.; Kawazoe, T.; Ohnishi, K.; Kitagawa, T.; Popa, C.; Valls, M.; Genin, S.; Nakamura, K.; Kuramitsu, Y.; Tanaka, N.; et al. RipAY, a plant pathogen effector protein, exhibits robust $\gamma$-glutamyl cyclotransferase activity when stimulated by eukaryotic thioredoxins. J. Biol. Chem. 2016, 291, 6813-6830. [CrossRef] 
84. Sun, Y.; Li, P.; Shen, D.; Wei, Q.; He, J.; Lu, Y. The Ralstonia solanacearum effector RipN suppresses plant PAMP-triggered immunity, localizes to the endoplasmic reticulum and nucleus, and alters the NADH/NAD ${ }^{+}$ratio in Arabidopsis. Mol. Plant Pathol. 2019, 20, 533-546. [CrossRef]

85. Hann, D.R.; Domínguez-Ferreras, A.; Motyka, V.; Dobrev, P.I.; Schornack, S.; Jehle, A.; Felix, G.; Chinchilla, D.; Rathjen, J.P.; Boller, T. The Pseudomonas type III effector HopQ1 activates cytokinin signaling and interferes with plant innate immunity. New Phytol. 2014, 201, 585-598. [CrossRef] [PubMed]

86. Gupta, M.K.; Nathawat, R.; Sinha, D.; Haque, A.S.; Sankaranarayanan, R.; Sonti, R.V. Mutations in the predicted active site of Xanthomonas oryzae pv. oryzae XopQ differentially affect virulence, suppression of host innate immunity, and induction of the HR in a nonhost plant. Mol. Plant-Microbe Interact. 2015, 28, 195-206. [CrossRef]

87. Washington, E.J.; Mukhtar, M.S.; Finkel, O.M.; Wan, L.; Banfield, M.J.; Kieber, J.J.; Dangl, J.L. Pseudomonas syringae type III effector HopAF1 suppresses plant immunity by targeting methionine recycling to block ethylene induction. Proc. Natl. Acad. Sci. USA 2016, 113, E3577-E3586. [CrossRef] [PubMed]

88. Nakano, M.; Mukaihara, T. Ralstonia solanacearum type III effector RipAL targets chloroplasts and induces jasmonic acid production to suppress salicylic acid-mediated defense responses in plants. Plant Cell Physiol. 2018, 59, 2576-2589. [CrossRef]

89. Chung, E.-H.; da Cunha, L.; Wu, A.-J.; Gao, Z.; Cherkis, K.; Afzal, A.J.; Mackey, D.; Dangl, J.L. Specific threonine phosphorylation of a host target by two unrelated type III effectors activates a host innate immune receptor in plants. Cell Host Microbe 2011, 9 , 125-136. [CrossRef]

90. Liu, J.; Elmore, J.M.; Lin, Z.D.; Coaker, G. A receptor-like cytoplasmic kinase phosphorylates the host target RIN4, leading to the activation of a plant innate immune receptor. Cell Host Microbe 2011, 9, 137-146. [CrossRef]

91. Cui, H.; Wang, Y.; Xue, L.; Chu, J.; Yan, C.; Fu, J.; Chen, M.; Innes, R.W.; Zhou, J. Pseudomonas syringae effector protein AvrB perturbs Arabidopsis hormone signaling by activating MAP kinase 4. Cell Host Microbe 2010, 7, 164-175. [CrossRef] [PubMed]

92. Kim, N.H.; Kim, D.S.; Chung, E.H.; Hwang, B.K. Pepper suppressor of the G2 allele of skp1 interacts with the receptor-like cytoplasmic kinase1 and type III effector AvrBsT and promotes the hypersensitive cell death response in a phosphorylationdependent manner. Plant Physiol. 2014, 165, 76-91. [CrossRef]

93. Jin, L.; Ham, J.H.; Hage, R.; Zhao, W.; Soto-Hernández, J.; Lee, S.Y.; Paek, S.-M.; Kim, M.G.; Boone, C.; Coplin, D.L.; et al. Direct and indirect targeting of PP2A by conserved bacterial type-III effector proteins. PLoS Pathog. 2016, 12, e1005609. [CrossRef] [PubMed]

94. Siamer, S.; Guillas, I.; Shimobayashi, M.; Kunz, C.; Hall, M.N.; Barny, M.A. Expression of the bacterial type III effector DspA/E in Saccharomyces cerevisiae down-regulates the sphingolipid biosynthetic pathway leading to growth arrest. J. Biol. Chem. 2014, 289, 18466-18477. [CrossRef] [PubMed]

95. Xiang, T.; Zong, N.; Zou, Y.; Wu, Y.; Zhang, J.; Xing, W.; Li, Y.; Tang, X.; Zhu, L.; Chai, J.; et al. Pseudomonas syringae effector AvrPto blocks innate immunity by targeting receptor kinases. Curr. Biol. 2008, 18, 74-80. [CrossRef]

96. Xiang, T.; Zong, N.; Zhang, J.; Chen, J.; Chen, M.; Zhou, J.-M. BAK1 is not a target of the Pseudomonas syringae effector AvrPto. Mol. Plant-Microbe Interact. 2011, 24, 100-107. [CrossRef]

97. Kim, Y.J.; Lin, N.-C.C.; Martin, G.B. Two distinct Pseudomonas effector proteins interact with the Pto kinase and activate plant immunity. Cell 2002, 109, 589-598. [CrossRef]

98. Wu, J.; van der Burgh, A.M.; Bi, G.; Zhang, L.; Alfano, J.R.; Martin, G.B.; Joosten, M.H.A.J. The bacterial effector AvrPto targets the regulatory coreceptor SOBIR1 and suppresses defense signaling mediated by the receptor-like protein Cf-4. Mol. Plant-Microbe Interact. 2018, 31, 75-85. [CrossRef]

99. Xing, Y.; Xu, N.; Bhandari, D.D.; Lapin, D.; Sun, X.; Luo, X.; Wang, Y.; Cao, J.; Wang, H.; Coaker, G.; et al. Bacterial effector targeting of a plant iron sensor facilitates iron acquisition and pathogen colonization. Plant Cell 2021. [CrossRef]

100. Sarris, P.F.; Duxbury, Z.; Huh, S.U.; Ma, Y.; Segonzac, C.; Sklenar, J.; Derbyshire, P.; Cevik, V.; Rallapalli, G.; Saucet, S.B.; et al. A plant immune receptor detects pathogen effectors that target WRKY transcription factors. Cell 2015, 161, 1089-1100. [CrossRef] [PubMed]

101. Cui, F.; Wu, S.; Sun, W.; Coaker, G.; Kunkel, B.; He, P.; Shan, L. The Pseudomonas syringae type III effector AvrRpt2 promotes pathogen virulence via stimulating Arabidopsis auxin/indole acetic acid protein turnover. Plant Physiol. 2013, 162, 1018-1029. [CrossRef]

102. Whalen, M.; Richter, T.; Zakhareyvich, K.; Yoshikawa, M.; Al-Azzeh, D.; Adefioye, A.; Spicer, G.; Mendoza, L.L.; Morales, C.Q.; Klassen, V.; et al. Identification of a host 14-3-3 protein that interacts with Xanthomonas effector AvrRxv. Physiol. Mol. Plant Pathol. 2008, 72, 46-55. [CrossRef]

103. Yang, L.; Teixeira, P.J.P.L.; Biswas, S.; Finkel, O.M.; He, Y.; Salas-Gonzalez, I.; English, M.E.; Epple, P.; Mieczkowski, P.; Dangl, J.L. Pseudomonas syringae type III effector HopBB1 promotes host transcriptional repressor degradation to regulate phytohormone responses and virulence. Cell Host Microbe 2017, 21, 156-168. [CrossRef] [PubMed]

104. Guo, M.; Kim, P.; Li, G.; Elowsky, C.G.; Alfano, J.R. A bacterial effector co-opts calmodulin to target the plant microtubule network. Cell Host Microbe 2016, 19, 67-78. [CrossRef]

105. Block, A.; Guo, M.; Li, G.; Elowsky, C.; Clemente, T.E.; Alfano, J.R. The Pseudomonas syringae type III effector HopG1 targets mitochondria, alters plant development and suppresses plant innate immunity. Cell. Microbiol. 2010, 12, 318-330. [CrossRef] 
106. Shimono, M.; Lu, Y.J.; Porter, K.; Kvitko, B.H.; Henty-Ridilla, J.; Creason, A.; He, S.Y.; Chang, J.H.; Staiger, C.J.; Day, B. The Pseudomonas syringae type III effector HopG1 induces actin remodeling to promote symptom development and susceptibility during infection. Plant Physiol. 2016, 171, 2239-2255. [CrossRef] [PubMed]

107. Jelenska, J.; Van Hal, J.A.; Greenberg, J.T. Pseudomonas syringae hijacks plant stress chaperone machinery for virulence. Proc. Natl. Acad. Sci. USA 2010, 107, 13177-13182. [CrossRef]

108. Nomura, K.; Debroy, S.; Lee, Y.H.; Pumplin, N.; Jones, J.; He, S.Y. A bacterial virulence protein suppresses host innate immunity to cause plant disease. Science 2006, 313, 220-223. [CrossRef]

109. Nomura, K.; Mecey, C.; Lee, Y.-N.; Imboden, L.A.; Chang, J.H.; He, S.Y. Effector-triggered immunity blocks pathogen degradation of an immunity-associated vesicle traffic regulator in Arabidopsis. Proc. Natl. Acad. Sci. USA 2011, 108, 10774-10779. [CrossRef] [PubMed]

110. Li, W.; Yadeta, K.A.; Elmore, J.M.; Coaker, G. The Pseudomonas syringae effector HopQ1 promotes bacterial virulence and interacts with tomato 14-3-3 proteins in a phosphorylation-dependent manner. Plant Physiol. 2013, 161, 2062-2074. [CrossRef] [PubMed]

111. Kang, Y.; Jelenska, J.; Cecchini, N.M.; Li, Y.; Lee, M.W.; Kovar, D.R.; Greenberg, J.T. HopW1 from Pseudomonas syringae disrupts the actin cytoskeleton to promote virulence in Arabidopsis. PLoS Pathog. 2014, 10, e1004232. [CrossRef]

112. Yu, G.; Xian, L.; Xue, H.; Yu, W.; Rufian, J.S.; Sang, Y.; Morcillo, R.J.L.; Wang, Y.; Macho, A.P. A bacterial effector protein prevents MAPK-mediated phosphorylation of SGT1 to suppress plant immunity. PLoS Pathog. 2020, 16, e1008933. [CrossRef]

113. Nakano, M.; Ichinose, Y.; Mukaihara, T. Ralstonia solanacearum type III effector RipAC targets SGT1 to suppress effector-triggered immunity. Plant Cell Physiol. 2021, 61, 2067-2076. [CrossRef]

114. Derkacheva, M.; Yu, G.; Rufian, J.S.; Jiang, S.; Derbyshire, P.; Morcillo, R.J.L.; Stransfeld, L.; Wei, Y.; Menke, F.L.H.; Zipfel, C.; et al. The Arabidopsis E3 ubiquitin ligase PUB4 regulates BIK1 homeostasis and is targeted by a bacterial type-III effector. bioRxiv 2020. [CrossRef]

115. Sun, Y.; Li, P.; Deng, M.; Shen, D.; Dai, G.; Yao, N.; Lu, Y. The Ralstonia solanacearum effector RipAK suppresses plant hypersensitive response by inhibiting the activity of host catalases. Cell. Microbiol. 2017, 19, e12736. [CrossRef] [PubMed]

116. Perez-Quintero, A.L.; Szurek, B. A decade decoded: Spies and hackers in the history of TAL effectors research. Annu. Rev. Phytopathol. 2019, 57, 459-481. [CrossRef]

117. Taylor, K.W.; Kim, J.G.; Su, X.B.; Aakre, C.D.; Roden, J.A.; Adams, C.M.; Mudgett, M.B. Tomato TFT1 is required for PAMPtriggered immunity and mutations that prevent T3S effector XopN from binding to TFT1 attenuate Xanthomonas virulence. PLoS Pathog. 2012, 8, 22-27. [CrossRef]

118. Ishikawa, K.; Yamaguchi, K.; Sakamoto, K.; Yoshimura, S.; Inoue, K.; Tsuge, S.; Kojima, C.; Kawasaki, T. Bacterial effector modulation of host E3 ligase activity suppresses PAMP-triggered immunity in rice. Nat. Commun. 2014, 5, 5430. [CrossRef] [PubMed]

119. Deb, S.; Gupta, M.K.; Patel, H.K.; Sonti, R.V. Xanthomonas oryzae pv. oryzae XopQ protein suppresses rice immune responses through interaction with two 14-3-3 proteins but its phospho-null mutant induces rice immune responses and interacts with another 14-3-3 protein. Mol. Plant Pathol. 2019, 20, 976-989. [CrossRef]

120. Schultink, A.; Qi, T.; Lee, A.; Steinbrenner, A.D.; Staskawicz, B. Roq1 mediates recognition of the Xanthomonas and Pseudomonas effector proteins XopQ and HopQ1. Plant J. 2017, 92, 787-795. [CrossRef] [PubMed]

121. Deb, S.; Ghosh, P.; Patel, H.K.; Sonti, R.V. Interaction of the Xanthomonas effectors XopQ and XopX results in induction of rice immune responses. Plant J. 2020, 104, 332-350. [CrossRef]

122. Oda, K. New families of carboxyl peptidases: Serine-carboxyl peptidases and glutamic peptidases. J. Biochem. 2012, 151, 13-25. [CrossRef] [PubMed]

123. Rawlings, N.D.; Barrett, A.J.; Thomas, P.D.; Huang, X.; Bateman, A.; Finn, R.D. The MEROPS database of proteolytic enzymes, their substrates and inhibitors in 2017 and a comparison with peptidases in the PANTHER database. Nucleic Acids Res. 2018, 46, D624-D632. [CrossRef] [PubMed]

124. Whalen, M.C.; Innes, R.W.; Bent, A.F.; Staskawicz, B.J. Identification of Pseudomonas syringae pathogens of Arabidopsis and a bacterial locus determining avirulence on both Arabidopsis and soybean. Plant Cell 1991, 3, 49-59.

125. Mindrinos, M.; Katagiri, F.; Yu, G.L.; Ausubel, F.M. The A. thaliana disease resistance gene RPS2 encodes a protein containing a nucleotide-binding site and leucine-rich repeats. Cell 1994, 78, 1089-1099. [CrossRef]

126. Axtell, M.J.; Chisholm, S.T.; Dahlbeck, D.; Staskawicz, B.J. Genetic and molecular evidence that the Pseudomonas syringae type III effector protein AvrRpt2 is a cysteine protease. Mol. Microbiol. 2003, 49, 1537-1546. [CrossRef]

127. Axtell, M.J.; Staskawicz, B.J. Initiation of RPS2-specified disease resistance in Arabidopsis is coupled to the AvrRpt2-directed elimination of RIN4. Cell 2003, 112, 369-377. [CrossRef]

128. Chen, Z.; Kloek, A.P.; Boch, J.; Katagiri, F.; Kunkel, B.N. The Pseudomonas syringae avrRpt2 gene product promotes pathogen virulence from inside plant cells. Mol. Plant-Microbe Interact. 2000, 13, 1312-1321. [CrossRef]

129. Kim, H.-S.; Desveaux, D.; Singer, A.U.; Patel, P.; Sondek, J.; Dangl, J.L. The Pseudomonas syringae effector AvrRpt2 cleaves its C-terminally acylated target, RIN4, from Arabidopsis membranes to block RPM1 activation. Proc. Natl. Acad. Sci. USA 2005, 102, 6496-6501. [CrossRef]

130. Belkhadir, Y.; Nimchuk, Z.; Hubert, D.A.; Mackey, D.; Dangl, J.L. Arabidopsis RIN4 negatively regulates disease resistance mediated by RPS2 and RPM1 downstream or independent of the NDR1 signal modulator and is not required for the virulence functions of bacterial type III effectors AvrRpt2 or AvrRpm1. Plant Cell 2004, 16, 2822-2835. [CrossRef] [PubMed] 
131. Lim, M.T.S.; Kunkel, B.N. Mutations in the Pseudomonas syringae avrRpt2 gene that dissociate its virulence and avirulence activities lead to decreased efficiency in AvrRpt2-induced disappearance of RIN4. Mol. Plant-Microbe Interact. 2004, 17, 313-321. [CrossRef]

132. Chisholm, S.T.; Dahlbeck, D.; Krishnamurthy, N.; Day, B.; Sjolander, K.; Staskawicz, B.J. Molecular characterization of proteolytic cleavage sites of the Pseudomonas syringae effector AvrRpt2. Proc. Natl. Acad. Sci. USA 2005, 102, 2087-2092. [CrossRef] [PubMed]

133. Eschen-Lippold, L.; Jiang, X.; Elmore, J.M.; Mackey, D.; Shan, L.; Coaker, G.; Scheel, D.; Lee, J. Bacterial AvrRpt2-like cysteine proteases block activation of the Arabidopsis mitogen-activated protein kinases, MPK4 and MPK11. Plant Physiol. 2016, 171, 2223-2238. [CrossRef] [PubMed]

134. Afzal, A.J.; Kim, J.H.; Mackey, D. The role of NOI-domain containing proteins in plant immune signaling. BMC Genom. 2013, 14, 1. [CrossRef]

135. Jenner, C.; Hitchin, E.; Mansfield, J.; Walters, K.; Betteridge, P.; Teverson, D.; Taylor, J. Gene-for-gene interactions between Pseudomonas syringae pv. phaseolicola and Phaseolus. Mol. Plant-Microbe Interact. 1991, 4, 553-562. [CrossRef] [PubMed]

136. Shao, F.; Merritt, P.M.; Bao, Z.; Innes, R.W.; Dixon, J.E. A Yersinia effector and a Pseudomonas avirulence protein define a family of cysteine proteases functioning in bacterial pathogenesis. Cell 2002, 109, 575-588. [CrossRef]

137. Puri, N.; Jenner, C.; Bennett, M.; Stewart, R.; Mansfield, J.; Lyons, N.; Taylor, J. Expression of avrPphB, an avirulence gene from Pseudomonas syringae pv. phaseolicola, and the delivery of signals causing the hypersensitive reaction in bean. Mol. Plant-Microbe Interact. 1997, 10, 247-256. [CrossRef]

138. Simonich, M.T.; Innes, R.W. A disease resistance gene in Arabidopsis with specificity for the avrPph3 gene of Pseudomonas syringae pv. phaseolicola. Mol. Plant-Microbe Interact. 1995, 8, 637-640. [CrossRef] [PubMed]

139. Warren, R.F.; Holub, E.; Innes, R.W. Identification of three putative signal transduction genes involved in R gene-specified disease resistance in Arabidopsis. Genetics 1999, 152, 401-412. [CrossRef]

140. Swiderski, M.R.; Innes, R.W. The Arabidopsis PBS1 resistance gene encodes a member of a novel protein kinase subfamily. Plant J. 2001, 26, 101-112. [CrossRef] [PubMed]

141. DeYoung, B.J.; Qi, D.; Kim, S.-H.; Burke, T.P.; Innes, R.W. Activation of a plant nucleotide binding-leucine rich repeat disease resistance protein by a modified self protein. Cell. Microbiol. 2012, 14, 1071-1084. [CrossRef]

142. Zhu, M.; Shao, F.; Innes, R.W.; Dixon, J.E.; Xu, Z. The crystal structure of Pseudomonas avirulence protein AvrPphB: A papain-like fold with a distinct substrate-binding site. Proc. Natl. Acad. Sci. USA 2004, 101, 302-307. [CrossRef]

143. Qi, D.; Dubiella, U.; Kim, S.H.; Isaiah Sloss, D.; Dowen, R.H.; Dixon, J.E.; Innes, R.W. Recognition of the protein kinase AVRPPHB SUSCEPTIBLE1 by the disease resistance protein RESISTANCE TO PSEUDOMONAS SYRINGAE5 is dependent on S-acylation and an exposed loop in AVRPPHB SUSCEPTIBLE1. Plant Physiol. 2014, 164, 340-351. [CrossRef]

144. Shinya, T.; Yamaguchi, K.; Desaki, Y.; Yamada, K.; Narisawa, T.; Kobayashi, Y.; Maeda, K.; Suzuki, M.; Tanimoto, T.; Takeda, J.; et al. Selective regulation of the chitin-induced defense response by the Arabidopsis receptor-like cytoplasmic kinase PBL27. Plant J. 2014, 79, 56-66. [CrossRef] [PubMed]

145. López-Solanilla, E.; Bronstein, P.A.; Schneider, A.R.; Collmer, A. HopPtoN is a Pseudonomas syringae Hrp (type III secretion system) cysteine protease effector that supresses pathogen-induced necrosis associated with both compatible and incompatible plant interactions. Mol. Microbiol. 2004, 54, 353-365. [CrossRef]

146. Melotto, M.; Underwood, W.; Koczan, J.; Nomura, K.; He, S.Y. Plant stomata function in innate immunity against bacterial invasion. Cell 2006, 126, 969-980. [CrossRef] [PubMed]

147. Katsir, L.; Schilmiller, A.L.; Staswick, P.E.; Sheng, Y.H.; Howe, G.A. COI1 is a critical component of a receptor for jasmonate and the bacterial virulence factor coronatine. Proc. Natl. Acad. Sci. USA 2008, 105, 7100-7105. [CrossRef] [PubMed]

148. Pauwels, L.; Goossens, A. The JAZ proteins: A crucial interface in the jasmonate signaling cascade. Plant Cell 2011, 23, 3089-3100. [CrossRef] [PubMed]

149. Lewis, J.D.; Lee, A.; Ma, W.; Zhou, H.; Guttman, D.S.; Desveaux, D. The YopJ superfamily in plant-associated bacteria. Mol. Plant Pathol. 2011, 12, 928-937. [CrossRef]

150. Ma, W.; Dong, F.F.T.; Stavrinides, J.; Guttman, D.S. Type III effector diversification via both pathoadaptation and horizontal transfer in response to a coevolutionary arms race. PLoS Genet. 2006, 2, e209. [CrossRef] [PubMed]

151. Üstün, S.; Bartetzko, V.; Börnke, F. The Xanthomonas campestris type III effector XopJ targets the host cell proteasome to suppress salicylic-acid mediated plant defence. PLoS Pathog. 2013, 9, e1003427. [CrossRef] [PubMed]

152. Üstün, S.; Bartetzko, V.; Börnke, F. The Xanthomonas effector XopJ triggers a conditional hypersensitive response upon treatment of N. benthamiana leaves with salicylic acid. Front. Plant Sci. 2015, 6, 1-11. [CrossRef]

153. Noël, L.; Thieme, F.; Nennstiel, D.; Bonas, U. Two novel type III-secreted proteins of Xanthomonas campestris pv. vesicatoria are encoded within the hrp pathogenicity island. J. Bacteriol. 2002, 184, 1340-1348. [CrossRef]

154. Chosed, R.; Tomchick, D.R.; Brautigam, C.A.; Mukherjee, S.; Negi, V.S.; Machius, M.; Orth, K. Structural analysis of Xanthomonas XopD provides insights into substrate specificity of ubiquitin-like protein proteases. J. Biol. Chem. 2007, 282, 6773-6782. [CrossRef]

155. Kim, J.G.; Taylor, K.W.; Hotson, A.; Keegan, M.; Schmelz, E.A.; Mudgett, M.B. XopD SUMO protease affects host transcription, promotes pathogen growth, and delays symptom development in Xanthomonas-infected tomato leaves. Plant Cell 2008, 20, 1915-1929. [CrossRef]

156. Kim, J.-G.; Mudgett, M.B. Tomato bHLH132 transcription factor controls growth and defense and is activated by Xanthomonas euvesicatoria effector XopD during pathogenesis. Mol. Plant-Microbe Interact. 2019, 32, 1614-1622. [CrossRef] [PubMed] 
157. Üstün, S.; Sheikh, A.; Gimenez-Ibanez, S.; Jones, A.; Ntoukakis, V.; Börnke, F. The proteasome acts as a hub for plant immunity and is targeted by Pseudomonas type III effectors. Plant Physiol. 2016, 172, 1941-1958. [CrossRef]

158. Sorel, M.; Mooney, B.; Marchi, R.; Graciet, E. Ubiquitin/proteasome system in plant pathogen responses. Annu. Plant Rev. Online 2019, 2, 65-116.

159. Callis, J. The ubiquitination machinery of the ubiquitin system. Arabidopsis Book 2014, 12, e0174. [CrossRef] [PubMed]

160. Smalle, J.; Vierstra, R.D. The ubiquitin 26S proteasome proteolytic pathway. Annu. Rev. Plant Biol. 2004, 55, 555-590. [CrossRef]

161. Trujillo, M.; Shirasu, K. Ubiquitination in plant immunity. Curr. Opin. Plant Biol. 2010, 13, 402-408. [CrossRef]

162. Dudler, R. Manipulation of host proteasomes as a virulence mechanism of plant pathogens. Annu. Rev. Phytopathol. 2013, 51, 521-542. [CrossRef]

163. Abramovitch, R.B.; Kim, Y.-J.; Chen, S.; Dickman, M.B.; Martin, G.B. Pseudomonas type III effector AvrPtoB induces plant disease susceptibility by inhibition of host programmed cell death. EMBO J. 2003, 22, 60-69. [CrossRef]

164. De Torres, M.; Mansfield, J.W.; Grabov, N.; Brown, I.R.; Ammouneh, H.; Tsiamis, G.; Forsyth, A.; Robatzek, S.; Grant, M.; Boch, J. Pseudomonas syringae effector AvrPtoB suppresses basal defence in Arabidopsis. Plant J. 2006, 47, 368-382. [CrossRef]

165. Janjusevic, R.; Abramovitch, R.B.; Martin, G.B.; Stebbins, C.E. A bacterial inhibitor of host programmed cell death defenses is an E3 ubiquitin ligase. Science 2006, 311, 222-226. [CrossRef]

166. Quezada, C.M.; Hicks, S.W.; Galán, J.E.; Stebbins, C.E. A family of Salmonella virulence factors functions as a distinct class of autoregulated E3 ubiquitin ligases. Proc. Natl. Acad. Sci. USA 2009, 106, 4864-4869. [CrossRef]

167. Svenning, S.; Lamark, T.; Krause, K.; Johansen, T. Plant NBR1 is a selective autophagy substrate and a functional hybrid of the mammalian autophagic adapters NBR1 and p62/SQSTM1. Autophagy 2011, 7, 993-1010. [CrossRef] [PubMed]

168. Zhuang, X.; Wang, H.; Lam, S.K.; Gao, C.; Wang, X.; Cai, Y.; Jiang, L. A BAR-domain protein SH3P2, which binds to phosphatidylinositol 3-phosphate and ATG8, regulates autophagosome formation in Arabidopsis. Plant Cell 2013, 25, 4596-4615. [CrossRef]

169. Gomes, L.C.; Dikic, I. Autophagy in antimicrobial immunity. Mol. Cell 2014, 54, 224-233. [CrossRef] [PubMed]

170. Perina, D.; Mikoč, A.; Ahel, J.; Ćetković, H.; Žaja, R.; Ahel, I. Distribution of protein poly(ADP-ribosyl)ation systems across all domains of life. DNA Repair 2014, 23, 4-16. [CrossRef] [PubMed]

171. Palazzo, L.; Mikoč, A.; Ahel, I. ADP-ribosylation: New facets of an ancient modification. FEBS J. 2017, 284, 2932-2946. [CrossRef]

172. Aravind, L.; Zhang, D.; de Souza, R.F.; Anand, S.; Iyer, L.M. The natural history of ADP-ribosyltransferases and the ADPribosylation system. Curr. Top. Microbiol. Immunol. 2015, 384, 3-32. [PubMed]

173. Nakano, T.; Takahashi-Nakaguchi, A.; Yamamoto, M.; Watanabe, M. Pierisins and CARP-1: ADP-ribosylation of DNA by ARTCs in butterflies and shellfish. Curr. Top. Microbiol. Immunol. 2015, 384, 127-149.

174. Munnur, D.; Bartlett, E.; Mikolčević, P.; Kirby, I.T.; Rack, J.G.M.; Mikoč, A.; Cohen, M.S.; Ahel, I. Reversible ADP-ribosylation of RNA. Nucleic Acids Res. 2019, 47, 5658-5669. [CrossRef] [PubMed]

175. Collier, R.J. Understanding the mode of action of diphtheria toxin: A perspective on progress during the 20th century. Toxicon 2001, 39, 1793-1803. [CrossRef]

176. Hottiger, M.O.; Hassa, P.O.; Lüscher, B.; Schüler, H.; Koch-Nolte, F. Toward a unified nomenclature for mammalian ADPribosyltransferases. Trends Biochem. Sci. 2010, 35, 208-219. [CrossRef] [PubMed]

177. Adams-Phillips, L.; Briggs, A.G.; Bent, A.F. Disruption of poly(ADP-ribosyl)ation mechanisms alters responses of Arabidopsis to biotic stress. Plant Physiol. 2010, 152, 267-280. [CrossRef]

178. Feng, B.; Liu, C.; de Oliveira, M.V.V.; Intorne, A.C.; Li, B.; Babilonia, K.; de Souza Filho, G.A.; Shan, L.; He, P. Protein poly(ADPribosyl)ation regulates Arabidopsis immune gene expression and defense responses. PLoS Genet. 2015, 11, e1004936. [CrossRef] [PubMed]

179. Song, J.; Keppler, B.D.; Wise, R.R.; Bent, A.F. PARP2 is the predominant poly(ADP-ribose) polymerase in Arabidopsis DNA damage and immune responses. PLoS Genet. 2015, 11, e1005200. [CrossRef] [PubMed]

180. Singer, A.U.; Desveaux, D.; Betts, L.; Chang, J.H.; Nimchuk, Z.; Grant, S.R.; Dangl, J.L.; Sondek, J. Crystal structures of the type III effector protein AvrPphF and its chaperone reveal residues required for plant pathogenesis. Structure 2004, 12, $1669-1681$. [CrossRef] [PubMed]

181. Seto, D.; Koulena, N.; Lo, T.; Menna, A.; Guttman, D.S.; Desveaux, D. Expanded type III effector recognition by the ZAR1 NLR protein using ZED1-related kinases. Nat. Plants 2017, 3, 25-28. [CrossRef] [PubMed]

182. Jeong, B.R.; Lin, Y.; Joe, A.; Guo, M.; Korneli, C.; Yang, H.; Wang, P.; Yu, M.; Cerny, R.L.; Staiger, D.; et al. Structure function analysis of an ADP-ribosyltransferase type III effector and its RNA-binding target in plant immunity. J. Biol. Chem. 2011, 286, 43272-43281. [CrossRef] [PubMed]

183. Debener, T.; Lehnackers, H.; Arnold, M.; Dangl, J.L. Identification and molecular mapping of a single Arabidopsis thaliana locus determining resistance to a phytopathogenic Pseudomonas syringae isolate. Plant J. 1991, 1, 289-302. [CrossRef]

184. Cherkis, K.A.; Temple, B.R.S.; Chung, E.-H.; Sondek, J.; Dangl, J.L. AvrRpm1 missense mutations weakly activate RPS2-mediated immune response in Arabidopsis thaliana. PLoS ONE 2012, 7, e42633. [CrossRef]

185. Liu, J.H.; Yang, J.Y.; Hsu, D.W.; Lai, Y.H.; Li, Y.P.; Tsai, Y.R.; Hou, M.H. Crystal structure-based exploration of arginine-containing peptide binding in the ADP-ribosyltransferase domain of the type III effector XopAI protein. Int. J. Mol. Sci. 2019, 20, 5085. [CrossRef] 
186. Nordlund, S.; Högbom, M. ADP-ribosylation, a mechanism regulating nitrogenase activity. FEBS J. 2013, 280, 3484-3490. [CrossRef]

187. Waldor, M.K.; Mekalanos, J.J. Lysogenic conversion by a filamentous phage encoding cholera toxin. Science 1996, $272,1910-1913$. [CrossRef]

188. Faruque, S.M.; Mekalanos, J.J. Phage-bacterial interactions in the evolution of toxigenic Vibrio cholerae. Virulence 2012, 3, 556-565. [CrossRef]

189. Da Silva, A.C.R.; Ferro, J.A.; Reinach, F.C.; Farah, C.S.; Furlan, L.R.; Quaggio, R.B.; Monteiro-Vitorello, C.B.; Van Sluys, M.A.; Almeida, N.F.; Alves, L.M.C.; et al. Comparison of the genomes of two Xanthomonas pathogens with differing host specificities. Nature 2002, 417, 459-463. [CrossRef] [PubMed]

190. Buell, C.R.; Joardar, V.; Lindeberg, M.; Selengut, J.; Paulsen, I.T.; Gwinn, M.L.; Dodson, R.J.; Deboy, R.T.; Durkin, A.S.; Kolonay, J.F.; et al. The complete genome sequence of the Arabidopsis and tomato pathogen Pseudomonas syringae pv. tomato DC3000. Proc. Natl. Acad. Sci. USA 2003, 100, 10181-10186. [CrossRef]

191. Koskella, B.; Taylor, T.B. Multifaceted impacts of bacteriophages in the plant microbiome. Annu. Rev. Phytopathol. 2018, 56, 361-380. [CrossRef]

192. Orth, K.; Xu, Z.; Mudgett, M.B.; Bao, Z.Q.; Palmer, L.E.; Bliska, J.B.; Mangel, W.F.; Staskawicz, B.; Dixon, J.E. Disruption of signaling by Yersinia effector YopJ, a ubiquitin-like protein protease. Science 2000, 290, 1594-1597. [CrossRef]

193. Lewis, J.D.; Abada, W.; Ma, W.; Guttman, D.S.; Desveaux, D. The HopZ family of Pseudomonas syringae type III effectors require myristoylation for virulence and avirulence functions in Arabidopsis thaliana. J. Bacteriol. 2008, 190, 2880-2891. [CrossRef]

194. Lewis, J.D.; Wu, R.; Guttman, D.S.; Desveaux, D. Allele-specific virulence attenuation of the Pseudomonas syringae HopZ1a type III effector via the Arabidopsis ZAR1 resistance protein. PLoS Genet. 2010, 6, e1000894. [CrossRef] [PubMed]

195. McCann, H.C.; Rikkerink, E.H.A.; Bertels, F.; Fiers, M.; Lu, A.; Rees-George, J.; Andersen, M.T.; Gleave, A.P.; Haubold, B.; Wohlers, M.W.; et al. Genomic analysis of the Kiwifruit pathogen Pseudomonas syringae pv. actinidiae provides insight into the origins of an emergent plant disease. PLoS Pathog. 2013, 9, e1003503. [CrossRef]

196. Qian, W.; Jia, Y.; Ren, S.-X.; He, Y.-Q.; Feng, J.-X.; Lu, L.-F.; Sun, Q.; Ying, G.; Tang, D.-J.; Tang, H.; et al. Comparative and functional genomic analyses of the pathogenicity of phytopathogen Xanthomonas campestris pv. campestris. Genome Res. 2005, 15, 757-767. [CrossRef] [PubMed]

197. Mittal, R.; Peak-Chew, S.Y.; Sade, R.S.; Vallis, Y.; McMahon, H.T. The acetyltransferase activity of the bacterial toxin YopJ of Yersinia is activated by eukaryotic host cell inositol hexakisphosphate. J. Biol. Chem. 2010, 285, 19927-19934. [CrossRef]

198. Ma, K.-W.; Jiang, S.; Hawara, E.; Lee, D.; Pan, S.; Coaker, G.; Song, J.; Ma, W. Two serine residues in Pseudomonas syringae effector HopZ1a are required for acetyltransferase activity and association with the host co-factor. New Phytol. 2015, 208, 1157-1168. [CrossRef] [PubMed]

199. Lewis, J.D.; Wilton, M.; Mott, G.A.; Lu, W.; Hassan, J.A.; Guttman, D.S.; Desveaux, D. Immunomodulation by the Pseudomonas syringae HopZ type III effector family in Arabidopsis. PLoS ONE 2014, 9, e116152. [CrossRef] [PubMed]

200. Collins, N.C.; Thordal-Christensen, H.; Lipka, V.; Bau, S.; Kombrink, E.; Qiu, J.-L.; Hückelhoven, R.; Stein, M.; Freialdenhoven, A.; Somerville, S.C.; et al. SNARE-protein-mediated disease resistance at the plant cell wall. Nature 2003, 425, 973-977. [CrossRef]

201. Assaad, F.F.; Qiu, J.-L.; Youngs, H.; Ehrhardt, D.; Zimmerli, L.; Kalde, M.; Wanner, G.; Peck, S.C.; Edwards, H.; Ramonell, K.; et al. The PEN1 syntaxin defines a novel cellular compartment upon fungal attack and is required for the timely assembly of papillae. Mol. Biol. Cell 2004, 15, 5118-5129. [CrossRef] [PubMed]

202. Yan, Y.; Stolz, S.; Chételat, A.; Reymond, P.; Pagni, M.; Dubugnon, L.; Farmer, E.E. A downstream mediator in the growth repression limb of the jasmonate pathway. Plant Cell 2007, 19, 2470-2483. [CrossRef]

203. Rushton, P.J.; Somssich, I.E.; Ringler, P.; Shen, Q.J. WRKY transcription factors. Trends Plant Sci. 2010, 15, 247-258. [CrossRef]

204. Zhou, H.; Lin, J.; Johnson, A.; Morgan, R.L.; Zhong, W.; Ma, W. Pseudomonas syringae type III effector HopZ1 targets a host enzyme to suppress isoflavone biosynthesis and promote infection in soybean. Cell Host Microbe 2011, 9, 177-186. [CrossRef] [PubMed]

205. Bastedo, D.P.; Khan, M.; Martel, A.; Seto, D.; Kireeva, I.; Zhang, J.; Masud, W.; Millar, D.; Lee, J.Y.; Lee, A.H.-Y.; et al. Perturbations of the ZED1 pseudokinase activate plant immunity. PLoS Pathog. 2019, 15, e1007900. [CrossRef] [PubMed]

206. Baudin, M.; Hassan, J.A.; Schreiber, K.J.; Lewis, J.D. Analysis of the ZAR1 immune complex reveals determinants for immunity and molecular interactions. Plant Physiol. 2017, 174, 2038-2053. [CrossRef] [PubMed]

207. Baudin, M.; Schreiber, K.J.; Martin, E.C.; Petrescu, A.J.; Lewis, J.D. Structure-function analysis of ZAR1 immune receptor reveals key molecular interactions for activity. Plant J. 2020, 101, 352-370. [CrossRef]

208. Wang, J.; Hu, M.; Wang, J.; Qi, J.; Han, Z.; Wang, G.; Qi, Y.; Wang, H.-W.; Zhou, J.-M.; Chai, J. Reconstitution and structure of a plant NLR resistosome conferring immunity. Science 2019, 364, eaav5870. [CrossRef]

209. Wang, J.; Wang, J.; Hu, M.; Wu, S.; Qi, J.; Wang, G.; Han, Z.; Qi, Y.; Gao, N.; Wang, H.-W.; et al. Ligand-triggered allosteric ADP release primes a plant NLR complex. Science 2019, 364, eaav5868. [CrossRef]

210. Hu, M.; Qi, J.; Bi, G.; Zhou, J.-M. Bacterial effectors induce oligomerization of immune receptor ZAR1 in vivo. Mol. Plant 2020, 13, 793-801. [CrossRef]

211. Jayaraman, J.; Choi, S.; Prokchorchik, M.; Choi, D.S.; Spiandore, A.; Rikkerink, E.H.; Templeton, M.D.; Segonzac, C.; Sohn, K.H. A bacterial acetyltransferase triggers immunity in Arabidopsis thaliana independent of hypersensitive response. Sci. Rep. 2017, 7, 3557. [CrossRef] 
212. Schultink, A.; Qi, T.; Bally, J.; Staskawicz, B. Using forward genetics in Nicotiana benthamiana to uncover the immune signaling pathway mediating recognition of the Xanthomonas perforans effector XopJ4. New Phytol. 2019, 221, 1001-1009. [CrossRef] [PubMed]

213. Deslandes, L.; Olivier, J.; Theulieres, F.; Hirsch, J.; Feng, D.X.; Bittner-Eddy, P.; Beynon, J.; Marco, Y. Resistance to Ralstonia solanacearum in Arabidopsis thaliana is conferred by the recessive RRS1-R gene, a member of a novel family of resistance genes. Proc. Natl. Acad. Sci. USA 2002, 99, 2404-2409. [CrossRef]

214. Deslandes, L.; Olivier, J.; Peeters, N.; Feng, D.X.; Khounlotham, M.; Boucher, C.; Somssich, I.; Genin, S.; Marco, Y. Physical interaction between RRS1-R, a protein conferring resistance to bacterial wilt, and PopP2, a type III effector targeted to the plant nucleus. Proc. Natl. Acad. Sci. USA 2003, 100, 8024-8029. [CrossRef]

215. Williams, S.J.; Sohn, K.H.; Wan, L.; Bernoux, M.; Sarris, P.F.; Segonzac, C.; Ve, T.; Ma, Y.; Saucet, S.B.; Ericsson, D.J.; et al. Structural basis for assembly and function of a heterodimeric plant immune receptor. Science 2014, 344, 299-303. [CrossRef] [PubMed]

216. Narusaka, M.; Shirasu, K.; Noutoshi, Y.; Kubo, Y.; Shiraishi, T.; Iwabuchi, M.; Narusaka, Y. RRS1 and RPS4 provide a dual Resistance-gene system against fungal and bacterial pathogens. Plant J. 2009, 60, 218-226. [CrossRef]

217. Lee, J.; Teitzel, G.M.; Munkvold, K.; del Pozo, O.; Martin, G.B.; Michelmore, R.W.; Greenberg, J.T. Type III secretion and effectors shape the survival and growth pattern of Pseudomonas syringae on leaf surfaces. Plant Physiol. 2012, 158, 1803-1818. [CrossRef]

218. Vinatzer, B.A.; Teitzel, G.M.; Lee, M.-W.; Jelenska, J.; Hotton, S.; Fairfax, K.; Jenrette, J.; Greenberg, J.T. The type III effector repertoire of Pseudomonas syringae pv. syringae B728a and its role in survival and disease on host and non-host plants. Mol. Microbiol. 2006, 62, 26-44. [CrossRef] [PubMed]

219. Kersten, B.; Agrawal, G.K.; Durek, P.; Neigenfind, J.; Schulze, W.; Walther, D.; Rakwal, R. Plant phosphoproteomics: An update. Proteomics 2009, 9, 964-988. [CrossRef]

220. Ajadi, A.A.; Cisse, A.; Ahmad, S.; Yifeng, W.; Yazhou, S.; Shufan, L.; Xixi, L.; Bello, B.K.; Tajo, S.M.; Xiaohong, T.; et al. Protein phosphorylation and phosphoproteome: An overview of rice. Rice Sci. 2020, 27, 184-200. [CrossRef]

221. He, Y.; Zhou, J.; Shan, L.; Meng, X. Plant cell surface receptor-mediated signaling-A common theme amid diversity. J. Cell Sci. 2018, 131, jcs209353. [CrossRef] [PubMed]

222. Fauman, E.B.; Saper, M.A. Structure and function of the protein tyrosine phosphatases. Trends Biochem. Sci. 1996, $21,413-417$. [CrossRef]

223. Bretz, J.R.; Mock, N.M.; Charity, J.C.; Zeyad, S.; Baker, C.J.; Hutcheson, S.W. A translocated protein tyrosine phosphatase of Pseudomonas syringae pv. tomato DC3000 modulates plant defence response to infection. Mol. Microbiol. 2003, 49, 389-400. [CrossRef]

224. Espinosa, A.; Guo, M.; Tam, V.C.; Fu, Z.Q.; Alfano, J.R. The Pseudomonas syringae type III-secreted protein HopPtoD2 possesses protein tyrosine phosphatase activity and suppresses programmed cell death in plants. Mol. Microbiol. 2003, 49, 377-387. [CrossRef]

225. Underwood, W.; Zhang, S.; He, S.Y. The Pseudomonas syringae type III effector tyrosine phosphatase HopAO1 suppresses innate immunity in Arabidopsis thaliana. Plant J. 2007, 52, 658-672. [CrossRef] [PubMed]

226. Kutschera, A.; Dawid, C.; Gisch, N.; Schmid, C.; Raasch, L.; Gerster, T.; Schäffer, M.; Smakowska-Luzan, E.; Belkhadir, Y.; Vlot, A.C.; et al. Bacterial medium-chain 3-hydroxy fatty acid metabolites trigger immunity in Arabidopsis plants. Science 2019, 364, 178-181. [PubMed]

227. Li, X.; Lin, H.; Zhang, W.; Zou, Y.; Zhang, J.; Tang, X.; Zhou, J.M. Flagellin induces innate immunity in nonhost interactions that is suppressed by Pseudomonas syringae effectors. Proc. Natl. Acad. Sci. USA 2005, 102, 12990-12995. [CrossRef]

228. Bigeard, J.; Hirt, H. Nuclear signaling of plant MAPKs. Front. Plant Sci. 2018, 9, 1-18. [CrossRef]

229. Li, H.; Xu, H.; Zhou, Y.; Zhang, J.; Long, C.; Li, S.; Chen, S.; Zhou, J.-M.; Shao, F. The phosphothreonine lyase activity of a bacterial type III effector family. Science 2007, 315, 1000-1003. [CrossRef]

230. Zhang, Z.; Liu, Y.; Huang, H.; Gao, M.; Wu, D.; Kong, Q.; Zhang, Y. The NLR protein SUMM2 senses the disruption of an immune signaling MAP kinase cascade via CRCK3. EMBO Rep. 2017, 18, 292-302. [CrossRef]

231. Ling, T.; Bellin, D.; Vandelle, E.; Imanifard, Z.; Delledonne, M. Host-mediated S-nitrosylation disarms the bacterial effector HopAI1 to reestablish immunity. Plant Cell 2017, 29, 2871-2881. [CrossRef] [PubMed]

232. Triplett, L.R.; Shidore, T.; Long, J.; Miao, J.; Wu, S.; Han, Q.; Zhou, C.; Ishihara, H.; Li, J.; Zhao, B.; et al. AvrRxo1 is a bifunctional type III secreted effector and toxin-antitoxin system component with homologs in diverse environmental contexts. PLoS ONE 2016, 11, 1-16. [CrossRef] [PubMed]

233. Han, Q.; Zhou, C.; Wu, S.; Liu, Y.; Triplett, L.; Miao, J.; Tokuhisa, J.; Deblais, L.; Robinson, H.; Leach, J.E.; et al. Crystal structure of Xanthomonas AvrRxo1-ORF1, a type III effector with a polynucleotide kinase domain, and its interactor AvrRxo1-ORF2. Structure 2015, 23, 1900-1909. [CrossRef]

234. Li, W.; Chiang, Y.-H.; Coaker, G. The HopQ1 effector's nucleoside hydrolase-like domain is required for bacterial virulence in Arabidopsis and tomato, but not host recognition in tobacco. PLoS ONE 2013, 8, e59684. [CrossRef] [PubMed]

235. Yu, S.; Hwang, I.; Rhee, S. The crystal structure of type III effector protein XopQ from Xanthomonas oryzae complexed with adenosine diphosphate ribose. Proteins Struct. Funct. Bioinform. 2014, 82, 2910-2914. [CrossRef] [PubMed]

236. Martin, R.; Qi, T.; Zhang, H.; Liu, F.; King, M.; Toth, C.; Nogales, E.; Staskawicz, B.J. Structure of the activated ROQ1 resistosome directly recognizing the pathogen effector XopQ. Science 2020, 370, eabd9993. [CrossRef] 
237. Lu, D.; Wu, S.; Gao, X.; Zhang, Y.; Shan, L.; He, P. A receptor-like cytoplasmic kinase, BIK1, associates with a flagellin receptor complex to initiate plant innate immunity. Proc. Natl. Acad. Sci. USA 2010, 107, 496-501. [CrossRef] [PubMed]

238. Xiao, J.; Worby, C.A.; Mattoo, S.; Sankaran, B.; Dixon, J.E. Structural basis of Fic-mediated adenylylation. Nat. Struct. Mol. Biol. 2010, 17, 1004-1010. [CrossRef]

239. Xu, R.-Q.; Blanvillain, S.; Feng, J.-X.; Jiang, B.-L.; Li, X.-Z.; Wei, H.-Y.; Kroj, T.; Lauber, E.; Roby, D.; Chen, B.; et al. AvrAC(Xcc8004), a type III effector with a leucine-rich repeat domain from Xanthomonas campestris pathovar campestris confers avirulence in vascular tissues of Arabidopsis thaliana ecotype Col-0. J. Bacteriol. 2008, 190, 343-355. [CrossRef]

240. Ronald, P.C.; Staskawicz, B.J. The avirulence gene avrBs1 from Xanthomonas campestris pv. vesicatoria encodes a 50-kD protein. Mol. Plant-Microbe Interact. 1988, 1, 191-198. [CrossRef]

241. Potnis, N.; Minsavage, G.; Smith, J.K.; Hurlbert, J.C.; Norman, D.; Rodrigues, R.; Stall, R.E.; Jones, J.B. Avirulence proteins AvrBs7 from Xanthomonas gardneri and AvrBs1.1 from Xanthomonas euvesicatoria contribute to a novel gene-for-gene interaction in pepper. Mol. Plant-Microbe Interact. 2012, 25, 307-320. [CrossRef] [PubMed]

242. Popov, G.; Fraiture, M.; Brunner, F.; Sessa, G. Multiple Xanthomonas euvesicatoria type III effectors inhibit flg22-triggered immunity. Mol. Plant-Microbe Interact. 2016, 29, 651-660. [CrossRef]

243. Murphy, A.M.; Otto, B.; Brearley, C.A.; Carr, J.P.; Hanke, D.E. A role for inositol hexakisphosphate in the maintenance of basal resistance to plant pathogens. Plant J. 2008, 56, 638-652. [CrossRef]

244. Sarwat, M.; Ahmad, A.; Abdin, M.Z.; Ibrahim, M.M. Trehalose: Metabolism and role in stress signaling in plants. In Stress Signaling in Plants: Genomics and Proteomics Perspective; Sarwat, M., Ahmad, A., Abdin, M.Z., Ibrahim, M.M., Eds.; Springer International Publishing: Berlin/Heidelberg, Germany, 2017; Volume 2, pp. 1-350.

245. Lunn, J.E.; Delorge, I.; Figueroa, C.M.; Van Dijck, P.; Stitt, M. Trehalose metabolism in plants. Plant J. 2014, 79, 544-567. [CrossRef] [PubMed]

246. Wilson, R.A.; Jenkinson, J.M.; Gibson, R.P.; Littlechild, J.A.; Wang, Z.-Y.; Talbot, N.J. Tps1 regulates the pentose phosphate pathway, nitrogen metabolism and fungal virulence. EMBO J. 2007, 26, 3673-3685. [CrossRef] [PubMed]

247. Djonović, S.; Urbach, J.M.; Drenkard, E.; Bush, J.; Feinbaum, R.; Ausubel, J.L.; Traficante, D.; Risech, M.; Kocks, C.; Fischbach, M.A.; et al. Trehalose biosynthesis promotes Pseudomonas aeruginosa pathogenicity in plants. PLoS Pathog. 2013, 9, e1003217. [CrossRef] [PubMed]

248. Aghdasi, M.; Smeekens, S.; Schluepman, H. Microarray analysis of gene expression patterns in Arabidopsis seedlings under trehalose, sucrose and sorbitol treatment. Int. J. Plant Prod. 2008, 2, 309-320.

249. Ge, X.; Li, G.-J.; Wang, S.-B.; Zhu, H.; Zhu, T.; Wang, X.; Xia, Y. AtNUDT7, a negative regulator of basal immunity in Arabidopsis, modulates two distinct defense response pathways and is involved in maintaining redox homeostasis. Plant Physiol. 2007, 145, 204-215. [CrossRef] [PubMed]

250. Kumar, A.; Tikoo, S.; Maity, S.; Sengupta, S.; Sengupta, S.; Kaur, A.; Bachhawat, A.K. Mammalian proapoptotic factor ChaC1 and its homologues function as $\gamma$-glutamyl cyclotransferases acting specifically on glutathione. EMBO Rep. 2012, 13, 1095-1101. [CrossRef]

251. Ghanta, S.; Chattopadhyay, S. Glutathione as a signaling molecule: Another challenge to pathogens. Plant Signal. Behav. 2011, 6, 783-788. [CrossRef]

252. Noctor, G.; Mhamdi, A.; Chaouch, S.; Han, Y.; Neukermans, J.; Marquez-Garcia, B.; Queval, G.; Foyer, C.H. Glutathione in plants: An integrated overview. Plant. Cell Environ. 2012, 35, 454-484. [CrossRef] [PubMed]

253. Macho, A.P.; Guidot, A.; Barberis, P.; Beuzón, C.R.; Genin, S. A competitive index assay identifies several Ralstonia solanacearum type III effector mutant strains with reduced fitness in host plants. Mol. Plant-Microbe Interact. 2010, 23, 1197-1205. [CrossRef] [PubMed]

254. Sang, Y.; Wang, Y.; Ni, H.; Cazalé, A.C.; She, Y.M.; Peeters, N.; Macho, A.P. The Ralstonia solanacearum type III effector RipAY targets plant redox regulators to suppress immune responses. Mol. Plant Pathol. 2018, 19, 129-142. [CrossRef]

255. Mukaihara, T.; Hatanaka, T.; Nakano, M.; Oda, K. Ralstonia solanacearum type III effector RipAY is a glutathione-degrading enzyme that is activated by plant cytosolic thioredoxins and suppresses plant immunity. mBio 2016, 7, 1-14. [CrossRef]

256. Wei, Y.; Sang, Y.; Macho, A.P. The Ralstonia solanacearum type III effector RipAY is phosphorylated in plant cells to modulate its enzymatic activity. Front. Plant Sci. 2017, 8, 1-7. [CrossRef]

257. Fujiwara, S.; Ikejiri, A.; Tanaka, N.; Tabuchi, M. Characterization of the mechanism of thioredoxin-dependent activation of $\gamma$-glutamylcyclotransferase, RipAY, from Ralstonia solanacearum. Biochem. Biophys. Res. Commun. 2020, 523, 759-765. [CrossRef] [PubMed]

258. He, P.; Shan, L.; Lin, N.-C.; Martin, G.B.; Kemmerling, B.; Nürnberger, T.; Sheen, J. Specific bacterial suppressors of MAMP signaling upstream of MAPKKK in Arabidopsis innate immunity. Cell 2006, 125, 563-575. [CrossRef]

259. Martin, G.; Brommonschenkel, S.; Chunwongse, J.; Frary, A.; Ganal, M.; Spivey, R.; Wu, T.; Earle, E.; Tanksley, S. Map-based cloning of a protein kinase gene conferring disease resistance in tomato. Science 1993, 262, 1432-1436. [CrossRef]

260. Salmeron, J.M.; Oldroyd, G.E.; Rommens, C.M.; Scofield, S.R.; Kim, H.S.; Lavelle, D.T.; Dahlbeck, D.; Staskawicz, B.J. Tomato Prf is a member of the leucine-rich repeat class of plant disease resistance genes and lies embedded within the Pto kinase gene cluster. Cell 1996, 86, 123-133. [CrossRef]

261. Tang, X.; Frederick, R.D.; Zhou, J.; Halterman, D.A.; Jia, Y.; Martin, G.B. Initiation of plant disease resistance by physical interaction of AvrPto and Pto kinase. Science 1996, 274, 2060-2063. [CrossRef] 
262. Mucyn, T.S.; Wu, A.-J.; Balmuth, A.L.; Arasteh, J.M.; Rathjen, J.P. Regulation of tomato Prf by Pto-like protein kinases. Mol. Plant-Microbe Interact. 2009, 22, 391-401. [CrossRef] [PubMed]

263. Xing, W.; Zou, Y.; Liu, Q.; Liu, J.; Luo, X.; Huang, Q.; Chen, S.; Zhu, L.; Bi, R.; Hao, Q.; et al. The structural basis for activation of plant immunity by bacterial effector protein AvrPto. Nature 2007, 449, 243-247. [CrossRef]

264. Ntoukakis, V.; Balmuth, A.L.; Mucyn, T.S.; Gutierrez, J.R.; Jones, A.M.E.; Rathjen, J.P. The tomato Prf complex is a molecular trap for bacterial effectors based on Pto transphosphorylation. PLoS Pathog. 2013, 9, e1003123. [CrossRef] [PubMed]

265. Lozano-Durán, R.; Robatzek, S. 14-3-3 Proteins in plant-pathogen interactions. Mol. Plant-Microbe Interact. 2015, 28, 511-518. [CrossRef] [PubMed]

266. Roden, J.A.; Belt, B.; Ross, J.B.; Tachibana, T.; Vargas, J.; Mudgett, M.B. A genetic screen to isolate type III effectors translocated into pepper cells during Xanthomonas infection. Proc. Natl. Acad. Sci. USA 2004, 101, 16624-16629. [CrossRef] [PubMed]

267. Kim, J.G.; Li, X.; Roden, J.A.; Taylor, K.W.; Aakre, C.D.; Su, B.; Lalonde, S.; Kirik, A.; Chen, Y.; Baranage, G.; et al. Xanthomonas T3S effector XopN suppresses PAMP-triggered immunity and interacts with a tomato atypical receptor-like kinase and TFT1. Plant Cell 2009, 21, 1305-1323. [CrossRef]

268. Sinha, D.; Gupta, M.K.; Patel, H.K.; Ranjan, A.; Sonti, R.V. Cell wall degrading enzyme induced rice innate immune responses are suppressed by the type 3 secretion system effectors XopN, XopQ, XopX and XopZ of Xanthomonas oryzae pv. oryzae. PLoS ONE 2013, 8, e75867. [CrossRef]

269. Giska, F.; Lichocka, M.; Piechocki, M.; Dadlez, M.; Schmelzer, E.; Hennig, J.; Krzymowska, M. Phosphorylation of HopQ1, a type III effector from Pseudomonas syringae, creates a binding site for host 14-3-3 proteins. Plant Physiol. 2013, 161, $2049-2061$. [CrossRef]

270. Teper, D.; Salomon, D.; Sunitha, S.; Kim, J.G.; Mudgett, M.B.; Sessa, G. Xanthomonas euvesicatoria type III effector XopQ interacts with tomato and pepper 14-3-3 isoforms to suppress effector-triggered immunity. Plant J. 2014, 77, 297-309. [CrossRef] [PubMed]

271. Dubrow, Z.; Sunitha, S.; Kim, J.G.; Aakre, C.D.; Girija, A.M.; Sobol, G.; Teper, D.; Chen, Y.C.; Ozbaki-Yagan, N.; Vance, H.; et al. Tomato 14-3-3 proteins are required for Xv3 disease resistance and interact with a subset of Xanthomonas euvesicatoria effectors. Mol. Plant-Microbe Interact. 2018, 31, 1301-1311. [CrossRef] [PubMed]

272. Mukhtar, M.S.; Carvunis, A.-R.; Dreze, M.; Epple, P.; Steinbrenner, J.; Moore, J.; Tasan, M.; Galli, M.; Hao, T.; Nishimura, M.T.; et al. Independently evolved virulence effectors converge onto hubs in a plant immune system network. Science 2011, 333, 596-601. [CrossRef]

273. Shirasu, K. The HSP90-SGT1 chaperone complex for NLR immune sensors. Annu. Rev. Plant Biol. 2009, 60, 139-164. [CrossRef] [PubMed]

274. Ranf, S.; Eschen-Lippold, L.; Fröhlich, K.; Westphal, L.; Scheel, D.; Lee, J. Microbe-associated molecular pattern-induced calcium signaling requires the receptor-like cytoplasmic kinases, PBL1 and BIK1. BMC Plant Biol. 2014, 14, 374. [CrossRef]

275. Kadota, Y.; Sklenar, J.; Derbyshire, P.; Stransfeld, L.; Asai, S.; Ntoukakis, V.; Jones, J.D.; Shirasu, K.; Menke, F.; Jones, A.; et al. Direct regulation of the NADPH oxidase RBOHD by the PRR-associated kinase BIK1 during plant immunity. Mol. Cell 2014, 54, 43-55. [CrossRef]

276. Selote, D.; Samira, R.; Matthiadis, A.; Gillikin, J.W.; Long, T.A. Iron-binding E3 ligase mediates iron response in plants by targeting basic helix-loop-helix transcription factors. Plant Physiol. 2015, 167, 273-286. [CrossRef]

277. Huh, S.U.; Cevik, V.; Ding, P.; Duxbury, Z.; Ma, Y.; Tomlinson, L.; Sarris, P.F.; Jones, J.D.G. Protein-protein interactions in the RPS4/RRS1 immune receptor complex. PLoS Pathog. 2017, 13, e1006376. [CrossRef]

278. Kim, S.H.; Son, G.H.; Bhattacharjee, S.; Kim, H.J.; Nam, J.C.; Nguyen, P.D.T.; Hong, J.C.; Gassmann, W. The Arabidopsis immune adaptor SRFR1 interacts with TCP transcription factors that redundantly contribute to effector-triggered immunity. Plant J. 2014, 78, 978-989. [CrossRef]

279. Kunkel, B.N.; Brooks, D.M. Cross talk between signaling pathways in pathogen defense. Curr. Opin. Plant Biol. $2002,5,325-331$. [CrossRef]

280. Shang, Y.; Li, X.; Cui, H.; He, P.; Thilmony, R.; Chintamanani, S.; Zwiesler-Vollick, J.; Gopalan, S.; Tang, X.; Zhou, J.-M. RAR1, a central player in plant immunity, is targeted by Pseudomonas syringae effector AvrB. Proc. Natl. Acad. Sci. USA 2006, 103, 19200-19205. [CrossRef]

281. Liu, J.; Elmore, J.M.; Fuglsang, A.T.; Palmgren, M.G.; Staskawicz, B.J.; Coaker, G. RIN4 functions with plasma membrane $\mathrm{H}^{+}$-ATPases to regulate stomatal apertures during pathogen attack. PLoS Biol. 2009, 7, e1000139. [CrossRef] [PubMed]

282. Lee, D.; Bourdais, G.; Yu, G.; Robatzek, S.; Coaker, G. Phosphorylation of the plant immune regulator RPM1-INTERACTING PROTEIN4 enhances plant plasma membrane $\mathrm{H}^{+}$-ATPase activity and inhibits flagellin-triggered immune responses in Arabidopsis. Plant Cell 2015, 27, 2042-2056. [CrossRef]

283. Zhou, Z.; Wu, Y.; Yang, Y.; Du, M.; Zhang, X.; Guo, Y.; Li, C.; Zhou, J.-M. An Arabidopsis plasma membrane proton ATPase modulates JA signaling and is exploited by the Pseudomonas syringae effector protein AvrB for stomatal invasion. Plant Cell 2015, 27, 2032-2041. [CrossRef]

284. Xu, N.; Luo, X.; Li, W.; Wang, Z.; Liu, J. The bacterial effector AvrB-induced RIN4 hyperphosphorylation is mediated by a receptor-like cytoplasmic kinase complex in Arabidopsis. Mol. Plant-Microbe Interact. 2017, 30, 502-512. [CrossRef]

285. Degrave, A.; Siamer, S.; Boureau, T.; Barny, M.A. The AvrE superfamily: Ancestral type III effectors involved in suppression of pathogen-associated molecular pattern-triggered immunity. Mol. Plant Pathol. 2015, 16, 899-905. [CrossRef] 
286. Bogdanove, A.J.; Kim, J.F.; Wei, Z.; Kolchinsky, P.; Charkowski, A.O.; Conlin, A.K.; Collmer, A.; Beer, S.V. Homology and functional similarity of an hrp-linked pathogenicity locus, dspEF, of Erwinia amylovora and the avirulence locus avrE of Pseudomonas syringae pathovar tomato. Proc. Natl. Acad. Sci. USA 1998, 95, 1325-1330. [CrossRef]

287. Frederick, R.D.; Ahmad, M.; Majerczak, D.R.; Arroyo-Rodriguez, A.S.; Manulis, S.; Coplin, D.L. Genetic organization of the Pantoea stewartii subsp. stewartii hrp gene cluster and sequence analysis of the hrpA, hrpC, hrpN, and wtsE operons. Mol. Plant-Microbe Interact. 2001, 14, 1213-1222. [CrossRef] [PubMed]

288. DebRoy, S.; Thilmony, R.; Kwack, Y.B.; Nomura, K.; He, S.Y. A family of conserved bacterial effectors inhibits salicylic acidmediated basal immunity and promotes disease necrosis in plants. Proc. Natl. Acad. Sci. USA 2004, 101, 9927-9932. [CrossRef]

289. Ham, J.H.; Majerczak, D.R.; Arroyo-Rodriguez, A.S.; Mackey, D.M.; Coplin, D.L. WtsE, an AvrE-family effector protein from Pantoea stewartii subsp. stewartii, causes disease-associated cell death in corn and requires a chaperone protein for stability. Mol. Plant-Microbe Interact. 2006, 19, 1092-1102. [CrossRef] [PubMed]

290. Kim, H.S.; Thammarat, P.; Lommel, S.A.; Hogan, C.S.; Charkowski, A.O. Pectobacterium carotovorum elicits plant cell death with DspE/F but the P. carotovorum DspE does not suppress callose or induce expression of plant genes early in plant-microbe interactions. Mol. Plant-Microbe Interact. 2011, 24, 773-786. [CrossRef]

291. Degrave, A.; Moreau, M.; Launay, A.; Barny, M.A.; Brisset, M.N.; Patrit, O.; Taconnat, L.; Vedel, R.; Fagard, M. The bacterial effector DspA/E is toxic in Arabidopsis thaliana and is required for multiplication and survival of fire blight pathogen. Mol. Plant Pathol. 2013, 14, 506-517. [CrossRef] [PubMed]

292. Jacobs, J.M.; Milling, A.; Mitra, R.M.; Hogan, C.S.; Ailloud, F.; Prior, P.; Allen, C. Ralstonia solanacearum requires PopS, an ancient AvrE-family effector, for virulence and to overcome salicylic acid-mediated defenses during tomato pathogenesis. MBio 2013, 4, e00875-13. [CrossRef]

293. Ham, J.H.; Majerczak, D.R.; Nomura, K.; Mecey, C.; Uribe, F.; He, S.-Y.; Mackey, D.; Coplin, D.L. Multiple activities of the plant pathogen type III effector proteins WtsE and AvrE require WxxxE motifs. Mol. Plant-Microbe Interact. 2009, 22, 703-712. [CrossRef]

294. Xin, X.F.; Nomura, K.; Ding, X.; Chen, X.; Wang, K.; Aung, K.; Uribe, F.; Rosa, B.; Yao, J.; Chen, J.; et al. Pseudomonas syringae effector avirulence protein $\mathrm{E}$ localizes to the host plasma membrane and down-regulates the expression of the NONRACE-SPECIFIC DISEASE RESISTANCE1/HARPIN-INDUCED1-LIKE13 gene required for antibacterial immunity in Arabidopsis. Plant Physiol. 2015, 169, 793-802. [CrossRef]

295. Orchard, R.C.; Alto, N.M. Mimicking GEFs: A common theme for bacterial pathogens. Cell. Microbiol. 2012, 14, 10-18. [CrossRef]

296. Zheng, H.; Rowland, O.; Kunst, L. Disruptions of the Arabidopsis enoyl-CoA reductase gene reveal an essential role for very-long-chain fatty acid synthesis in cell expansion during plant morphogenesis. Plant Cell 2005, 17, 1467-1481. [CrossRef]

297. Markham, J.E.; Molino, D.; Gissot, L.; Bellec, Y.; Hématy, K.; Marion, J.; Belcram, K.; Palauqui, J.C.; Satiat-Jeunemaître, B.; Faure, J.D. Sphingolipids containing very-long-chain fatty acids define a secretory pathway for specific polar plasma membrane protein targeting in Arabidopsis. Plant Cell 2011, 23, 2362-2378. [CrossRef]

298. Chen, M.; Han, G.; Dietrich, C.R.; Dunn, T.M.; Cahoon, E.B. The essential nature of sphingolipids in plants as revealed by the functional identification and characterization of the Arabidopsis LCB1 subunit of serine palmitoyltransferase. Plant Cell 2006, 18, 3576-3593. [CrossRef]

299. Dietrich, C.R.; Han, G.; Chen, M.; Berg, R.H.; Dunn, T.M.; Cahoon, E.B. Loss-of-function mutations and inducible RNAi suppression of Arabidopsis LCB2 genes reveal the critical role of sphingolipids in gametophytic and sporophytic cell viability. Plant J. 2008, 54, 284-298. [CrossRef]

300. Meng, X.; Bonasera, J.M.; Kim, J.F.; Nissinen, R.M.; Beer, S.V. Apple proteins that interact with DspA/E, a pathogenicity effector of Erwinia amylovora, the fire blight pathogen. Mol. Plant-Microbe Interact. 2006, 19, 53-61. [CrossRef]

301. Guttman, D.S.; Vinatzer, B.A.; Sarkar, S.F.; Ranall, M.V.; Kettler, G.; Greenberg, J.T. A functional screen for the type III (Hrp) secretome of the plant pathogen Pseudomonas syringae. Science 2002, 295, 1722-1726. [CrossRef]

302. Pulido, P.; Leister, D. Novel DNAJ-related proteins in Arabidopsis thaliana. New Phytol. 2018, 217, 480-490. [CrossRef] [PubMed]

303. Jelenska, J.; Yao, N.; Vinatzer, B.A.; Wright, C.M.; Brodsky, J.L.; Greenberg, J.T. A J domain virulence effector of Pseudomonas syringae remodels host chloroplasts and suppresses defenses. Curr. Biol. 2007, 17, 499-508. [CrossRef]

304. Chen, Z.; Agnew, J.L.; Cohen, J.D.; He, P.; Shan, L.; Sheen, J.; Kunkel, B.N. Pseudomonas syringae type III effector AvrRpt2 alters Arabidopsis thaliana auxin physiology. Proc. Natl. Acad. Sci. USA 2007, 104, 20131-20136. [CrossRef] [PubMed]

305. Camejo, D.; Guzmán-Cedeño, Á.; Moreno, A. Reactive oxygen species, essential molecules, during plant-pathogen interactions. Plant Physiol. Biochem. 2016, 103, 10-23. [CrossRef]

306. Qi, J.; Wang, J.; Gong, Z.; Zhou, J.M. Apoplastic ROS signaling in plant immunity. Curr. Opin. Plant Biol. 2017, 38, 92-100. [CrossRef] [PubMed]

307. de Lange, O.; Schreiber, T.; Schandry, N.; Radeck, J.; Braun, K.H.; Koszinowski, J.; Heuer, H.; Strauß, A.; Lahaye, T. Breaking the DNA-binding code of Ralstonia solanacearum TAL effectors provides new possibilities to generate plant resistance genes against bacterial wilt disease. New Phytol. 2013, 199, 773-786. [CrossRef] [PubMed]

308. Carter, M.E.; Carpenter, S.C.D.; Dubrow, Z.E.; Sabol, M.R.; Rinaldi, F.C.; Lastovetsky, O.A.; Mondo, S.J.; Pawlowska, T.E.; Bogdanove, A.J. A TAL effector-like protein of an endofungal bacterium increases the stress tolerance and alters the transcriptome of the host. Proc. Natl. Acad. Sci. USA 2020, 117, 17122-17129. [CrossRef] [PubMed]

309. Yang, Y.; Gabriel, D.W. Xanthomonas avirulence/pathogenicity gene family encodes functional plant nuclear targeting signals. Mol. Plant-Microbe Interact. 1995, 8, 627-631. [CrossRef] [PubMed] 
310. Van den Ackerveken, G.; Marois, E.; Bonas, U. Recognition of the bacterial avirulence protein AvrBs3 occurs inside the host plant cell. Cell 1996, 87, 1307-1316. [CrossRef]

311. Zhu, W.; Yang, B.; Chittoor, J.M.; Johnson, L.B.; White, F.F. AvrXa10 contains an acidic transcriptional activation domain in the functionally conserved C terminus. Mol. Plant-Microbe Interact. 1998, 11, 824-832. [CrossRef]

312. Rossier, O.; Wengelnik, K.; Hahn, K.; Bonas, U. The Xanthomonas Hrp type III system secretes proteins from plant and mammalian bacterial pathogens. Proc. Natl. Acad. Sci. USA 1999, 96, 9368-9373. [CrossRef]

313. Yang, B.; Zhu, W.; Johnson, L.B.; White, F.F. The virulence factor AvrXa7 of Xanthomonas oryzae pv. oryzae is a type III secretion pathway-dependent nuclear-localized double-stranded DNA-binding protein. Proc. Natl. Acad. Sci. USA 2000, 97, 9807-9812. [CrossRef]

314. Szurek, B.; Marois, E.; Bonas, U.; Van den Ackerveken, G. Eukaryotic features of the Xanthomonas type III effector AvrBs3: Protein domains involved in transcriptional activation and the interaction with nuclear import receptors from pepper. Plant J. 2001, 26, 523-534. [CrossRef]

315. Szurek, B.; Rossier, O.; Hause, G.; Bonas, U. Type III-dependent translocation of the Xanthomonas AvrBs3 protein into the plant cell. Mol. Microbiol. 2002, 46, 13-23. [CrossRef]

316. Boch, J.; Scholze, H.; Schornack, S.; Landgraf, A.; Hahn, S.; Kay, S.; Lahaye, T.; Nickstadt, A.; Bonas, U. Breaking the code of DNA binding specificity of TAL-type III effectors. Science 2009, 326, 1509-1512. [CrossRef] [PubMed]

317. Moscou, M.J.; Bogdanove, A.J. A simple cipher governs DNA recognition by TAL effectors. Science 2009, 326, 1501. [CrossRef] [PubMed]

318. Deng, D.; Yan, C.; Pan, X.; Mahfouz, M.; Wang, J.; Zhu, J.-K.; Shi, Y.; Yan, N. Structural basis for sequence-specific recognition of DNA by TAL effectors. Science 2012, 335, 720-723. [CrossRef]

319. Mak, A.N.-S.; Bradley, P.; Cernadas, R.A.; Bogdanove, A.J.; Stoddard, B.L. The crystal structure of TAL effector PthXo1 bound to its DNA target. Science 2012, 335, 716-719. [CrossRef] [PubMed]

320. Yuan, M.; Ke, Y.; Huang, R.; Ma, L.; Yang, Z.; Chu, Z.; Xiao, J.; Li, X.; Wang, S. A host basal transcription factor is a key component for infection of rice by TALE-carrying bacteria. Elife 2016, 5, 1-17. [CrossRef]

321. Hui, S.; Liu, H.; Zhang, M.; Chen, D.; Li, Q.; Tian, J.; Xiao, J.; Li, X.; Wang, S.; Yuan, M. The host basal transcription factor IIA subunits coordinate for facilitating infection of TALEs-carrying bacterial pathogens in rice. Plant Sci. 2019, 284, 48-56. [CrossRef] [PubMed]

322. Yang, B.; Sugio, A.; White, F.F. Os8N3 is a host disease-susceptibility gene for bacterial blight of rice. Proc. Natl. Acad. Sci. USA 2006, 103, 10503-10508. [CrossRef]

323. Sugio, A.; Yang, B.; Zhu, T.; White, F.F. Two type III effector genes of Xanthomonas oryzae pv. oryzae control the induction of the host genes OsTFIIA $\gamma 1$ and OsTFX1 during bacterial blight of rice. Proc. Natl. Acad. Sci. USA 2007, 104, 10720-10725. [CrossRef]

324. Streubel, J.; Pesce, C.; Hutin, M.; Koebnik, R.; Boch, J.; Szurek, B. Five phylogenetically close rice SWEET genes confer TAL effector-mediated susceptibility to Xanthomonas oryzae pv. oryzae. New Phytol. 2013, 200, 808-819. [CrossRef]

325. Cernadas, R.A.; Doyle, E.L.; Niño-Liu, D.O.; Wilkins, K.E.; Bancroft, T.; Wang, L.; Schmidt, C.L.; Caldo, R.; Yang, B.; White, F.F.; et al. Code-assisted discovery of TAL effector targets in bacterial leaf streak of rice reveals contrast with bacterial blight and a novel susceptibility gene. PLoS Pathog. 2014, 10, e1003972. [CrossRef] [PubMed]

326. Peng, Z.; Hu, Y.; Zhang, J.; Huguet-Tapia, J.C.; Block, A.K.; Park, S.; Sapkota, S.; Liu, Z.; Liu, S.; White, F.F. Xanthomonas translucens commandeers the host rate-limiting step in ABA biosynthesis for disease susceptibility. Proc. Natl. Acad. Sci. USA 2019, 116, 20938-20946. [CrossRef]

327. Grau, J.; Wolf, A.; Reschke, M.; Bonas, U.; Posch, S.; Boch, J. Computational predictions provide insights into the biology of TAL effector target sites. PLoS Comput. Biol. 2013, 9, e1002962. [CrossRef] [PubMed]

328. Hutin, M.; Pérez-Quintero, A.L.; Lopez, C.; Szurek, B. MorTAL Kombat: The story of defense against TAL effectors through loss-of-susceptibility. Front. Plant Sci. 2015, 6, 535. [CrossRef] [PubMed]

329. Yoshimura, S.; Yamanouchi, U.; Katayose, Y.; Toki, S.; Wang, Z.X.; Kono, I.; Kurata, N.; Yano, M.; Iwata, N.; Sasaki, T. Expression of Xa1, a bacterial blight-resistance gene in rice, is induced by bacterial inpculation. Proc. Natl. Acad. Sci. USA 1998, 95, 1663-1668 [CrossRef] [PubMed]

330. Iyer, A.S.; McCouch, S.R. The rice bacterial blight resistance gene xa5 encodes a novel form of disease resistance. Mol. Plant-Microbe Interact. 2004, 17, 1348-1354. [CrossRef] [PubMed]

331. Schornack, S.; Ballvora, A.; Gürlebeck, D.; Peart, J.; Ganal, M.; Baker, B.; Bonas, U.; Lahaye, T. The tomato resistance protein Bs4 is a predicted non-nuclear TIR-NB-LRR protein that mediates defense responses to severely truncated derivatives of AvrBs4 and overexpressed AvrBs3. Plant J. 2004, 37, 46-60. [CrossRef] [PubMed]

332. Gu, K.; Yang, B.; Tian, D.; Wu, L.; Wang, D.; Sreekala, C.; Yang, F.; Chu, Z.; Wang, G.L.; White, F.F.; et al. R gene expression induced by a type-III effector triggers disease resistance in rice. Nature 2005, 435, 1122-1125. [CrossRef]

333. Ji, Z.; Ji, C.; Liu, B.; Zou, L.; Chen, G.; Yang, B. Interfering TAL effectors of Xanthomonas oryzae neutralize R-gene-mediated plant disease resistance. Nat. Commun. 2016, 7, 1-9. [CrossRef]

334. Read, A.C.; Rinaldi, F.C.; Hutin, M.; He, Y.Q.; Triplett, L.R.; Bogdanove, A.J. Suppression of Xo1-mediated disease resistance in rice by a truncated, non-DNA-binding TAL effector of Xanthomonas oryzae. Front. Plant Sci. 2016, 7, 1-14. [CrossRef] [PubMed]

335. Washington, E.J.; Banfield, M.J.; Dangl, J.L. What a difference a Dalton makes: Bacterial virulence factors modulate eukaryotic host cell signaling systems via deamidation. Microbiol. Mol. Biol. Rev. 2013, 77, 527-539. [CrossRef] 
336. Felix, G.; Grosskopf, D.G.; Regenass, M.; Basse, C.W.; Boller, T. Elicitor-induced ethylene biosynthesis in tomato cells: Characterization and use as a bioassay for elicitor action. Plant Physiol. 1991, 97, 19-25. [CrossRef]

337. Liu, Y.; Zhang, S. Phosphorylation of 1-aminocyclopropane-1-carboxylic acid synthase by MPK6, a stress-responsive mitogenactivated protein kinase, induces ethylene biosynthesis in Arabidopsis. Plant Cell 2004, 16, 3386-3399. [CrossRef]

338. Bürstenbinder, K.; Rzewuski, G.; Wirtz, M.; Hell, R.; Sauter, M. The role of methionine recycling for ethylene synthesis in Arabidopsis. Plant J. 2007, 49, 238-249. [CrossRef]

339. Ishiguro, S.; Kawai-Oda, A.; Ueda, J.; Nishida, I.; Okada, K. The DEFECTIVE IN ANTHER DEHISCIENCE gene encodes a novel phospholipase A1 catalyzing the initial step of jasmonic acid biosynthesis, which synchronizes pollen maturation, anther dehiscence, and flower opening in Arabidopsis. Plant Cell 2001, 13, 2191-2209. [CrossRef]

340. Hyun, Y.; Choi, S.; Hwang, H.-J.; Yu, J.; Nam, S.-J.; Ko, J.; Park, J.-Y.; Seo, Y.S.; Kim, E.Y.; Ryu, S.B.; et al. Cooperation and functional diversification of two closely related galactolipase genes for jasmonate biosynthesis. Dev. Cell 2008, 14, 183-192. [CrossRef]

341. Ellinger, D.; Stingl, N.; Kubigsteltig, I.I.; Bals, T.; Juenger, M.; Pollmann, S.; Berger, S.; Schuenemann, D.; Mueller, M.J. DONGLE and DEFECTIVE IN ANTHER DEHISCENCE1 lipases are not essential for wound- and pathogen-induced jasmonate biosynthesis: Redundant lipases contribute to jasmonate formation. Plant Physiol. 2010, 153, 114-127. [CrossRef]

342. Brooks, D.M.; Bender, C.L.; Kunkel, B.N. The Pseudomonas syringae phytotoxin coronatine promotes virulence by overcoming salicylic acid-dependent defences in Arabidopsis thaliana. Mol. Plant Pathol. 2005, 6, 629-639. [CrossRef] [PubMed]

343. Popa, C.M.; Tabuchi, M.; Valls, M. Modification of bacterial effector proteins inside eukaryotic host cells. Front. Cell. Infect. Microbiol. 2016, 6, 1-13. [CrossRef]

344. Jiang, H.; Zhang, X.; Chen, X.; Aramsangtienchai, P.; Tong, Z.; Lin, H. Protein lipidation: Occurrence, mechanisms, biological functions, and enabling technologies. Chem. Rev. 2018, 118, 919-988. [CrossRef]

345. Dowen, R.H.; Engel, J.L.; Shao, F.; Ecker, J.R.; Dixon, J.E. A family of bacterial cysteine protease type III effectors utilizes acylation-dependent and -independent strategies to localize to plasma membranes. J. Biol. Chem. 2009, 284, 15867-15879. [CrossRef]

346. Shan, L.; Thara, V.K.; Martin, G.B.; Zhou, J.M.; Tang, X. The Pseudomonas avrPto protein is differentially recognized by tomato and tobacco and is localized to the plant plasma membrane. Plant Cell 2000, 12, 2323-2337. [CrossRef]

347. Robert-Seilaniantz, A.; Shan, L.; Zhou, J.M.; Tang, X. The Pseudomonas syringae pv. tomato DC3000 type III effector HopF2 has a putative myristoylation site required for its avirulence and virulence functions. Mol. Plant-Microbe Interact. 2006, 19, 130-138. [CrossRef]

348. Thieme, F.; Szczesny, R.; Urban, A.; Kirchner, O.; Hause, G.; Bonas, U. New type III effectors from Xanthomonas campestris pv. vesicatoria trigger plant reactions dependent on a conserved N-myristoylation motif. Mol. Plant-Microbe Interact. 2007, 20, 1250-1261. [CrossRef]

349. Liu, H.; Chang, Q.; Feng, W.; Zhang, B.; Wu, T.; Li, N.; Yao, F.; Ding, X.; Chu, Z. Domain dissection of AvrRxo1 for suppressor, avirulence and cytotoxicity functions. PLoS ONE 2014, 9, 1-23. [CrossRef]

350. Nimchuk, Z.; Marois, E.; Kjemtrup, S.; Leister, R.T.; Katagiri, F.; Dangl, J.L. Eukaryotic fatty acylation drives plasma membrane targeting and enhances function of several type III effector proteins from Pseudomonas syringae. Cell 2000, 101, 353-363. [CrossRef]

351. Zhou, H.; Morgan, R.L.; Guttman, D.S.; Ma, W. Allelic variants of the Pseudomonas syringae type III effector HopZ1 are differentially recognized by plant resistance systems. Mol. Plant-Microbe Interact. 2009, 22, 176-189. [CrossRef] [PubMed]

352. Meinnel, T.; Dian, C.; Giglione, C. Myristoylation, an ancient protein modification mirroring eukaryogenesis and evolution. Trends Biochem. Sci. 2020, 45, 619-632. [CrossRef] [PubMed]

353. Helgren, T.R.; Wangtrakuldee, P.; Staker, B.L.; Hagen, T.J. Advances in bacterial methionine aminopeptidase inhibition. Curr. Top. Med. Chem. 2015, 16, 397-414. [CrossRef]

354. Yamauchi, S.; Fusada, N.; Hayashi, H.; Utsumi, T.; Uozumi, N.; Endo, Y.; Tozawa, Y. The consensus motif for N-myristoylation of plant proteins in a wheat germ cell-free translation system. FEBS J. 2010, 277, 3596-3607. [CrossRef]

355. Xiao, F.; Giavalisco, P.; Martin, G.B. Pseudomonas syringae type III effector AvrPtoB is phosphorylated in plant cells on serine 258 , promoting its virulence activity. J. Biol. Chem. 2007, 282, 30737-30744. [CrossRef]

356. Lei, L.; Stevens, D.M.; Coaker, G. Phosphorylation of the Pseudomonas effector AvrPtoB by Arabidopsis SnRK2.8 is required for bacterial virulence. Mol. Plant 2020, 13, 1513-1522. [CrossRef] [PubMed]

357. Ntoukakis, V.; Mucyn, T.S.; Gimenez-Ibanez, S.; Chapman, H.C.; Gutierrez, J.R.; Balmuth, A.L.; Jones, A.M.E.; Rathjen, J.P. Host inhibition of a bacterial virulence effector triggers immunity to infection. Science 2009, 324, 784-787. [CrossRef]

358. Xu, N.; Luo, X.; Wu, W.; Xing, Y.; Liang, Y.; Liu, Y.; Zou, H.; Wei, H.L.; Liu, J. A plant lectin receptor-like kinase phosphorylates the bacterial effector AvrPtoB to dampen its virulence in Arabidopsis. Mol. Plant 2020, 13, 1499-1512. [CrossRef] [PubMed]

359. Anderson, J.C.; Pascuzzi, P.E.; Xiao, F.; Sessa, G.; Martin, G.B. Host-mediated phosphorylation of type III effector AvrPto promotes Pseudomonas virulence and avirulence in tomato. Plant Cell 2006, 18, 502-514. [CrossRef]

360. Yeam, I.; Nguyen, H.P.; Martin, G.B. Phosphorylation of the Pseudomonas syringae effector AvrPto is required for FLS2/BAK1independent virulence activity and recognition by tobacco. Plant J. 2010, 61, 16-24. [CrossRef] [PubMed]

361. Desveaux, D.; Singer, A.U.; Wu, A.-J.; McNulty, B.C.; Musselwhite, L.; Nimchuk, Z.; Sondek, J.; Dangl, J.L. Type III effector activation via nucleotide binding, phosphorylation, and host target interaction. PLoS Pathog. 2007, 3, e48. 
362. Abramovitch, R.B.; Janjusevic, R.; Stebbins, C.E.; Martin, G.B. Type III effector AvrPtoB requires intrinsic E3 ubiquitin ligase activity to suppress plant cell death and immunity. Proc. Natl. Acad. Sci. USA 2006, 103, 2851-2856. [CrossRef]

363. Sohn, K.H.; Zhang, Y.; Jones, J.D.G. The Pseudomonas syringae effector protein, AvrRPS4, requires in planta processing and the KRVY domain to function. Plant J. 2009, 57, 1079-1091. [CrossRef] [PubMed]

364. Li, G.; Froehlich, J.E.; Elowsky, C.; Msanne, J.; Ostosh, A.C.; Zhang, C.; Awada, T.; Alfano, J.R. Distinct Pseudomonas type-III effectors use a cleavable transit peptide to target chloroplasts. Plant J. 2014, 77, 310-321. [CrossRef]

365. Halane, M.K.; Kim, S.H.; Spears, B.J.; Garner, C.M.; Rogan, C.J.; Okafor, E.C.; Su, J.; Bhattacharjee, S.; Gassmann, W. The bacterial type III-secreted protein AvrRps4 is a bipartite effector. PLoS Pathog. 2018, 14, e1006984. [CrossRef]

366. Coaker, G.; Falick, A.; Staskawicz, B. Activation of a phytopathogenic bacterial effector protein by a eukaryotic cyclophilin. Science 2005, 308, 548-550. [CrossRef]

367. Coaker, G.; Zhu, G.; Ding, Z.; Van Doren, S.R.; Staskawicz, B. Eukaryotic cyclophilin as a molecular switch for effector activation. Mol. Microbiol. 2006, 61, 1485-1496. [CrossRef]

368. Mudgett, M.B.; Staskawicz, B.J. Characterization of the Pseudomonas syringae pv. tomato AvrRpt2 protein: Demonstration of secretion and processing during bacterial pathogenesis. Mol. Microbiol. 1999, 32, 927-941. [CrossRef]

369. Zhang, Z.; Ma, K.-W.; Yuan, S.; Luo, Y.; Jiang, S.; Hawara, E.; Pan, S.; Ma, W.; Song, J. Structure of a pathogen effector reveals the enzymatic mechanism of a novel acetyltransferase family. Nat. Struct. Mol. Biol. 2016, 23, 847-852. [CrossRef] [PubMed]

370. Zhang, Z.; Ma, K.-W.; Gao, L.; Hu, Z.; Schwizer, S.; Ma, W.; Song, J. Mechanism of host substrate acetylation by a YopJ family effector. Nat. Plants 2017, 3, 17115. [CrossRef]

371. Poovaiah, B.W.; Du, L.; Wang, H.; Yang, T. Recent advances in calcium/calmodulin-mediated signaling with an emphasis on plant-microbe interactions. Plant Physiol. 2013, 163, 531-542. [CrossRef]

372. Laloi, C.; Mestres-Ortega, D.; Marco, Y.; Meyer, Y.; Reichheld, J.P. The Arabidopsis cytosolic thioredoxin $h 5$ gene induction by oxidative stress and its W-box-mediated response to pathogen elicitor. Plant Physiol. 2004, 134, 1006-1016. [CrossRef] [PubMed]

373. Kneeshaw, S.; Gelineau, S.; Tada, Y.; Loake, G.J.; Spoel, S.H. Selective protein denitrosylation activity of thioredoxin-h5 modulates plant immunity. Mol. Cell 2014, 56, 153-162. [CrossRef] [PubMed]

374. Weßling, R.; Epple, P.; Altmann, S.; He, Y.; Yang, L.; Henz, S.R.; McDonald, N.; Wiley, K.; Bader, K.C.; Gläßer, C.; et al. Convergent targeting of a common host protein-network by pathogen effectors from three kingdoms of life. Cell Host Microbe 2014, 16, 364-375. [CrossRef] [PubMed]

375. Kim, S.H.; Qi, D.; Ashfield, T.; Helm, M.; Innes, R.W. Using decoys to expand the recognition specificity of a plant disease resistance protein. Science 2016, 351, 684-687. [CrossRef]

376. Helm, M.; Qi, M.; Sarkar, S.; Yu, H.; Whitham, S.A.; Innes, R.W. Engineering a decoy substrate in soybean to enable recognition of the soybean mosaic virus NIa protease. Mol. Plant-Microbe Interact. 2019, 32, 760-769. [CrossRef]

377. Van Schie, C.C.N.; Takken, F.L.W. Susceptibility genes 101: How to be a good host. Annu. Rev. Phytopathol. 2014, 52, 551-581. [CrossRef]

378. Engelhardt, S.; Stam, R.; Hückelhoven, R. Good riddance? Breaking disease susceptibility in the era of new breeding technologies. Agronomy 2018, 8, 114. [CrossRef]

379. Zaidi, S.S.E.A.; Mukhtar, M.S.; Mansoor, S. Genome editing: Targeting susceptibility genes for plant disease resistance. Trends Biotechnol. 2018, 36, 898-906. [CrossRef]

380. Schreiber, K.; Lewis, J.D. Identification of a putative DNA-binding protein in Arabidopsis that acts as a susceptibility hub and interacts with multiple Pseudomonas syringae effectors. Mol. Plant-Microbe Interact. 2020, 34, 410-425. [CrossRef]

381. Schreiber, K.J.; Hassan, J.A.; Lewis, J.D. Arabidopsis Abscisic Acid Repressor 1 is a susceptibility hub that interacts with multiple Pseudomonas syringae effectors. Plant J. 2021, 105, 1274-1292. [CrossRef] 